Particionamento de processos lógicos em simulação distribuída utilizando algoritmo genético

Michel Pires da Silva 



\section{Particionamento de processos lógicos em simulação distribuída utilizando algoritmo genético}

Michel Pires da Silva

Orientadora: Prof ${ }^{a}$. Dr ${ }^{a}$. Regina Helena Carlucci Santana

Dissertação apresentada ao Instituto de Ciências Matemáticas e de Computação - ICMC-USP, como parte dos requisitos para obtenção do título de Mestre em Ciência da Computação e MatemáticaComputacional

USP - São Carlos

Novembro de 2005 

À Fabrícia e aos meus pais,

Antônio Carlos e Vânia 



\section{Agradecimentos}

Agradeço primeiramente a Deus, pois sem o dom divino não poderia estar concluindo esta grande etapa de minha vida.

Aos meus pais e a minha noiva por estarem sempre ao meu lado em todos os momentos, apoiando-me incondicionamente e sendo um alicerce nos momentos difíceis.

Às professoras Regina e Sarita e aos professores Rodrigo e Marcos pelas críticas construtivas e apoio em todas as etapas de desenvolvimento e conclusão deste trabalho.

Aos demais professores e funcionários do ICMC, pelo profissionalismo e disponibilidade.

À minha mãe Vania, meu pai Antônio, minha irmã Melina, minha noiva Fabrícia, minha avó Laura e demais familiares. Sem esquecer dos que deixaram saudades: meu avô Lupercio e minha avó Benedita.

Aos meus amigos Juliano e Renato (Japa), companheiros de todas as horas durante esse período, pelas conversas, brincadeiras, conselhos e incentivos.

Aos amigos e colegas do LaSDPC: Douglas, Hermes, Renato (Japa), Luciano e Lilian, Márcio, Mário, Caio, Juliano. E também ao Álvaro, Célia, Edmilson, Jaqueline, Thaís, Valéria, William e Bárbara, Gustavo e outros.

Aos demais colegas e amigos da USP: Vinícius, Tanaka, Bruno, Valdo, Daniel, Julio, Sandro, Camilo, Dornelas, Robertão e tantos outros. 

"É mais fácil gerenciar o mundo do que encontrar uma pessoa que gerencie seus próprios pensamentos"

Algusto Cury 



\section{Sumário}

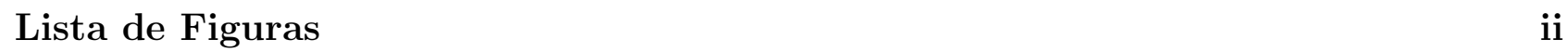

Lista de Tabelas $\quad$ iv

\begin{tabular}{lll}
\hline & Introdução & $\mathbf{1}$
\end{tabular}

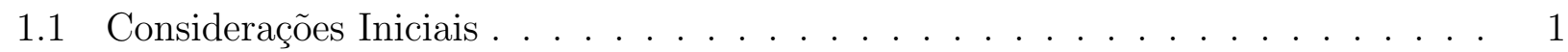

1.2 Objetivos do Trabalho $\ldots \ldots \ldots \ldots$. . . . . . . . . . . . . . . . . 3

1.3 Estrutura da Dissertação $\ldots \ldots \ldots$. . . . . . . . . . . . . . . . . . . . . . . . . . 3

2 Simulação e Simulação Distribuída 5

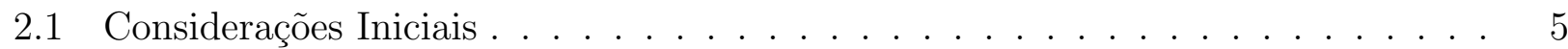

$2.2 \quad$ Etapas do Desenvolvimento de uma Simulação . . . . . . . . . . . . . . . . . . . 6

$2.2 .1 \quad$ Abordagem Seqüencial . . . . . . . . . . . . . . . . 6

2.2 .2 Abordagem Distribuída . . . . . . . . . . . . . . . . . 8

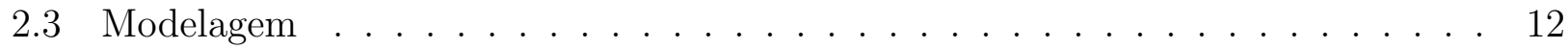

2.3 .1 Redes de Filas . . . . . . . . . . . . . . . . . . . . . . . . . . . . . . . . 12

2.4 Ferramentas para o Desenvolvimento de Simulações . . . . . . . . . . . . . . . . 14

2.5 Considerações Finais $\ldots \ldots \ldots \ldots$

3 Ferramentas de Auxílio à Tomada de Decisões $\quad 23$

3.1 Considerações Iniciais . . . . . . . . . . . . . . . . . . . . . . . . . . . . . 23

3.2 Redes Neurais Artificiais $\ldots \ldots \ldots \ldots$. . . . . . . . . . . . . . . . . . . . 24

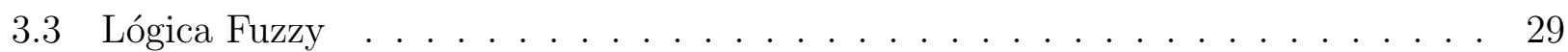

3.4 Algoritmos Evolutivos $\ldots \ldots$. . . . . . . . . . . . . . . . . . 30

3.5 Comparação entre as Técnicas . . . . . . . . . . . . . . . . . . . . . 31

3.6 Algoritmo Genético . . . . . . . . . . . . . . . . . . . . . . . . . 32

3.6 .1 Crossover . . . . . . . . . . . . . . . . . . . . . . . 34

3.6 .2 Mutação . . . . . . . . . . . . . . . . . . . . . 34

3.6 .3 Processo Classificatório . . . . . . . . . . . . . . . . . . . . . . 35 
3.7 Considerações Finais $\ldots \ldots \ldots$

\begin{tabular}{|lll}
\hline 4 & Trabalhos Relacionados & 37
\end{tabular}

4.1 Considerações Iniciais . . . . . . . . . . . . . . . . . . . . . . . . . . . . . . . . . 37

4.2 Técnicas de Particionamento Para Problemas Gerais ～. . . . . . . . . . . . . . 37

4.3 Técnicas de Particionamento para Problemas Específicos . . . . . . . . . . . . . 39

4.4 Considerações Finais . . . . . . . . . . . . . . . . . . . . . . . . . 41

5 Algoritmo Genético para Particionamento de Processos 43

5.1 Considerações Iniciais . . . . . . . . . . . . . . . . . . . . . . . . . . . . . . . . . . . . . . . . .

5.2 Etapas de Desenvolvimento do Algoritmo Genético . . . . . . . . . . . . . . . . 44

5.3 Visão Geral para a Obtenção do Particionamento . . . . . . . . . . . . . . . . . 46

5.4 Obtenção dos Parâmetros do Modelo . . . . . . . . . . . . . . . . . . . . 47

5.5 Obtenção dos Parâmetros da Arquitetura . . . . . . . . . . . . . . . . . . . . . . 49

5.6 Algoritmo Genético . . . . . . . . . . . . . . . . . . . . . . . . . . . . 50

5.7 Particionamento Sugerido pelo Algoritmo Genético . . . . . . . . . . . . . . . 54

5.8 Considerações Finais $\ldots \ldots \ldots \ldots$

\begin{tabular}{lll}
\hline & Estudos de Casos & 57
\end{tabular}

6.1 Considerações Iniciais . . . . . . . . . . . . . . . . . . . . . . . 57

6.2 Metodologia Adotada . . . . . . . . . . . . . . . . . . . . 57

6.3 Características das Arquiteturas . . . . . . . . . . . . . . . . . . . . . . 59

6.4 Modelos e Particionamentos Avaliados . . . . . . . . . . . . . . . . . . . . . . . 60

6.4 .1 Características do Modelo 01 . . . . . . . . . . . . . . . 60

6.4 .2 Características do Modelo 02 . . . . . . . . . . . . . . . 62

6.4 .3 Características do Modelo 03 . . . . . . . . . . . . . . . . . . . . . 64

6.4 .4 Características do Modelo 04 . . . . . . . . . . . . . . . . . 65

6.5 Análise dos Resultados . . . . . . . . . . . . . . . . . . . . 67

6.5 .1 Estudo de Caso 1 . . . . . . . . . . . . . . . . . . . . 67

6.5 .2 Estudo de Caso $2 \ldots \ldots \ldots$

6.5 .3 Estudo de Caso $3 \ldots \ldots \ldots$. . . . . . . . . . . . . . . . . 70

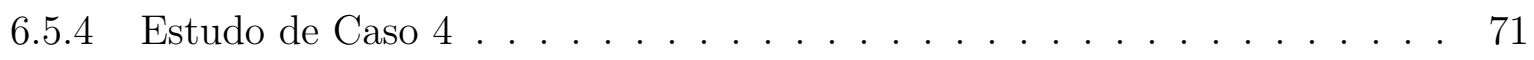

6.6 Considerações Finais . . . . . . . . . . . . . . . . . . . . . 72

\begin{tabular}{lll}
\hline & Conclusões & 73 \\
\hline
\end{tabular}

7.1 Considerações Finais . . . . . . . . . . . . . . . . . . . . . . 73

7.2 Relacionamento com Trabalhos do Grupo de Pesquisa . . . . . . . . . . . . . . . 74

7.3 Contribuições $\ldots \ldots \ldots \ldots$. . . . . . . . . . . . . . . . . . . . . 75

7.4 Trabalhos Futuros $\ldots \ldots \ldots \ldots$. . . . . . . . . . . . . . . 76 


\section{Lista de Figuras}

2.1 Etapas para o desenvolvimento de uma simulação seqüencial (BANKd: 1998$)$. . . 7

\begin{tabular}{|lll|l|ll|}
\hline 2.2 & Fases de desenvolvimento de uma simulação distribuída (BRUSCH], 2002) & . . . . . 9 \\
\hline
\end{tabular}

2.3 Representação de um modelo por redes de filas . . . . . . . . . . . . . . . . . . 13

2.4 Representação da descrição utilizada nos modelos deste trabalho . . . . . . . . . 14

2.5 Simulação de uma rede Token Ring utilizando OMNet++ (IRME et al [| 2001)| . . 15

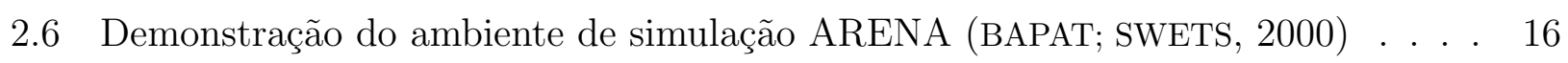

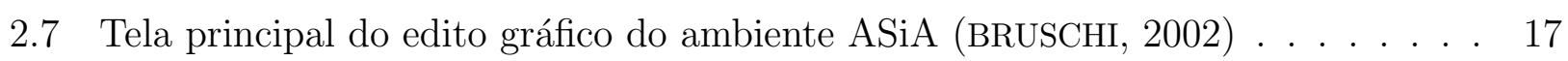

\begin{tabular}{|lll|ll|}
\hline 2.8 & Exemplo de script utilizado pelo NS2 (FALL; VARADHAN & $2000)$ & . . . . . . . . . . 18 & \\
\hline
\end{tabular}

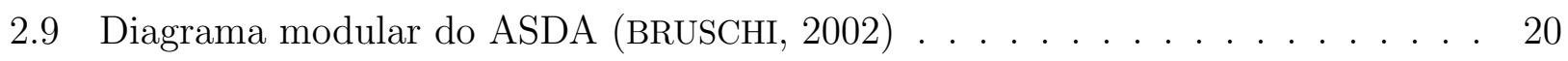

\begin{tabular}{|lll|l|l|}
\hline 3.1 & Neurônio apresentado por McCulloch e Pitts em 1943 (MCCULLOCH; PITTS, 1943) & 24 \\
\hline
\end{tabular}

3.2 Representação de uma rede organizada em múltiplas camadas . . . . . . . . . . 26

\begin{tabular}{|lll|l|l|}
\hline 3.3 & Diagrama do aprendizado supervisionado (BRAGA; CARVALHO; LUDERMIRE[ 2000) & 27 \\
\hline
\end{tabular}

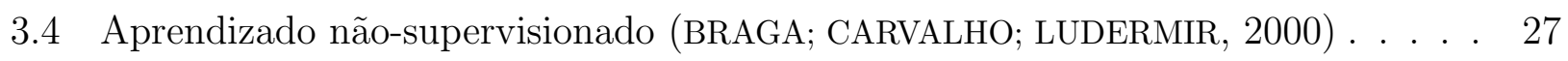

3.5 Representação gráfica das funções de ativação (REZENDE[ $\mid 2003)$. . . . . . . . . . 28

\begin{tabular}{|lll|ll|}
\hline 3.6 & Gráfico fuzzy para representar a temperatura ambiente (WEBER; KLEIN [2003) . 29 \\
\hline
\end{tabular}

3.7 Processo de criação de novos indivíduos . . . . . . . . . . . . . . . . . . . . 33

3.8 Representação do processo de fitness em uma população . . . . . . . . . . . . . 35

\begin{tabular}{|lll|ll|}
\hline 4.1 & Etapas realizadas em $(\mathrm{XU}$; AMMAR $\mid 2004)$ para o particionamento & $\ldots$ & $\ldots$
\end{tabular}

5.1 Modelo utilizado na avaliação dos algoritmos genéticos . . . . . . . . . . . . . . 44

5.2 Classificação dos algoritmos genéticos avaliados . . . . . . . . . . . . . . . . . 45

5.3 Fluxograma aplicado para a obtenção dos particionamentos . . . . . . . . . . . 46

5.4 Transcrição utilizada no ambiente ASDA para a representação de modelos . . . 47

5.5 Representação da comunicação na Matriz Communication . . . . . . . . . . . . 48

\begin{tabular}{lll||ll|}
5.6 & Descrição do carga de processamento para o grafo da figura & 5.4 & . . . . . . . . . . 48 & 48 \\
\hline
\end{tabular}

\begin{tabular}{|lll||ll|}
5.7 & Representação do vetor mipsCapacity para os dados da tabela & 5.2 & $\ldots$ & . . . . . . . 50 \\
\hline
\end{tabular}

5.8 Cromossomo utilizado pelo algoritmo genético . . . . . . . . . . . . . . . . 51 


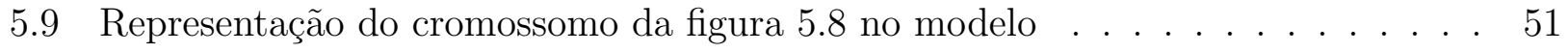

5.10 Processo executado pelo crossover . . . . . . . . . . . . . . . . . . . 54

5.11 Processo de execução do algoritmo genético . . . . . . . . . . . . . . . . . . 54

6.1 Notação gráfica do modelo 01 . . . . . . . . . . . . . . . . . . . . 61

6.2 Partições definidas para o modelo 01 . . . . . . . . . . . . . . . . . . 61

6.3 Representação do segundo modelo avaliado . . . . . . . . . . . . . . . . . . . . 62

6.4 Partições definidas para o modelo $02 \ldots \ldots$. . . . . . . . . . . . . 63

6.5 Notação gráfica do modelo 03 . . . . . . . . . . . . . . . . . . . . . . 64

6.6 Partições definidas para o modelo 03 . . . . . . . . . . . . . . . . . . . . . 65

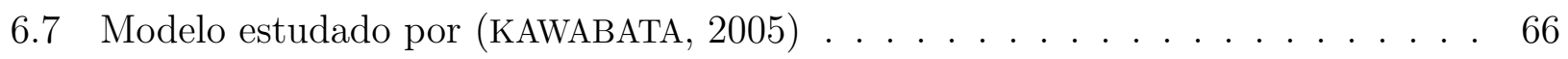

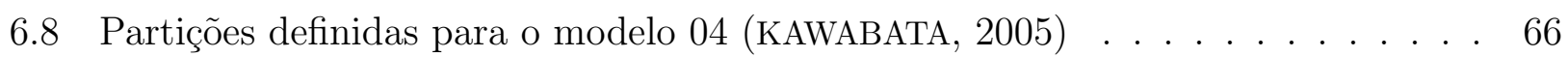

6.9 Resultados obtidos para o modelo 01 . . . . . . . . . . . . . . . . . . . . 68

6.10 Resultados obtidos para o modelo 02 . . . . . . . . . . . . . . . . . . 70

6.11 Resultados obtidos para o modelo $03 \ldots \ldots$. . . . . . . . . . . . 71 


\section{Lista de Tabelas}

5.1 Configurações dos algoritmos genéticos avaliados . . . . . . . . . . . . . . . . 45

5.2 Descrição das máquinas utilizadas nos testes . . . . . . . . . . . . . . . . . 50

5.3 Representação das informações ao usuário . . . . . . . . . . . . . . . . . . 55

6.1 Configuração da arquitetura 01 . . . . . . . . . . . . . . . . . . . . 59

6.2 Configuração da arquitetura 02 . . . . . . . . . . . . . . . . . . . . . . 59

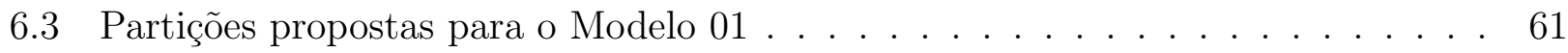

6.4 Partições propostas para o Modelo $02 \ldots \ldots$. . . . . . . . . . . . . . 63

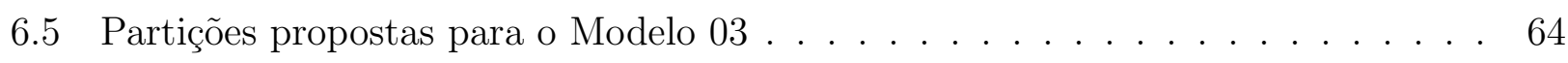

6.6 Configuração da arquitetura utilizada . . . . . . . . . . . . . . . . . . 66

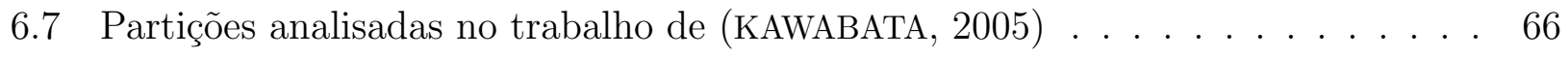

6.8 Avaliação das partições do modelo 01 para a arquitetura 01 . . . . . . . . . . . . 67

6.9 Avaliação das partições do modelo 01 para a arquitetura 02 . . . . . . . . . . . . 68

6.10 Avaliação das partições do modelo 02 para a arquitetura 01 . . . . . . . . . . . . 69

6.11 Avaliação das partições do modelo 02 para a arquitetura 02 . . . . . . . . . . . . 69

6.12 Avaliação das partições do modelo 03 para a arquitetura 01 . . . . . . . . . . . 70

6.13 Avaliação das partições do modelo 03 para a arquitetura 02 . . . . . . . . . . . . 71

\begin{tabular}{|ll|l|l|l|l|}
\hline 6.14 & Speedup alcançado na execução das simulações - (KAWABATA & $2005)$ & . . . . . . . . & 71 \\
\hline
\end{tabular} 


\section{Resumo}

SILVA, M. P. Particionamento de processos lógicos em simulação distribuída utilizando algoritmo genético. Dissertação (Mestrado) - Instituto de Ciências Matemáticas e de Computação - Universidade de São Paulo, São Carlos, 2005.

Esta dissertação tem por objetivo apresentar uma abordagem baseada em técnicas de inteligência artificial para automatizar a etapa de particionamento de modelos em simulação distribuída. Essa abordagem utiliza os conceitos da computação evolutiva para o desenvolvimento de um algoritmo genético capaz de otimizar o processo de particionamento e auxiliar a tomada de decisões na tarefa de obtenção dos processos lógicos. Objetiva-se com sua aplicação minimizar o tempo de execução da simulação distribuída, evitando que o pior tempo de execução seja utilizado. Para alcançar esse objetivo, o particionamento apresentado como solução é caracterizado pelo balanceamento de carga e pela baixa latência de comunicação entre processos. Isso é possível porque o algoritmo genético utiliza informações contidas no modelo e na arquitetura de onde a simulação será executada. Esses padrões são utilizados para obter informações sobre a comunicação entre processos, a carga de processamento por centro de serviço e a capacidade de processamento das máquinas.

Palavras-chave: simulação distribuída, particionamento, algoritmo genético 


\section{Abstract}

SILVA, M. P. Logical process partitioning in distributed simulation using genetic algorithmic. Dissertação (Mestrado) - Instituto de Ciências Matemáticas e de Computação - Universidade de São Paulo, São Carlos, 2005.

This dissertation presents an approach based on intelligence artificial technics to automatize the model partitioning stage in distributed simulation. This approach makes uses evolutive computing concepts to developed a genetic algorithmic that can optimize the partitioning process and help to take decisions in the task to get the logical process. The propose of this algorithm is reduce to execution time the distributed simulation and to avoid the use of the worst execution time. To reach this target, the partitioning obtained has characteristics such as load balance and the low-communication interprocess. This is possible because the genetic algorithmic uses as input information from the model and the architect where the simulation with be executed. These inputs are used to get information about the interprocess communication, processing load per service center and processing capacity in the machines.

Keywords: distributed simulation, partitioning, genetic algorithmic 


\section{Capítulo}

\section{1}

\section{Introdução}

\subsection{Considerações Iniciais}

Ao decorrer dos tempos, com o avanço da tecnologia e das pesquisas científicas, surgiram várias inovações que permitiram o rápido progresso da humanidade. Entretanto, essa rápida evolução trouxe preocupações voltadas à otimização dos recursos disponíveis. Essas preocupações foram tornando-se mais intensas à medida que o limite físico de cada recurso estivesse próximo de ser alcançado.

$\mathrm{Na}$ computação, os limites foram identificados, na maioria das vezes, ao redor do poder tecnológico e da informação. Esses limites, por sua vez, tornaram-se tão importantes que algumas áreas de pesquisa foram criadas e/ou aprimoradas para prover soluções para o assunto. Essas áreas buscaram, como objetivo, prover métodos, técnicas e normas para maximizar os recursos computacionalmente disponíveis e, com isso, obter soluções para os mais diversos problemas até então não solucionados. Esse avanço na computação foi tornando-se possível à medida que algumas áreas, tais como, a avaliação de desempenho, a inteligência artificial e os sistemas distribuídos, surgiram.

A princípio, todas as áreas foram associadas a técnicas de auxílio para direcionar o processo de desenvolvimento. Podem ser citadas como exemplos de técnicas utilizadas para isso, a simulação, a aferição e a modelagem analítica (JAIN, 1991).

A modelagem é uma técnica que permite representar características de sistemas computacionais por meio de modelos. A solução desses modelos pode ser obtida através da técnica de aferição ou simulação.

As técnicas baseadas em aferição são atrativas devido a precisão que pode ser alcançada através da sua utilização na busca de resultados. Entretanto, a falta de flexibilidade e a dificuldade em se representar mudanças contínuas de estado tornam a solução da modelagem por tal técnica não aconselhável na maioria dos casos de avaliação de sistemas computacionais 
(BRUSCHI, 2002).

Ao utilizar a técnica de simulação, pode-se obter uma outra forma de solucionar os modelos. Neste caso, o sistema representado pelo modelo é codificado em um programa de simulação, o qual apresenta ao término de sua execução os resultados encontrados. Apresentando-se como uma técnica flexível e de baixo custo, a simulação tornou-se bastante atrativa. Isso porque qualquer alteração no sistema real é facilmente refletida no programa de simulação, fazendo com que os resultados sejam rapidamente obtidos. No entanto, os resultados gerados não são considerados adequadamente precisos para conclusões, sendo necessário a aplicação de técnicas estatísticas.

Uma outra desvantagem da simulação está relacionada à quantidade de etapas associadas ao seu processo de desenvolvimento. Essas etapas, dependendo do sistema a ser avaliado, tornamse complexas de serem executadas por usuários com níveis de conhecimento restrito sobre o assunto. Para auxiliar os usuários que optam pela utilização da técnica, um novo conceito foi criado: o ambiente de simulação. Esses ambientes têm como objetivo prover ao usuário uma forma simples de executar cada etapa do processo de desenvolvimento e obter os resultados necessários a um esforço mínimo. Alguns dos ambientes criados para auxilar o processo de desenvolvimento de simulações são: ASiA (SANTANA et al., 1996b) (SANTANA et al., 1996a), OMNet ++ (IRME et al., 2001), ARENA (BAPAT; SWETS, 2000), NS2 (FALL; VARADHAN, 2000), OPNet (DIAS; CORREA; ABRãO, 2003) e ASDA (BRUSCHI, 2002).

Inicialmente, as simulações criadas para avaliar sistemas computacionais eram executadas seqüencialmente em uma única máquina. Devido à aleatoriedade das variáveis de entrada, uma simulação deve ser executada várias vezes até alcançar resultados válidos. Isso consistiu em uma terceira desvantagem da simulação: o tempo de execução.

Com o objetivo de diminuir o tempo de execução, uma nova abordagem foi criada: a simulação distribuída. Nessa, os modelos apresentados como entrada são convertidos em um programa de simulação, o qual é particionado em vários processos menores (processos lógicos). Cada processo lógico é então executado por uma máquina, minimizando assim o tempo para se obter os resultados.

Para prover a mesma flexibilidade existente na simulação seqüencial, foram também, ao longo dos anos, criados ambientes específicos para o desenvolvimento de simulações distribuídas. A diferença principal desses ambientes foi o acréscimo das etapas não existentes na abordagem seqüencial: a etapa de particionamento e a etapa de configuração da arquitetura. Alguns ambientes projetados para dar suporte ao desenvolvimento desse tipo de simulação são: ASDA (Ambiente de Simulação Distribuída Automático) (BRUSCHI, 2002) e o Akaroa-2 (EWING; MCNICKLE; PAWLIKOWSKI, 1998).

Os ambientes que trabalham com simulação distribuída apresentam como desvantagem o aumento da complexidade de utilização. Esse aumento é devido ao acréscimo das etapas que não são utilizadas pela abordagem seqüencial. Essas etapas exigem que o usuário possua um conhecimento um pouco maior, para que ao executá-la não comprometa a técnica distribuída. Um exemplo que pode prejudicar a utilização da simulação distribuída é o particionamento 
incorreto aplicado ao modelo.

A etapa de particionamento, se executada de forma incorreta pelo usuário, pode apresentar um elevado tempo de execução. Para evitar que isso ocorra, este trabalho propõe uma solução automática de particionamento que pode ser integrada a ambientes de simulação para, não só auxiliar o particionamento em si, mas, também balancear a carga entre os processos lógicos e minimizar o tráfego de mensagens na rede. Algumas das técnicas disponíveis para alcançar tais objetivos podem ser encontradas nas áreas da Inteligência Artificial (redes neurais, lógica fuzzy e algoritmos evolutivos) ou nas áreas matemáticas apoiadas em heurísticas.

\subsection{Objetivos do Trabalho}

O objetivo central do projeto de mestrado apresentado nessa dissertação é a definição de um método que permita realizar o particionamento de modelos quando a abordagem SRIP for utilizada. A escolha por um bom particionamento deve atender a dois fatores importantes: o balanceamento de carga entre os processadores e a redução da comunicação entre processos.

O método selecionado deve ser capaz de interpretar as informações providas pelo ASDA, e a partir dessas, automatizar a etapa de particionamento, independentemente, do tamanho e/ou complexidade do modelo. Para tanto, informações referentes a carga de processamento de cada centro de serviço, taxa de comunicação entre centros de serviço e capacidade total de processamento em MIPS das máquinas da arquitetura, devem ser consideradas.

Uma vez que, para se obter resultados estatisticamente adequados faz-se necessário a execução da simulação com diferentes valores atribuídos a algumas de suas variáveis, tem-se também como objetivo a escolha da técnica que melhor pode operar com tais especificações. Para melhor descrever a pesquisa realizada, tem-se na próxima seção a descrição da estrutura criada para esta dissertação.

\subsection{Estrutura da Dissertação}

A escolha de uma técnica para auxiliar a tarefa de particionamento, sua definição, implementação e a análise de seus resultados são etapas deste trabalho de mestrado. De modo a relatar essas etapas, esta dissertação está organizada em 6 capítulos. No capítulo 2 são apresentados os principais conceitos sobre simulação e simulação distribuída. São discutidos os conceitos gerais das abordagens seqüencial e distribuída, apresentando no decorrer do capítulo as etapas pertencentes a cada abordagem. Ao fim da descrição dos conceitos, são apresentados alguns dos ambientes de simulação mais utilizados nos ambientes educacional e empresarial.

No capítulo 3 são apresentadas algumas das técnicas que podem ser utilizadas para automatizar o processo de particionamento. Essas técnicas são baseadas em inteligência artificial, sendo no decorrer do capítulo detalhadas as visões gerais das técnicas de redes neurais artificiais, lógica fuzzy e algoritmos evolutivos. Também são apresentadas as vantagens e desvantagens de se aplicar cada uma dessas técnicas no problema de particionamento de modelos em simulação distribuída. Neste capítulo a técnica da computação evolutiva baseada em algoritmos genéticos é escolhida para solução do problema, sendo então detalhada. 
No capítulo 4 são apresentadas as adequações realizadas no algoritmo genético apresentado no capítulo 3 para prover soluções que visem um bom particionamento, o balanceamento de carga entre processos lógicos e a minimização da comunicação na rede. Neste capítulo são apresentados os parâmetros utilizados pelo algoritmo genético para prover as soluções e as funções matemáticas que foram criadas para alcançar os objetivos propostos neste trabalho.

No capítulo 5 são apresentados os estudos de caso aplicados para ilustrar o desempenho e a eficiência das partições automaticamente obtidas ao utilizar o algoritmo genético proposto. Nesse capítulo são apresentadas: a metodologia adotada para a coleta de resultados e execução das simulações, os modelos e partições avaliadas e as arquiteturas utilizadas para os testes. Como conclusão, são detalhados os resultados e análises realizadas para reforçar as conclusões apresentadas.

Finalmente, no capítulo 6 são apresentadas as conclusões juntamente com as principais contribuições deste trabalho. Nesse capítulo também são apresentados os relacionamentos com trabalhos do grupo de Sistemas Distribuídos e Programação Concorrente do ICMC-USP e os trabalhos futuros. 


\section{Capítulo}

\section{2}

\section{Simulação e Simulação Distribuída}

\subsection{Considerações Iniciais}

Atualmente, a avaliação de desempenho é uma área de pesquisa indispensável quando se deseja medir e prever o comportamento de sistemas computacionais. Com a evolução dessa área, várias técnicas foram criadas e/ou aprimoradas para fornecer recursos que reduzam o esforço do pesquisador na obtenção de resultados. Podem ser citadas como exemplos de técnicas utilizadas para isso, a simulação, a aferição e a modelagem analítica (JAIN, 1991).

A simulação se tornou uma das técnicas mais utilizadas para analisar o desempenho de sistemas computacionais (JAIN, 1991) (BRUSCHI, 2002). Essa técnica oferece como vantagens o baixo custo de implementação e a fácil adaptação a diferentes situações e ocasiões. Como exemplo de sua utilização, pode-se citar: aplicações militares, sistemas legados, sistemas manufaturados e sistemas computacionais, os quais envolvem hardware e software (redes de computadores e arquiteturas computacionais) (FUJIMOTO, 2000).

O processo de desenvolvimento de uma simulação compreende várias etapas de construção e pode seguir duas diferentes abordagens: a seqüencial e a distribuída. Independente da abordagem selecionada, tem-se como um dos passos de desenvolvimento a criação de um modelo conceitual utilizado para representar o sistema computacional a ser avaliado. O modelo criado representa uma idéia do que deseja simular, sendo utilizado pelas demais fases para direcionar o desenvolvimento.

Para uma melhor compreensão de todo esse processo, este capítulo será estruturado da seguinte forma: na seção 2.2 serão apresentadas as etapas necessárias para o desenvolvimento de uma simulação utilizando uma das duas abordagem existentes. Na seção 2.3 serão apresentados os conceitos de modelagem juntamente com uma das técnicas utilizadas para representar sistemas computacionais, já que o enfoque deste trabalho é voltado a tais sistemas. E por fim, serão apresentadas na seção 2.4 algumas das ferramentas utilizadas para auxiliar o processo de 
desenvolvimento e elaboração de uma simulação.

\subsection{Etapas do Desenvolvimento de uma Simulação}

O processo de desenvolvimento de um determinado produto é realizado por meio de uma seqüencia de fases de construção. Essas fases são responsáveis por criar um produto final condizente com a especificação inicial projetadas.

Na simulação, esse processo de construção pode ser realizado em duas diferentes abordagens: a abordagem seqüencial e a abordagem distribuída. O processo de desenvolvimento contido em cada uma dessas abordagens diferencia-se pelo acréscimo de duas etapas na abordagem distribuída. Para melhor compreender quais as etapas de desenvolvimento estão associadas a cada abordagem, tem-se apresentado a seguir uma descrição para cada uma delas.

\subsubsection{Abordagem Seqüencial}

A abordagem seqüencial ou simulação seqüencial foi a primeira técnica desenvolvida para medir e avaliar sistemas computacionais por meio de simulação. Essa técnica possui algumas etapas em seu processo de construção que podem ser observadas na (figura 2.1) (BANKS, 1998), as quais serão relatadas a seguir.

- Formulação do Problema: O primeiro passo a ser realizado na construção de uma simulação é conhecer o problema, identificando quais os pontos mais importantes a serem considerados. Dessa forma, características relevantes não podem ser deixadas de lado para que detalhes desnecessários sejam relatados.

- Ajuste dos objetivos e planos: É nessa etapa que se deve identificar os objetivos a serem alcançados com a execução da simulação (BANKS, 1998). Dentre esses objetivos é necessário a criação de um plano que descreva quais as questões a serem respondidas e quais as situações a serem investigadas durante o período de observação da simulação.

- Construção do modelo: A criação de um modelo é a maneira mais adequada para se representar o sistema real a ser simulado (BANKS, 1998). Essa etapa representa uma visão detalhada do sistema, onde as características essenciais coletadas na formulação do problema são apresentadas. Nessa etapa é recomendado que o modelo inicial seja criado a partir de um processo simples e vá se tornando complexo, se necessário, conforme o propósito a ser alcançado.

- Coleta de dados: Quando o modelo está pronto, tem-se uma boa idéia de quais serão os níveis de detalhamento e de dados necessários para a construção da simulação. Dessa forma, uma nova fase do processo denominada coleta de dados é iniciada. Objetiva-se nessa etapa, a coleta dos parâmetros de entrada que serão necessários para a execução da simulação. A execução dessa etapa pode ser realizada paralelamente com a construção do modelo, pois ambos devem ser corrigidos se detectado alguma característica nova ainda não relatada. 


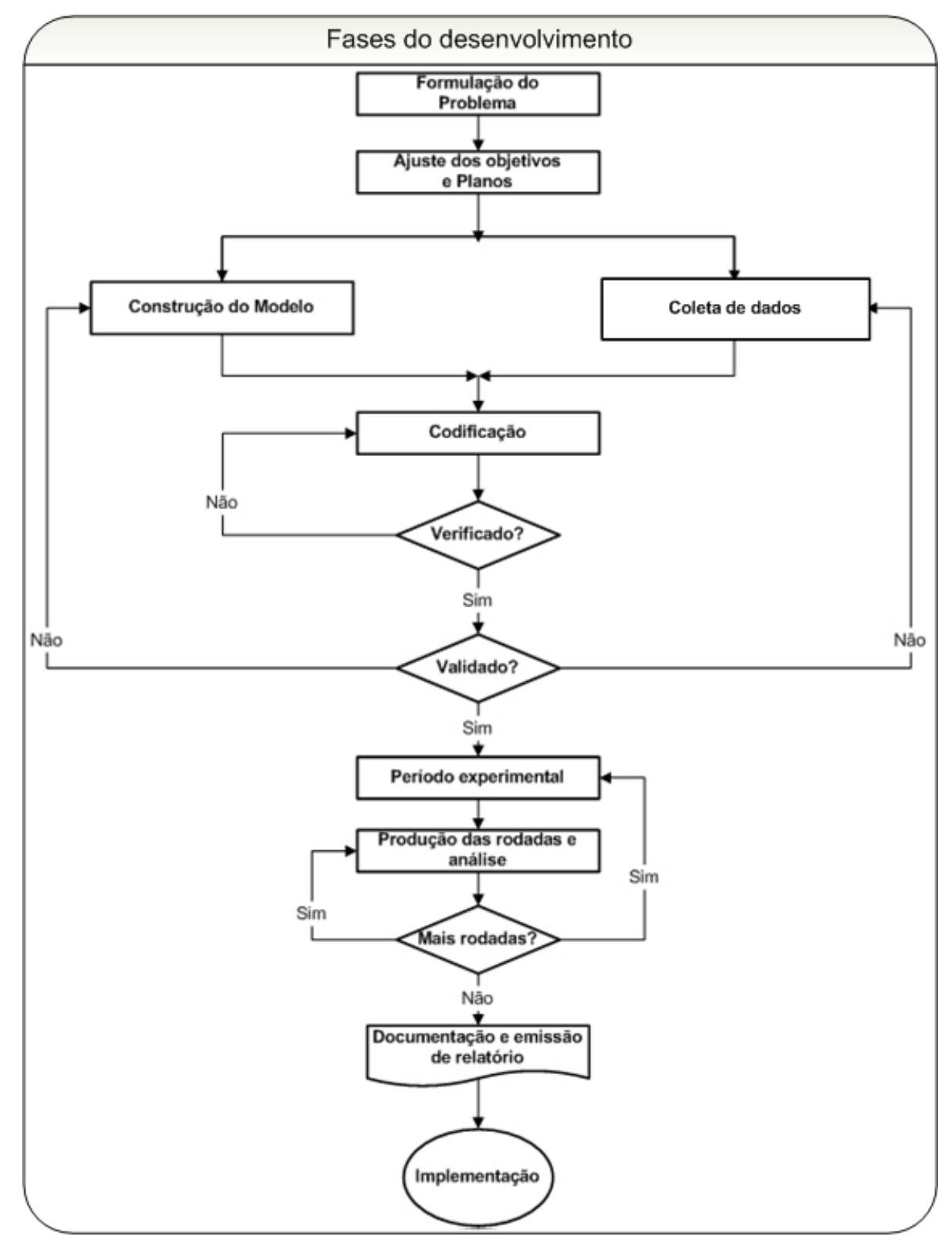

Figura 2.1: Etapas para o desenvolvimento de uma simulação seqüencial (BANKS, 1998)

- Codificação: A próxima etapa a ser executada, após coletados os dados necessários e já prescrito o modelo, é a transcrição das características obtidas para um código fonte. Nessa etapa de transcrição, alguns fatores, tais como, os computadores onde a simulação será executada, as linguagens disponíveis para o desenvolvimento e as ferramentas que serão utilizadas na codificação do modelo apresentado, poderão influenciar no processo de obtenção dos resultados (BANKS, 1998). Desse modo, ao identificar tal influência, deve-se considerar esses fatores como características ao desenvolver o código fonte.

- Verificação: Essa parte do processo está relacionada com a codificação criada na etapa anterior. Seu objetivo é verificar se o programa de simulação criado atende os requisitos propostos nas etapas anteriores. Essa etapa deve ser tratada como um processo contínuo, sendo desaconselhável iniciá-la somente depois que todo o modelo já tenha sido codificado. Para tornar a verificação confiável é aconselhável a utilização de ferramentas, tais como 
debuggers para auxiliar o desenvolvedor na checagem do código recebido da etapa de codificação.

- Validação: Na validação é determinado se o programa de simulação codificado e verificado representa o sistema real de forma adequada (BANKS, 1998). A validação feita nessa etapa é extremamente importante, pois garante que os resultados obtidos do modelo conceitual serão estatisticamente equivalentes se comparados com os resultados gerados no modelo real.

- Período experimental: Nessa fase muitas decisões devem ser tomadas para garantir que as informações desejadas sejam obtidas a um custo mínimo de execução (BANKS, 1998). Essas decisões abrangem requisitos do tipo: qual o tamanho da simulação, o número de replicações dessa simulação e até mesmo o modo como a simulação será inicializada.

- Produção das rodadas e análise: Nessa etapa são realizadas execuções do programa de simulação desenvolvido. Os resultados gerados com essas rodada são analisados para verificar se o modelo proposto está condizente com as características descritas do sistema real.

- Rodadas adicionais: Após a etapa de aquisição dos primeiros resultados (produção de rodadas e análise), é verificado se existe a necessidade de serem executadas rodadas adicionais ou situações diferentes das criadas para se obter novos resultados.

- Emissão de relatório: A emissão de relatórios fornece como resultado a documentação necessária para descrever todo o processo que a simulação passou durante seu período de observação. Essa etapa é necessária, pois a análise dos resultados nem sempre é feita por uma única pessoa responsável, sendo recomendável que todos os envolvidos compreendam como a simulação opera. Um outro fator que torna a documentação importante é quando existe a necessidade de adequar o modelo a novas metas.

\subsubsection{Abordagem Distribuída}

Com o avanço nas pesquisas, a simulação distribuída tem atraido, cada vez mais, pesquisadores de diversas áreas, tais como: engenheiros, economistas, militares, cientistas da computação, etc. O aumento dessa procura pode ser justificado por alguns fatores que tornam a técnica atrativa AYANI, 1993):

- O grande potencial na redução do tempo de uma simulação.

- Muitos sistemas reais possuem uma quantidade substancial de paralelismo.

- Do ponto de vista acadêmico, essa metodologia possui problemas semelhantes aos encontrados em computação distribuída, tais como - sincronismo, comunicação eficiente de mensagens, gerenciamento de deadlocks e balanceamento de carga. 
A simulação distribuída é utilizada quando o tempo para se obter resultados em quantidade suficiente, através da simulação seqüencial, é comprometido (FERSCHA; TRIPATHI, 1995) (FUJIMOTO, 2000). A metodologia utilizada na abordagem distribuída se diferencia da aplicada nas simulações seqüenciais, sendo seu processo de desenvolvimento acrescido de duas etapas o particionamento e a configuração da arquitetura (BRUSCHI, 2002). Essa modificação pode ser observada no diagrama da figura 2.2 ou através das descrições realizadas a seguir.

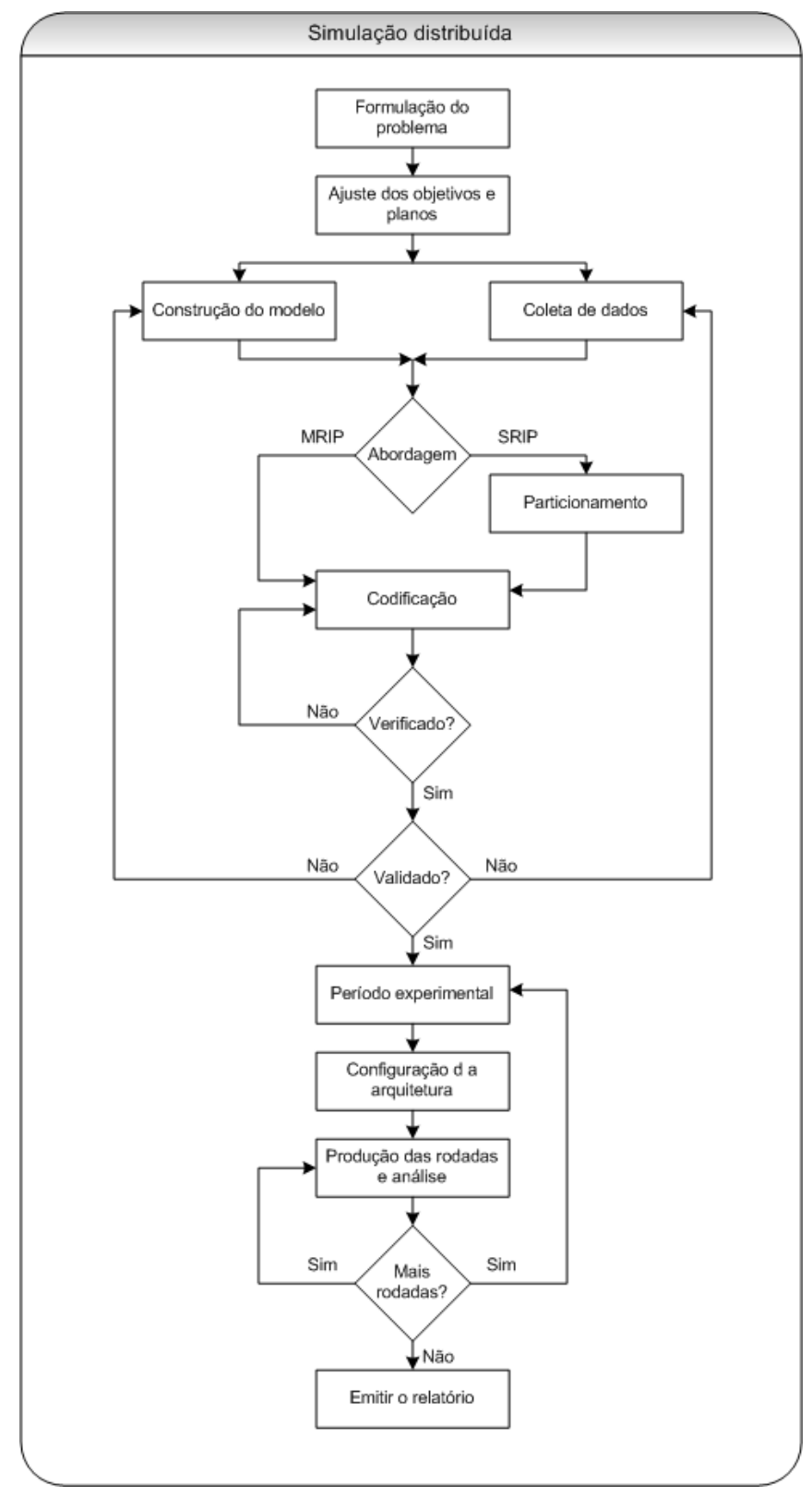

Figura 2.2: Fases de desenvolvimento de uma simulação distribuída (BRUSCHI, 2002)

- Particionamento: O particionamento é a etapa da abordagem distribuída responsável por dividir adequadamente o programa de simulação entre os elementos de processamento disponíveis. Para isso, é preciso avaliar as influências que podem prejudicar o desempenho da abordagem na obtenção dos resultados necessários. Essas influências estão relacionadas com a complexidade do modelo e/ou da arquitetura utilizada para a execução. Sabendose desse fato, torna-se inviável e dispendioso a obtenção de um bom particionamento por 
meio de tentativas manuais, sendo necessário, nesses casos, a utilização de ferramentas e/ou técnicas de apoio a tomada de decisão para obter partições adequadas.

- Configuração da arquitetura: Nessa etapa são selecionadas as máquinas que serão utilizadas para constituir a arquitetura de execução. As possíveis arquiteturas disponíveis para se executar uma simulação distribuída são: arquiteturas com multiprocessadores, arquiteturas de multicomputadores e os sistemas distribuídos. Ao escolher uma das arquiteturas é necessário verificar se essa apresenta comunicação entre as máquinas e processos (ambientes de passagem de mensagem) (BRUSCHI, 2002). Caso a comunicação exista, é realizada a classificação das máquinas existentes para selecionar quais farão parte do núcleo que executará a simulação.

Antes de optar pelo particionamento adequado e pela configuração a ser utilizada, deve-se primeiramente definir qual método de execução será aplicado para a obtenção dos resultados. Em simulação distribuída existem dois métodos:

- SRIP (Single Replication in Parallel): o programa de simulação é dividido em diversos processos menores, denominados processos lógicos. Esses, por sua vez, são distribuídos entre os elementos de processamento da arquitetura utilizada. Nesse método é necessário a utilização de um protocolo de comunicação para o envio e recebimento das mensagens entre processos (ex. PVM) e uma abordagem de sincronização para controlar a execução dos processos lógicos. Dentre as abordagens utilizadas para garantir o sincronismo, tem-se as conservativas e as otimistas:

- A abordagem conservativa garante quando a execução de um determinado evento é seguro, sendo este executado somente quando houver certeza que nenhum outro após ele apresentará um valor de timestamp(tempo de execução) menor. Para isso, todos os processos lógicos são bloqueados até que o evento com o menor timestamp seja obtido. No entanto, esse processo de bloqueio pode gerar uma queda no desempenho e o aparecimento de situações de deadlock. Atualmente, existem diferentes mecanismos para tratar o problema do deadlock, sendo alguns utilizados para preveni-lo e outros para tratá-lo assim que ocorra. Dentre os protocolos mais utilizados, tem-se o CMB (Chandy, Mirsa e Bryant).

O CMB foi a primeira solução apresentada para garantir o sincronismo de simulações distribuídas. Desenvolvido independentemente por Chandy e Misra (CHANDY; MISRA, 1979) e por Bryant (BRYANT, 1977), esse protocolo previne o deadlock através da utilização de mensagens nulas. Essas mensagens, embora tratadas como qualquer outra mensagem, são utilizadas somente para efeitos de sincronização e não correspondem a eventos reais do sistema.

- Na abordagem otimista não existem garantias de quando um evento torna-se seguro. Ao identificar um erro de causa e efeito, um procedimento é chamado para recuperar 
o sistema e voltá-lo a um ponto seguro (rollback). A principal vantagem dessa abordagem, comparada com a conservativa, é a possibilidade de explorar completamente o paralelismo em casos onde erros poderiam vir a ocorrer mas não ocorrem. Um dos protocolos mais conhecidos e utilizados nessa abordagem é o Time Warp.

O protocolo Time Warp (JEFFERSON, 1985) permite que um processo lógico execute eventos em seu tempo local, independentemente do restante dos tempos que estão sendo gerados pela simulação. Para isso, um relógio local, denominado Local Virtual Time (LVT) é utilizado. Entretanto, para manter o sincronismo e, se necessário, ativar o procedimento de rollback, um relógio global (Global Virtual Time (GVT)) sempre armazena o menor dos LVT's. Dessa forma, se um timestamp menor for gerado, o valor de LVT se torna errado e o processo de rollback é executado para voltar a simulação a um ponto seguro.

- MRIP (Multiple Replication in Parallel): várias replicações do programa de simulação são enviados para os elementos de processamento da arquitetura computacional utilizada. Em cada replicação é gerada uma quantidade de resultados distintos e independentes. O objetivo desse método é coletar os resultados fornecidos por cada replicação para gerar um resultado final entatisticamente válido.

Identificar o método a ser utilizado durante a simulação é uma tarefa que ajuda a garantir a eficiência da mesma. Sendo assim, durante o processo de escolha é necessário avaliar alguns fatores influentes. Os fatores comumente analisados nesse caso, são (HEIDELBERGER, 1986):

- Capacidade de processamento exigido para executar a simulação no tempo mínimo possível;

- Capacidade de comunicação exigida entre os processos contidos em cada elemento de processamento;

- Tempo de duração da simulação;

- warm-up ou período em que o sistema ainda não está estatisticamente em equilíbrio;

- Tamanho do modelo;

- Número de processadores disponíveis;

Independente da abordagem escolhida para a execução da simulação (seqüencial ou distribuída), o sistema deve ser representado por uma técnica de modelagem. Por ser importante no desenvolvimento de uma simulação, está fase será detalhada na próxima seção. 


\subsection{Modelagem}

Ao escolher a simulação como técnica de compreensão e análise de sistemas computacionais, deve-se, como primeiro passo, criar modelos conceituais que possam representar todas as características relevantes do sistema real. Sendo assim, pode-se classificar a etapa de descrição do modelo (modelagem) como etapa de orientação utilizada no processo de desenvolvimento para a criação da simulação.

O principal passo da modelagem é abstrair as características relevantes do sistema real em um modelo conceitual. Esse modelo deve ter a capacidade de representar claramente as características existentes no sistema real atendendo à precisão exigida pela simulação a ser executada (MACDOUGALL, 1987).

Após a identificação das características que serão utilizadas para a descrição do sistema é necessário definir qual técnica será aplicada. Para essa etapa, existem algumas técnicas disponíveis, sendo cada uma específica para um determinado tipo de representação. Dentre as técnicas mais conhecidas, encontram-se: redes de petri (MOORE; BRENNAN, 1995), statecharts (HAREL et al., 1987), queueing statecharts (FRANCÊS, 2001), statecharts estocásticos (FRANCÊS, 2001) e redes de filas (JAIN, 1991) (MENASCé; ALMEIDA, 2003). Dentre essas, será detalhado a seguir a técnica de rede de filas, pois é por meio dessa que os modelos utilizados neste trabalho são representados.

\subsubsection{Redes de Filas}

A técnica de rede de filas é utilizada nas mais diversas áreas da computação para representar sistemas que possuem um grande número de solicitações para a utilização de um recurso em particular (BOLCH et al., 1998). A forma de representação dessa técnica pode ser utilizada para descrever, por exemplo: servidores web (MENASCé; ALMEIDA, 2003) e sistemas computacionais (JAIN, 1991). Esse fato está relacionado ao tipo de funcionamento desses sistemas, visto que existem servidores que recebem diversas solicitações para a utilização de um determinado recurso. Entretanto, para que todas as solicitações sejam atendidas, muitas vezes, essas aguardam um determinado tempo por sua execução. Isso ocorre porque o número de servidores é menor que o número de solicitações, fazendo com que muitas dessas permaneçam em buffers (filas) até a liberação do recurso. A técnica mais utilizada para representar esse tipo de situação são as redes de filas (JAIN, 1991).

Para representar sistemas computacionais, a técnica de redes de filas utiliza alguns componentes básicos: os servidores, as filas de espera e os clientes, os quais são responsáveis por detalhar os recursos disponíveis no sistema. Um exemplo de um modelo descrito utilizando essa técnica pode ser observado na figura 2.3 .

Entretanto, para que a descrição de um sistema se torne realmente completo é necessário, segundo Jain (1991), representar juntamente com a descrição por rede de filas outras variáveis relevantes, tais como:

- Chegada de Clientes: determina o intervalo de tempo entre chegadas de clientes no sistema. 


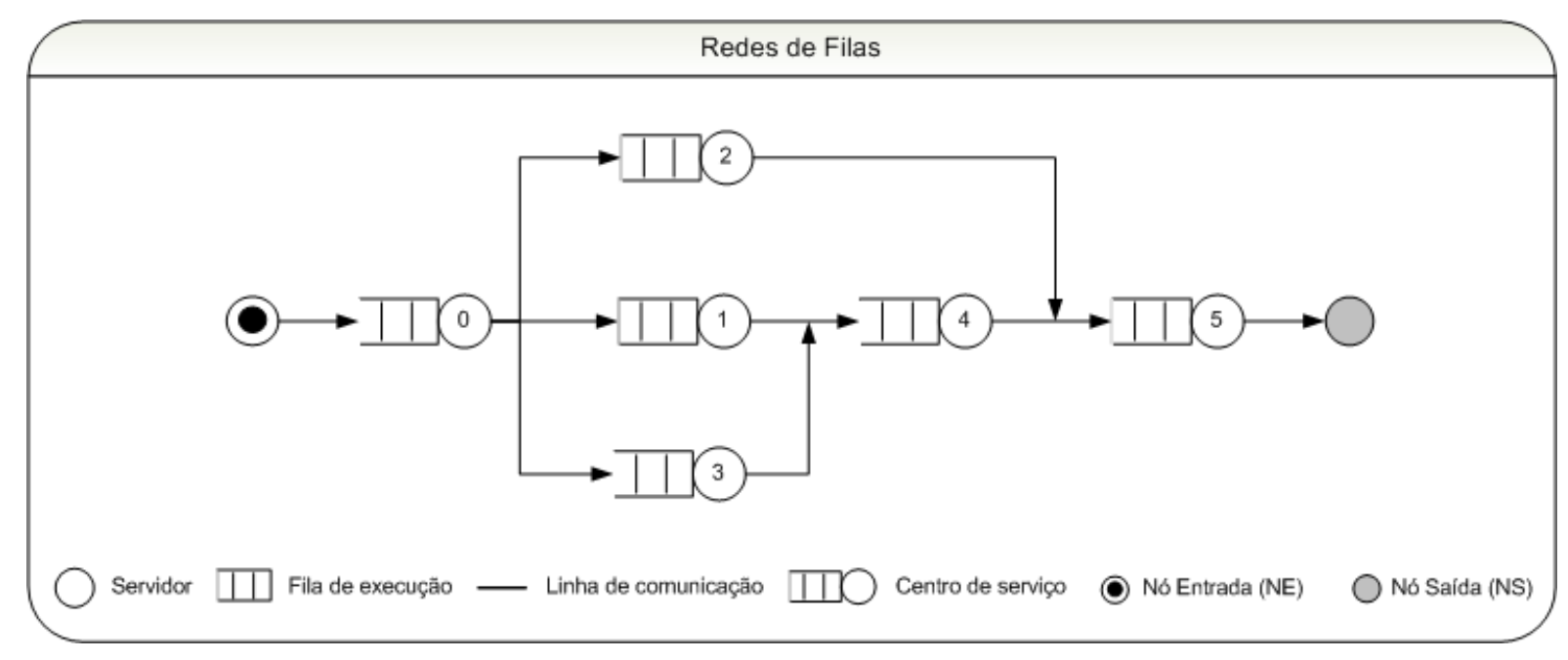

Figura 2.3: Representação de um modelo por redes de filas

- Tempo de Serviço: tempo necessário para o atendimento dos clientes que chegam no sistema. Os valores utilizados nessa variável, freqüentemente seguem uma função de distribuição de probabilidade.

- Número de Servidores: quantidade de servidores existentes em cada centro de serviço.

- Capacidade do Sistema: número máximo de clientes suportado pelo sistema. Essa capacidade máxima é alcançada somando-se os clientes em espera por atendimento com os clientes em fase de atendimento.

- Tamanho da População: quantidade total de clientes que podem vir a chegar no sistema. Essa quantidade também pode ser representada por um número finito ou infinito de clientes.

- Disciplina de Serviço: ordem pela qual os clientes contidos em uma fila são atendidos. A disciplina normalmente utilizada é a FCFS (First Come, First Service). Outras possíveis disciplinas são, LCFS (Last Come, First Service), LCFS-PR (Last Come, First Service with Preempt and Resume).

Embora as variáveis descritas em Jain (1991) possam ser aplicadas para representar as mais diversas situações, estas podem, algumas vezes, tornar a descrição do modelo complexa. Como um dos objetivos deste trabalho é simplificar tal descrição, é associada à técnica de rede de filas mais duas variáveis, as quais são detalhadas a seguir.

- Probabilidade de comunicação: representa a probabilidade de um cliente, saindo de um determinado centro de serviço, seguir para um dos demais centros de serviço com os quais se comunica. De acordo com a figura 2.4, uma mensagem gerada no servidor 0 tem a probabilidade de $40 \%$ de ser enviada ao centro de serviço 1, $30 \%$ de probabilidade ao centro de serviço 2 e $30 \%$ de probabilidade ao centro de serviço 3. 
- Carga de processamento: essa variável indica a carga em MIPS que cada centro de serviço utiliza durante a execução de determinada requisição. Essa carga é utilizada no balanceamento dos processos lógicos que serão submetidos para a execução na arquitetura selecionada. Cada centro de serviço descreve essa carga no próprio servidor juntamente com o número utilizado para classificá-lo no modelo. Por exemplo, o centro de serviço 0 representado na figura 2.4, tem como carga 25 MIPS.

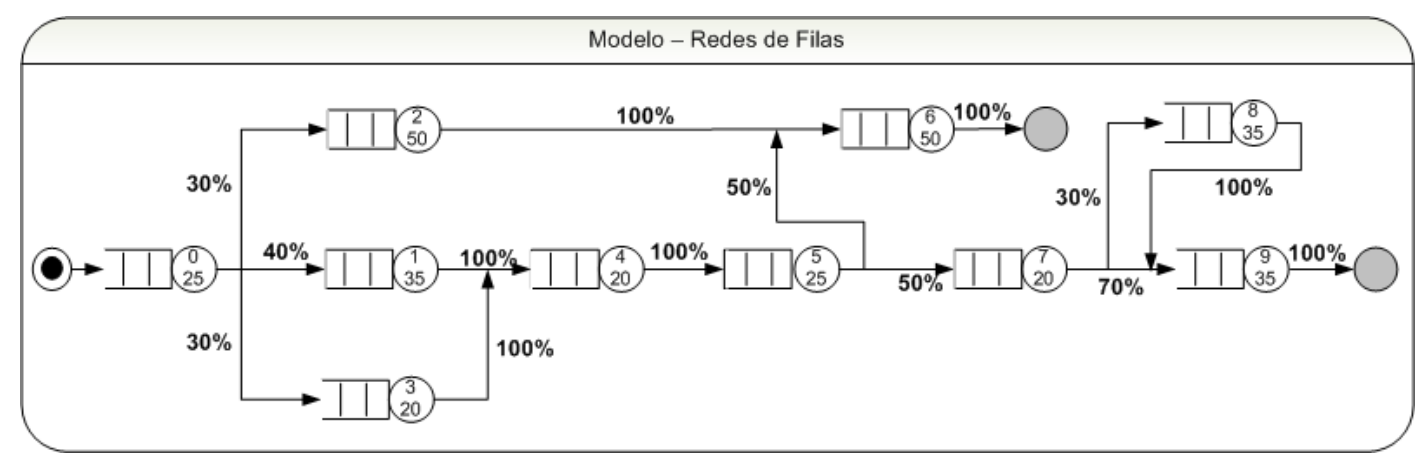

Figura 2.4: Representação da descrição utilizada nos modelos deste trabalho

A variável associada a carga de processamento, quando não detalhada no modelo, é considerada homogênea para todos os servidores existentes. Essa homogeneidade é obtida ao dividir a capacidade total de processamento da arquitetura computacional utilizada pela quantidade de centros de serviço existentes.

Para fazer com que as etapas de uma simulação não se tornem tão complexas e acabem exigindo do usuário um conhecimento avançado sobre o assunto, na próxima seção são apresentadas algumas das ferramentas que podem auxiliá-lo durante o processo de desenvolvimento.

\subsection{Ferramentas para o Desenvolvimento de Simulações}

Como já mencionado anteriormente, o desenvolvimento de uma simulação é constituído de diversas etapas. Nem sempre essas etapas são fáceis de serem executadas, principalmente quando o conhecimento do usuário sobre simulação é mínimo. Para auxiliar o usuário no processo de desenvolvimento de uma simulação, foi criado o conceito de ambientes de simulação. Esses ambientes são estruturados para fornecer ao desenvolvedor a flexibilidade necessária para a compreensão, execução e interpretação de uma simulação. Atualmente, existem vários ambientes com propósitos semelhantes, sendo alguns voltados para simulações comerciais e outros de código aberto para simulações em geral. A seguir são apresentados alguns desses ambientes e suas principais características.

\section{- $\mathrm{OMNet}++$}

O OMNet++ é um ambiente criado no meio acadêmico para simular redes de computadores, multiprocessadores, sistemas distribuídos e sistemas industriais. Algumas de suas características, segundo Irme et al. (2001), são: 
- O OMNet tem como vantagem, ao ser comparado com os demais ambientes, a utilização de uma linguagem padrão já muito conhecida, o $\mathrm{C}++$. Isso facilita a sua manipulação por programadores já experientes nessa linguagem.

- Oferece ao usuário suporte a uma interface gráfica.

- A ferramenta oferece portabilidade das simulações para diversos sistemas, como SO's baseados em Unix e Windows.

- Muitas estruturas diferentes podem ser simuladas modificando o código fonte e recompilando o sistema.

- A existência da linguagem de descrição de topologias NED (Network Description Language), a qual desconsidera a necessidade de escrita do código de todos os módulos $\mathrm{C}++$ para a construção de uma simulação, fazendo boa parte do processo de forma automática.

- A própria interface gráfica oferece muitas possibilidades para a execução e verificação de erros na simulação.

- O usuário pode utilizar muitas classes e módulos pré-definidos pela linguagem.

Uma demonstração gráfica desse ambiente pode ser observado na figura 2.5, onde uma rede do tipo Token Ring é representada.

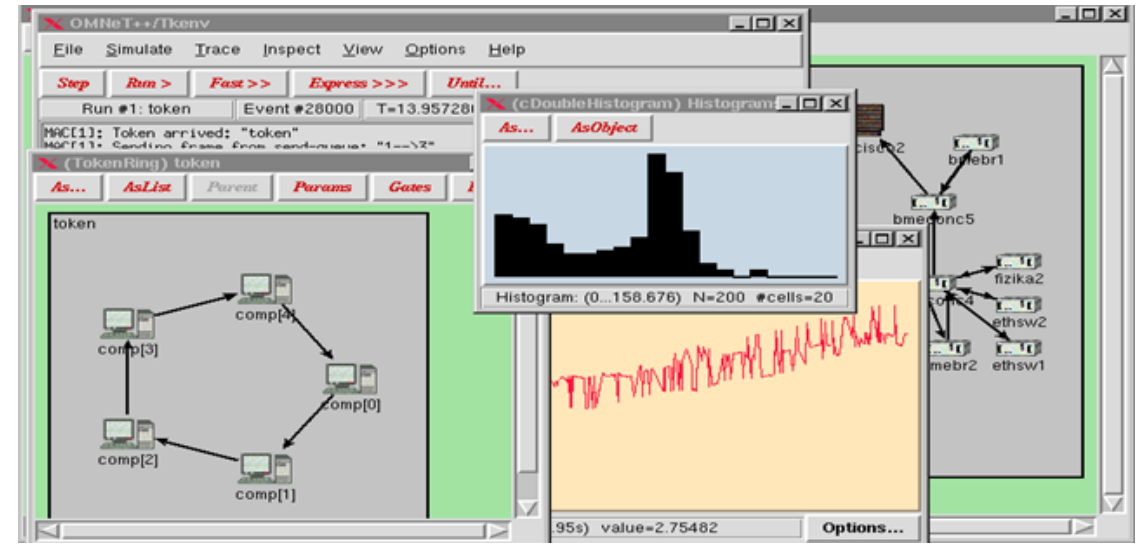

Figura 2.5: Simulação de uma rede Token Ring utilizando OMNet++ (IRME et al., 2001)

Uma característica negativa desse ambiente é a pouca flexibilidade de manipulação de suas funções. Isso faz com que o ambiente se torne complexo para usuários providos de pouco conhecimento no assunto.

\section{- ARENA}

O Arena é um ambiente para simulações comerciais de propósito geral. Seu objetivo é fornecer métodos que sejam capazes de auxiliar a tomada de decisões estatísticas, ou seja, fornecer suporte ao usuário durante o processo de compreensão e interpretação de dados referentes ao funcionamento de uma empresa. Sua interface disponibiliza métodos e procedimentos que podem representar, de forma precisa, até mesmo uma linha de produção 
completa, onde informações como, capacidade máxima de produção e funcionamento de determinado processo, podem ser observados e avaliados. Uma demonstração da interface utilizada pelo ARENA pode ser observada na figura 2.6 .

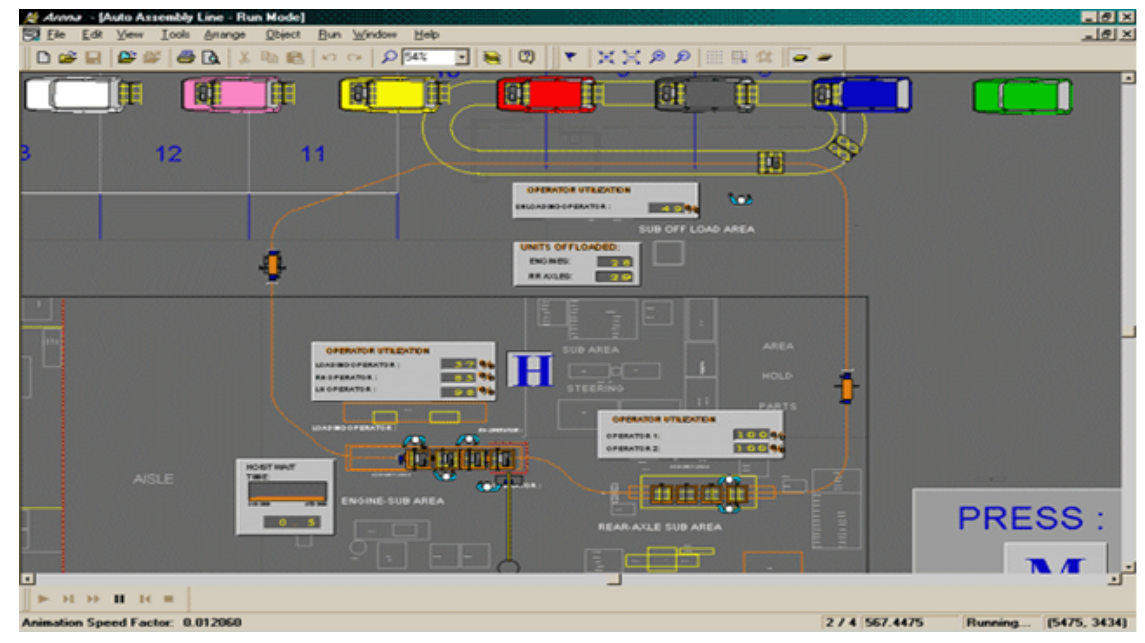

Figura 2.6: Demonstração do ambiente de simulação ARENA (BAPAT; SWETS, 2000)

Para a construção de simulações, o ARENA utiliza como linguagem de programação o SIMAN (SIMulation Analysis). Essa linguagem é proprietária do ambiente, sendo necessário que o usuário aprenda a codificar suas simulações a partir das instruções nela contidas. O SIMAN pode ser apresentado como o ponto negativo do ambiente ARENA, pois se trata de uma linguagem especifica para simulação.

\section{- $\mathrm{ASiA}$}

O ASiA (Ambiente de Simulação Automático) foi desenvolvido na área acadêmica para a obtenção de resultados de forma seqüencial em simulação. Sua finalidade é fornecer uma interface gráfica amigável (figura 2.7) que receba o modelo proposto como entrada e, a partir desse, execute as demais fases do desenvolvimento automaticamente. A vantagem desse ambiente está em afastar o usuário da tarefa de codificação da simulação, deixando isso a cargo da própria ferramenta. Para a construção de seu projeto, foram considerados quatro etapas principais:

- Editor Gráfico: utilizado para o desenvolvimento de modelos a partir de uma interface amigável. Essa interface permite ao usuário modelar os sistemas por meio da técnica de rede de filas.

- Gerador de aplicações: essa etapa recebe o modelo desenvolvido na fase anterior e o transcreve para um programa de simulação utilizando a biblioteca SMPL (MACDOUGALL, 1987).

- Execução da simulação: a partir da transcrição do modelo e a geração de todo código da simulação é iniciado a etapa de execução para a coleta de resultados.

- Estágio de saída: por fim tem-se a fase de estágios de saída, onde é fornecido ao usuário uma série de gráficos que facilitaram o processo de análise e validação. 


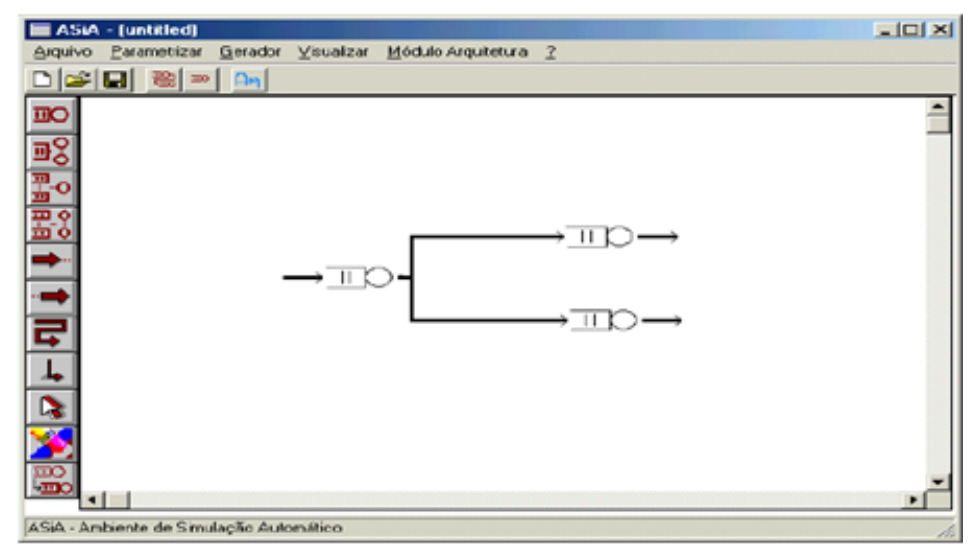

Figura 2.7: Tela principal do edito gráfico do ambiente ASiA (BRUSCHI, 2002)

A única forma de coletar resultados no ASiA é por meio de execuções seqüenciais da simulação. Essa característica pode se tornar negativa, visto que, a execução seqüencial pode, em alguns casos, prejudicar o desempenho da simulação devido ao alto tempo para se obter os resultados válidos para a análise.

\section{- NS2}

O NS2 (Network Simulation 2) é um simulador orientado a objetos que utiliza como linguagens para o desenvolvimento de simulações o C++ e o OTcl. Seu objetivo é simular redes de computadores e protocolos de comunicação. Os motivos que levam o NS2 a utilizar duas linguagens de programação são (FALL; VARADHAN, 2000):

- Ao se simular uma rede de computadores, tem-se que essa rede pode ser modelada para se comportar de diversas formas distintas. Sendo assim, para acelerar o processo de modificações, o NS2 fornece a linguagem OTcl. Essa linguagem, mesmo lenta nas execuções, fornece uma metodologia de modificações rápida se comparada com as oferecidas pela linguagem $\mathrm{C}$.

- A utilização da linguagem C++ no NS2 fornece um maior suporte quando, o estudo da simulação é voltada para protocolos de comunicação. Isso é porque o $\mathrm{C}++$ pode solicitar de maneira fácil uma série de chamadas ao sistema através de systems calls, as quais possibilitam modelar os protocolos de forma confiável. Outro aspecto positivo é que os protocolos de comunicação não possuem modificações contínuas mas devem ser executados de forma rápida, o que faz da linguagem $\mathrm{C}++$ uma linguagem eficaz para esse tipo de simulação.

Um trecho de script TCL utilizado para representar uma rede simples com quatro nós no NS2 pode ser observado na figura 2.8 .

O script apresentado na figura 2.8, pode ser utilizado para verificar uma característica negativa desse ambiente. Essa característica está associada à dificuldade de utilização e codificação de modelos, sendo necessário que o usuário tenha conhecimento prévio sobre as linguagens e recursos disponíveis exigidos pelas etapas de construção da simulação. 


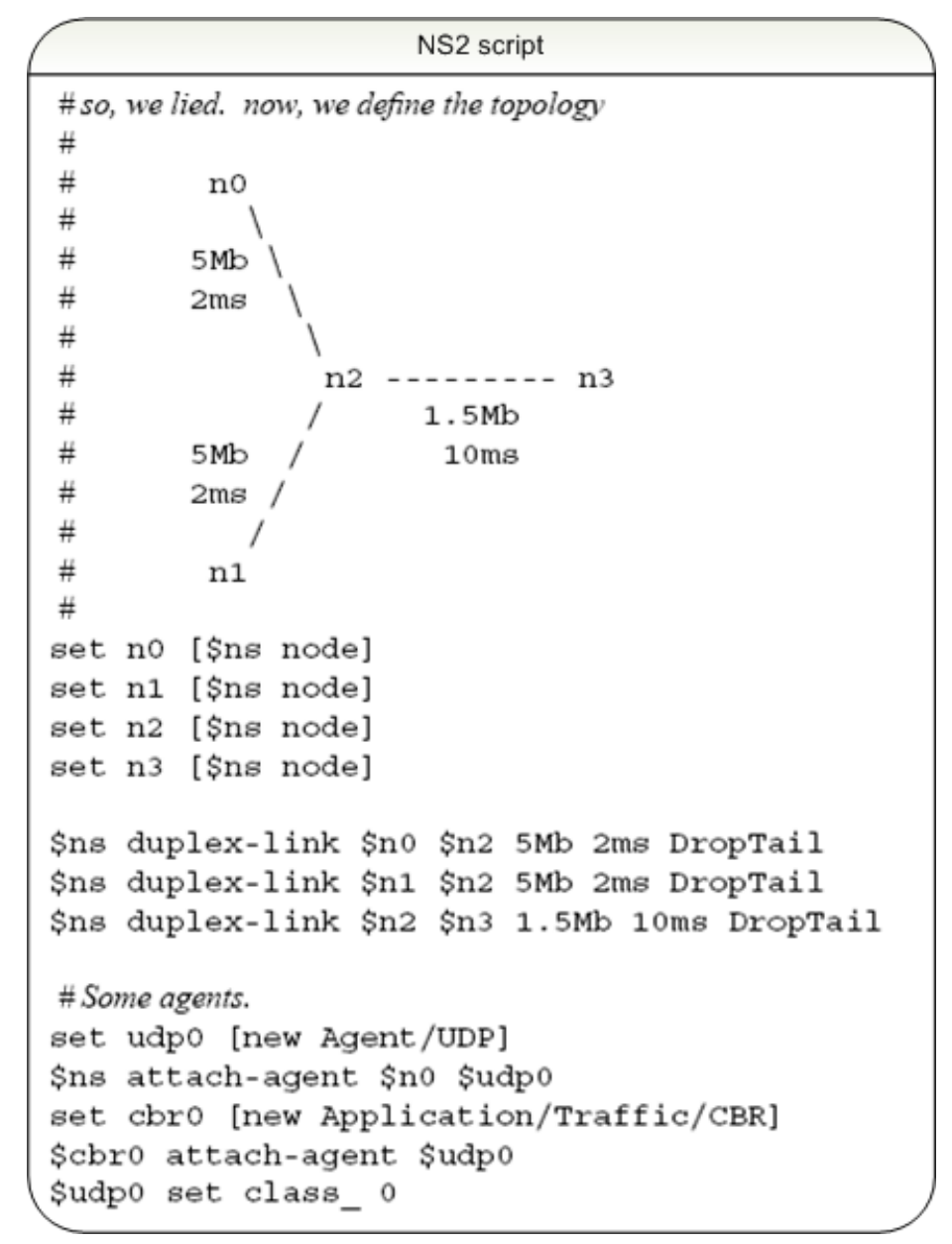

Figura 2.8: Exemplo de script utilizado pelo NS2 (FALL; VARADHAN, 2000)

\section{- OPNet}

O OPNet é um ambiente de simulação utilizado para especificar, simular e analisar a performance de redes de computadores. Esse ambiente fornece diversos tipos distintos de equipamentos (roteadores) já configurados com os requisitos estipulados pelo próprio fabricante. O processo utilizado por esse ambiente durante a construção e análise de uma simulação pode ser dividido em cinco fases (DIAS; CORREA; ABRãO, 2003):

- Definição do problema: nessa etapa é feito o levantamento dos equipamentos e serviços disponíveis na rede, bem como a definição de quais problemas serão analisados durante a execução da simulação.

- Construção do modelo: nessa fase, a partir do problema já definido, tem-se início a construção do modelo.

- Simulação: após definido quais parâmetros serão considerados no modelo, inicia-se a execução da simulação.

- Análise: é nessa etapa do processo que a compreensão dos dados gerados pelo simulador é realizada.

- Resultados: a partir da análise dos resultados, feita pelas etapas anteriores, as conclusões sobre alterações e melhorias no ambiente devem ser tomadas. 
Atualmente, o OPNet é considerado o mais completo e poderoso ambiente de simulação para redes de computadores. As características negativas encontradas nesse ambiente são: o seu elevado preço comercial (aquisição de licenças de uso) e a impossibilidade de acesso a seu código fonte (não se tem conhecimento de como o processo de execução é realizado).

\section{- ASDA}

O ASDA (Ambiente de Simulação Distribuída Automático) é um ambiente desenvolvido para analisar o comportamento de sistemas computacionais. Esse ambiente tem por objetivo automatizar todo processo de desenvolvimento de uma simulação distribuída, permitindo que diferentes níveis de usuários possam utilizá-lo. Esses níveis estão relacionados com o conhecimento que o usuário possui sobre assunto, permitindo assim classificá-los da seguinte forma (BRUSCHI, 2002):

- Usuários que possuem conhecimento superficial tanto de simulação quanto de computação paralela.

- Usuários com conhecimento em simulação e computação paralela, mas que disponham de pouco tempo para o desenvolvimento de simulações.

- Usuários que desejam simular um sistema de maneira seqüencial e distribuída de forma a analisar o desempenho do mesmo.

- Usuários que apresentam um grande conhecimento em simulação e pouco conhecimento em computação paralela.

Para oferecer um ambiente que atenda diferentes níveis de usuário, o ASDA tem como metodologia de construção dois princípios básicos: a flexibilidade do ambiente e a modularização na construção da simulação. A flexibilidade tem por objetivo prover os seguintes fatores de auxílio durante o desenvolvimento (BRUSCHI, 2002):

- Oferecer ao usuário um ambiente de fácil aprendizagem e utilização.

- Possibilitar a geração completa de um programa de simulação para um usuário com menor experiência em simulação.

- Oferecer flexibilidade necessária para que um usuário mais experiente possa modificar os programas gerados.

- Possibilitar a utilização de simulações seqüenciais já desenvolvidas.

- Oferecer diretrizes para que o usuário possa escolher entre abordagens de simulações distribuída. Se o usuário preferir, o ambiente deve ser capaz de selecionar a abordagem mais adequada de maneira automática.

- Facilitar a obtenção de dados confiáveis por meio da avaliação estatística dos resultados gerados pela simulação.

- Minimizar o tempo de execução da simulação, oferecendo uma partição adequada ao modelo, quando esse utilizar a abordagem SRIP. 
Sabendo-se da dificuldade para prover todas as flexibilidade de uma única vez, o projeto de construção do ambiente ASDA foi dividido em vários módulos. A seqüencia de desenvolvimento do ASDA pode ser observado no diagrama apresentado na figura 2.9, sendo o detalhamento desses realizado logo a seguir (BRUSCHI, 2002):

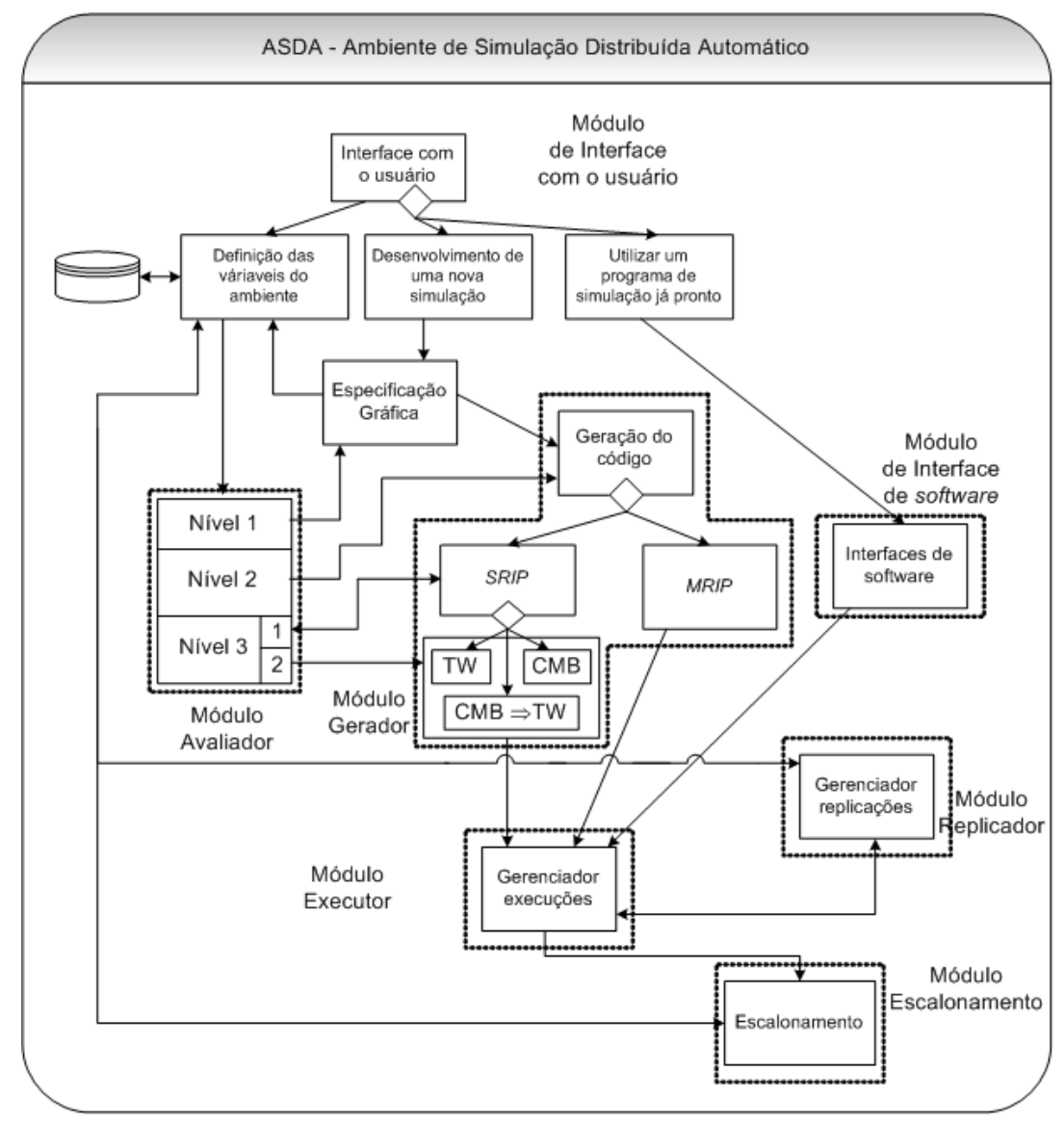

Figura 2.9: Diagrama modular do ASDA (BRUSCHI, 2002)

- Módulo de interface com o usuário: responsável por oferecer ao usuário uma interface que possibilite um acesso fácil às opções disponibilizadas pelo ambiente, ao mesmo tempo que oferece flexibilidade para usuários que prefiram tomar suas próprias decisões. Esse módulo é responsável ainda por oferecer ao usuário um editor gráfico para definir os modelos a serem simulados.

- Módulo avaliador: tendo como base as variáveis do ambiente e o modelo a ser simulado, esse módulo é responsável por orientar o usuário na difícil tarefa de escolher o melhor método (MRIP ou SRIP) para a simulação.

- Módulo gerador: ao finalizar as etapas de especificação do modelo e decisão do método de simulação a ser utilizado, esse módulo criará a partir dos dados fornecidos pelo usuário o código fonte da simulação.

- Módulo executor: responsável por controlar a execução do programa de simulação. Esse módulo acessá a base de dados de projetos do usuário, identifica qual o projeto que será executado e inicia a execução da simulação. 
- Módulo de interface de software: fornece ao usuário uma interface entre os programas de simulação já desenvolvidos e o módulo replicador.

- Módulo replicador: gerencia as replicações da simulação e garante a obtenção de resultados confiáveis, utilizando para isso o método MRIP.

- Módulo escalonador: responsável pelo escalonamento dos processos gerados pelo módulo executor.

Para fazer do ASDA um ambiente de simulação ainda mais completo, este trabalho visa desenvolver uma técnica para automatizar a etapa de particionamento de modelos quando a execução da simulação for realizada pelo método SRIP. O objetivo é fornecer o auxílio necessário, evitando que um particionamento ruim possa prejudicar a etapa do módulo executor.

\subsection{Considerações Finais}

Os ambientes desenvolvidos para a criação e execução de simulações são facilitadores que apresentam como vantagens o baixo custo da criação e execução da simulação e a flexibilidade de manipulação das etapas de desenvolvimento associada às abordagens seqüencial e distribuída. Sua aplicação tem como objetivo simplificar as etapas de construção de uma simulação fazendo com que usuários com pouco conhecimento possam utilizar dessas ferramentas como formas de auxílio.

O tipo de auxílio provido pelos ambientes de simulação vêm sendo modificado a cada novo ambiente criado. Muitos desses ambientes já fazem uso da inteligência artificial para prover ao usuário a automatização de etapas do desenvolvimento de simulações. Algumas das técnicas de inteligência artificial que podem ser aplicadas com esse objetivo são apresentadas no próximo capítulo. 


\section{Capítulo}

\section{3}

\section{Ferramentas de Auxílio à Tomada de Decisões}

\subsection{Considerações Iniciais}

Atualmente, algumas áreas do conhecimento vêm enfrentando problemas com graus de complexidade cada vez mais altos. A dificuldade em compreende-los está fazendo com que várias dessas áreas adotem ferramentas que possam auxiliar a tomada de determinadas decisões.

Em simulação, ferramentas de auxílio à tomada de decisões vêm sendo utilizadas para minimizar o esforço do usuário no processo de desenvolvimento e criação de simulações. Essas ferramentas apresentam, dentre suas características, a automatização de algumas etapas desse processo por meio da aplicação de técnicas de inteligência artificial (IA). Uma das etapas que é possível aplicar técnicas de IA para auxiliar a tomada de decisão é o particionamento de modelos. Como o presente trabalho tem por objetivo propor uma forma de automatizar a etapa de particionamento, este capítulo é destinado a detalhar algumas técnicas de IA que podem ser aplicadas com esta finalidade.

Este capítulo apresenta as técnicas de IA que foram consideradas neste trabalho, comparandoas de modo a apresentar as vantagens e desvantagens de cada uma. Para tanto, a seção 3.2 apresenta as características de uma rede neural artificial e seus passos de construção. A seção 3.3 é utilizada para detalhar a lógica fuzzy e problemas que podem ser aplicados a sua estrutura de desenvolvimento. Para fins de comparação com essas técnicas são apresentados na seção 3.4 os algoritmos evolutivos. A seção 3.5 detalha um comparativo realizado entre as técnicas apresentadas, sendo logo a seguir, na seção 3.6 apresentado o algoritmo escolhido para prover o auxílio à tomada de decisão para o particionamento de modelos em simulação distribuída. 


\subsection{Redes Neurais Artificiais}

As redes neurais artificiais surgiram em 1943, sendo McCulloch e Pitts os pesquisadores que apresentaram em McCulloch e Pitts (1943) o que seria a primeira tentativa de se descrever um neurônio artificial (figura 3.1). A idéia básica apresentada por esses pesquisadores prevalece até hoje e visa descrever as funcionalidades de um cérebro humano, utilizando-se para isso modelos matemáticos aplicados a uma estrutura básica de construção (neurônio artificial).

O neurônio artificial possui em sua estrutura uma série de entradas $\left(X_{n}\right)$ que representam os padrões a serem avaliados. Esses padrões, por sua vez, são combinados aos pesos sinápticos $\left(W_{n}\right)$ da rede. Para cada uma das entradas $X_{n}$, há um peso $W_{n}$ associado a entrada no neurônio. Cada peso armazena um valor entre 0.1 e 1 para representar o conhecimento da rede. Esse conhecimento é aplicado a um somatório juntamente com as entradas (equação 3.1) para gerar uma saída linear $Y$. Essa saída, chamada de saída de ativação, é obtida ao aplicar a saída da função somatório à função de ativação $f($.), como por exemplo, as funções da figura 3.5 . Um exemplo da descrição do neurônio associado a suas variáveis pode ser observado na figura 3.1 .

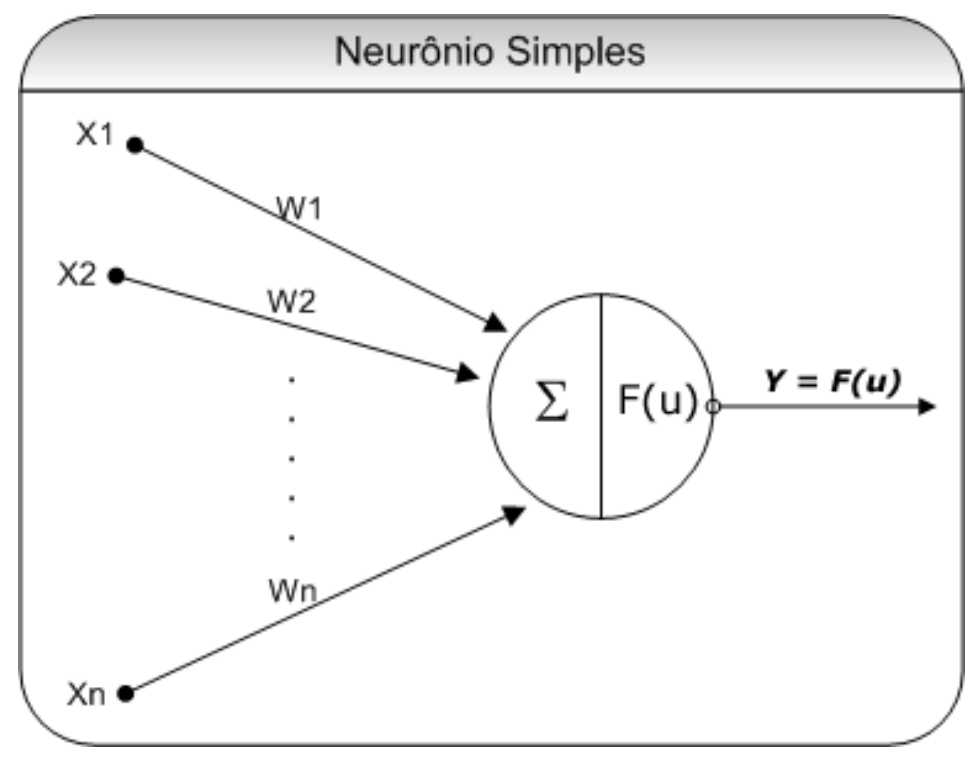

Figura 3.1: Neurônio apresentado por McCulloch e Pitts em 1943 (MCCULLOCH; PITTS, 1943)

$$
F(u)=\sum_{n=1}^{m} W_{n} * X_{n}
$$

Como o cérebro humano é capaz de assimilar conhecimento e tomar decisões baseadas em aprendizagem, a idéia inicial apresentada por McCulloch e Pitts não foi totalmente aceita, visto que a capacidade para o armazenamento de conhecimento era muito limitada. Com isso, as pesquisas referentes as redes neurais artificiais, na década de 40, pararam por falta de motivações.

Em 1982, com o reinício das pesquisas, teve-se o surgimento de uma representação mais próxima do que poderia vir a ser um cérebro artificial baseado na biologia humana HAYKIN, 2001). Essa representação, um tempo mais tarde, seria apresentada como a técnica conhecida 
por redes neurais artificiais.

Com a evolução da técnica das redes neurais, notou-se que para representa-la a partir de modelos matemáticos, seria necessário a utilização de alguns componentes básicos. Esses componentes seriam responsáveis por fazer com que a rede realmente adquirisse conhecimento para trabalhar com problemas complexos. Tais componentes são: os canais de comunicação, os pesos sinápticos e a função de ativação.

A comunicação realizada em uma rede neural tem por objetivo interligar os neurônios, construindo uma estrutura maciçamente paralela e distribuída para resolução dos mais diversos tipos de problemas (HAYKIN, 2001). De acordo com essa estrutura, uma rede neural pode ser classificada em uma das seguintes categorias (BRAGA; CARVALHO; LUDERMIR, 2003):

- Redes de camada única

- Redes de múltiplas camadas

A rede de camada única é a forma mais simples utilizada para representar uma rede neural. Basicamente, sua descrição foi definida nas pesquisas de 1943, as quais descrevem a utilização de um único neurônio para solucionar problemas. Esse tipo de rede possui várias limitações que restringem sua capacidade de aprender e solucionar problemas complexos. Por essa razão, não se pode utilizá-las quando o problema a ser analisado apresenta uma grande quantidade de informações que devem ser aplicadas como padrões de entrada. Essas limitações fizeram com que as pesquisas nessa área parassem, voltando somente em meados da década de 80, quando as redes conhecidas como redes de múltiplas camadas foram apresentadas.

As redes de múltiplas camadas ou MLP's (Multi Layer Perceptron), representaram a evolução das redes neurais, visto que sua estrutura pode apresentar uma descrição aproximada do cérebro humano. Essa estrutura utiliza em sua definição vários neurônios artificiais distribuídos em diferentes camadas de atuação (figura 3.2). Essas camadas são classificadas como: camada de entrada, camadas intermediárias e camada de saída.

A camada de entrada de uma rede MLP é utilizada para receber os padrões do mundo externo e iniciar a processamento dos mesmos. O resultado gerado por essa camada é passado para a camada intermediária por meio das conexões estabelecidas com os neurônios. Sabendose que todo neurônio possui uma linha de conexão com os demais neurônios a sua frente, os valores resultantes de cada camada são passados para todos os neurônios da camada seguinte.

Dependendo do problema, as redes neurais MLP podem apresentar diferentes formas de conexão. Essa forma de conexão pode classificar o tipo da rede em duas diferentes categorias apresentadas a seguir (BRAGA; CARVALHO; LUDERMIR, 2003):

- Redes feedforward ou acíclicas: Redes interligadas continuamente, ou seja, todas as saídas de cada camada devem ser ligadas somente nas camadas sucessoras a ela (figura 3.2 .

- Redes feedback ou cíclicas: São redes que, usualmente, fazem interligações da i-ésima camada com camadas antecessoras a ela. Esse tipo de ligação é utilizado para minimizar o tempo que a rede gasta na compreensão dos padrões a serem analisados. 


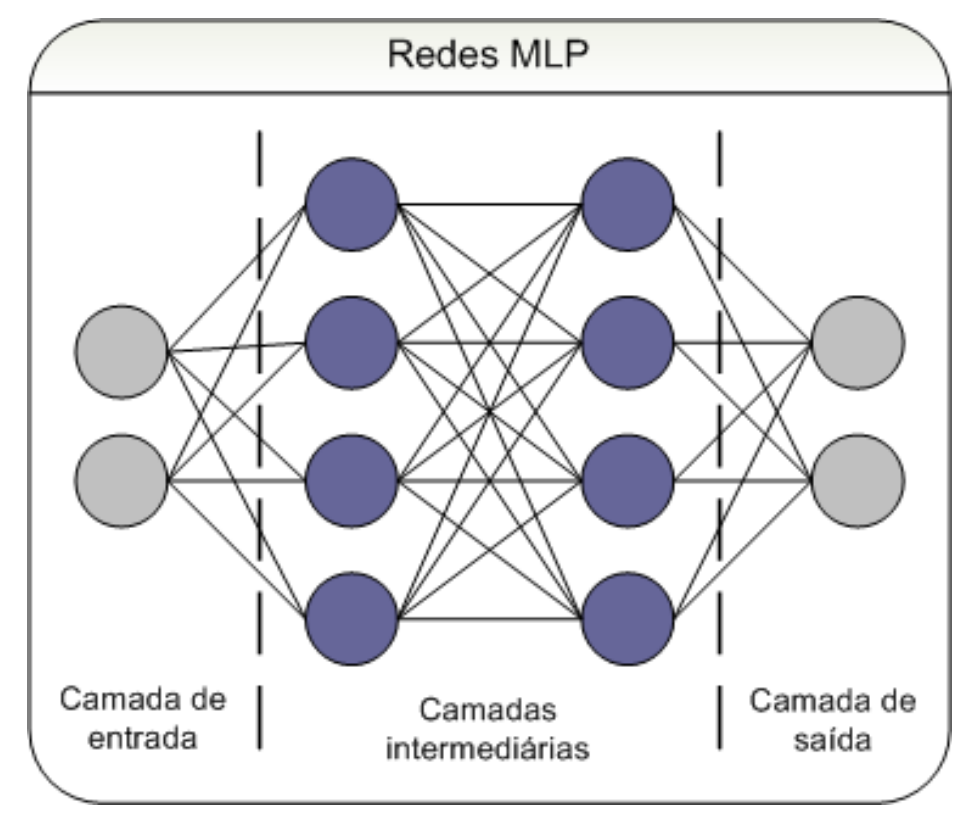

Figura 3.2: Representação de uma rede organizada em múltiplas camadas

A principal diferença entre as redes do tipo feedforward e feedback é a maneira com que cada uma trata as modificações dos pesos sinápticos associados a seus neurônios. A feedforward faz o ajuste de uma maneira contínua, ou seja, ajusta todos os pesos da rede de uma só vez e a rede feedback utiliza um algoritmo de programação de erro, o qual realiza a alteração dos mesmos por camada.

Mesmo tendo a forma de alteração dos pesos distinta, as redes feedforward e feedback possuem o mesmo procedimento de treinamento. Isso permite que alterações sejam realizadas em cada peso sináptico fazendo com que esses armazenem todo o conhecimento que a rede adquirir. Existem diferentes formas de se executar o treinamento de uma rede, sendo os métodos clássicos denominados: Aprendizagem supervisionada e Aprendizagem não-supervisionada. Uma descrição da forma de utilização de cada método pode ser observada a seguir (HAYKIN, 2001) (BRAGA; CARVALHO; LUDERMIR, 2003):

- Aprendizagem supervisionada: Esse método utiliza um supervisor (professor) externo, o qual compara os parâmetros fornecidos como entrada com os obtidos como saída. Sua função no processo de aprendizagem é identificar as semelhanças entre os parâmetros, realizando se necessário, a modificação dos valores dos pesos sinápticos. O funcionamento desse método pode ser observado na figura 3.3 , onde o professor é o encarregado de observar as saídas da função somatório e submeter para a rede neural, se for o caso, um novo valor de erro. Esse erro é utilizado pela rede neural para modificar os pesos sinápticos, adequando-os para prover soluções corretas.

- Aprendizagem não-supervisionada: No método não-supervisionado, não existe um professor para auxiliar ou criticar o processo de aprendizagem da rede (figura 3.4). Esse método é utilizado em bases de dados complexas, cuja compreensão é dificultada. O aprendizado não-supervisionado utiliza, para substituir o professor, uma função que calcula o valor de erro automaticamente e, se necessário, ajusta os pesos sinápticos para 


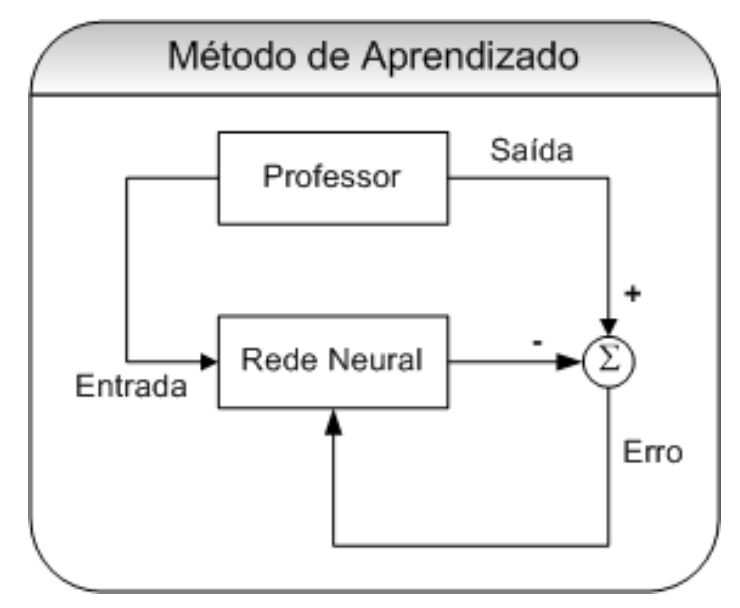

Figura 3.3: Diagrama do aprendizado supervisionado (BRAGA; CARVALHO; LUDERMIR, 2000)

emitirem saídas adequadas. Seu processo de aprendizagem pode se basear, por exemplo, na filosofia de competitividade entre respostas, cujos neurônios de uma mesma camada competem entre si para identificar o padrão submetido como entrada (HAYKIN, 2001).

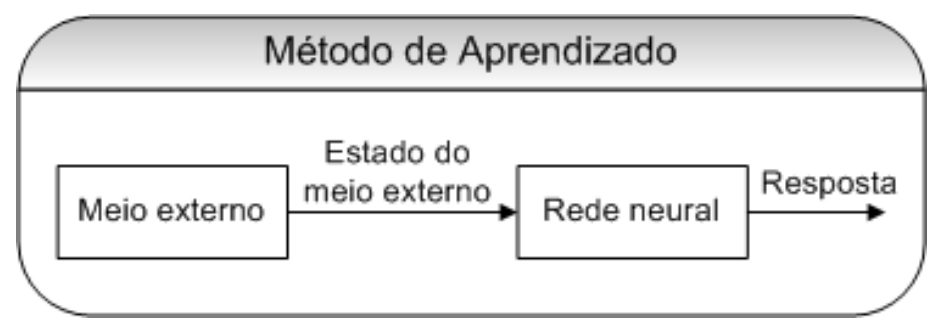

Figura 3.4: Aprendizado não-supervisionado (BRAGA; CARVALHO; LUDERMIR, 2000)

A forma como uma rede neural passa pela fase de treinamento pode influenciar o resultado final almejado. Para que o desempenho da rede não se torne insatifatório para solucionar determinados problemas, deve-se avaliar alguns fatores antes de selecionar o método de treinamento a ser adotado. Alguns dos fatores que podem vir a ocorrer são:

- Se o problema for complexo, a utilização de um professor não será a melhor alternativa a ser utilizada. Isso porque há uma grande dificuldade em se tentar descobrir semelhanças entre os padrões de entrada e de saída.

- O treinamento supervisionado é geralmente considerado um treinamento mais rápido. Dessa maneira, um tempo deve ser disponibilizado para testes, visto que, essa metodologia não utiliza um professor para validar as respostas.

- A possibilidade do crescimento das informações pode confundir o professor, fazendo com que esse nunca ache um ponto adequado de convergência entre os padrões de entrada e de saída. Esse tipo de situação pode afetar o desempenho da técnica, obtendo soluções não tão adequadas quanto necessário.

Se o treinamento for finalizado com sucesso, será gerado como resultado uma rede neural artificial capaz de reconhecer padrões idênticos ou semelhantes aos utilizados no processo de 
aprendizado. Sendo assim, a próxima etapa de construção a ser realizada é a fase de testes, a qual identifica se a rede neural foi treinada corretamente para prover soluções adequadas.

$\mathrm{Na}$ fase de teste são inseridos como entrada para a rede padrões semelhantes aos utilizados na faze de aprendizagem. Tais padrões são submetidos a um processo de execução responsável por gerar entradas para a função de ativação implementada em cada neurônio. Essa função de ativação faz uma verificação para validar essas entradas e submeter como saída um valor que possa ativar ou não o neurônio, de forma a permitir que esse possa emitir essa valor como resposta.

Atualmente, existem várias funções de ativação utilizadas para realizar o processo de verificação de padrões. As funções clássicas utilizadas nesse processo são (BRAGA; CARVALHO; LUDERMIR, 2003): função linear, função rampa, função degrau e função sigmóide, as quais possuem intervalos de confiança distintos que são utilizados para representar uma certa quantidade diferente de valores de saída, os quais estão entre o intervalo - 1 à 1 . A representação desse intervalo e os possíveis valores compreendidos por cada uma dessas funções pode ser observado nos gráficos representados na figura 3.5 .

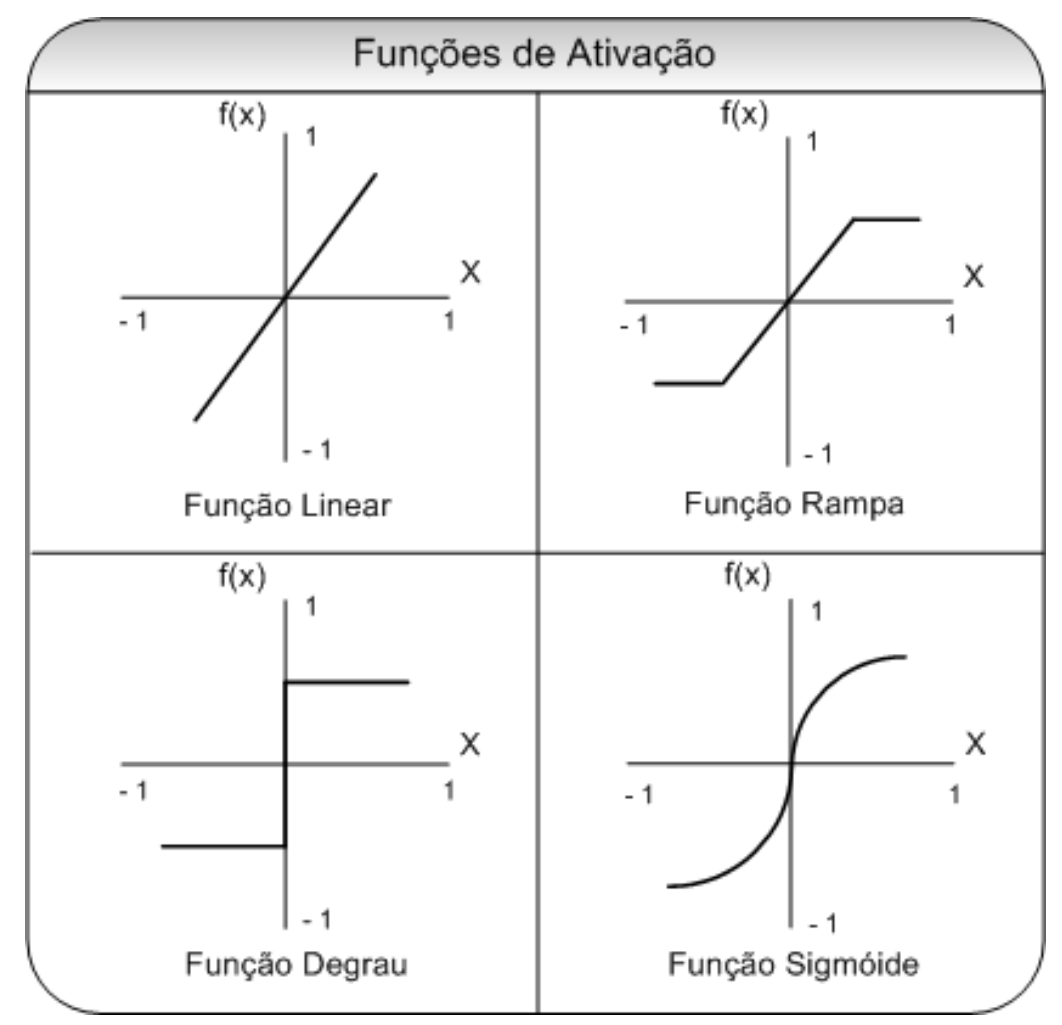

Figura 3.5: Representação gráfica das funções de ativação (REZENDE, 2003)

Ao utilizar uma rede neural artificial como forma de auxílio na solução de um problema, deve-se levar em consideração algumas desvantagens que podem afetar os resultados a serem obtidos. Uma desvantagem é a dificuldade em se compreender as respostas fornecidas pela rede, pois não há como saber qual o caminho seguido para obter os resultados. Por essa razão, uma rede neural artificial é conhecida na área da IA como técnica da caixa preta. Outra desvantagem das redes neurais é a necessidade de se obter uma base de dados relativamente grande para que a rede possa passar pelas etapas de treinamento e teste. Isso faz com que essa técnica torne-se 
inviável para auxiliar problemas do tipo: pouco conhecidos, com dados imprecisos ou problemas com mudanças contínua de estado. De forma a prover boas soluções nesses casos, a inteligência artificial utiliza lógica fuzzy como técnica de auxílio.

\subsection{Lógica Fuzzy}

A lógica fuzzy ou lógica nebulosa foi desenvolvida tendo como objetivo se obter conclusões a partir de dados imprecisos, vagos, incertos e ambíguos (ALMEIDA; EVSUKOFF, 2003) (SANDRI; CORREA, 2004). Originada da teoria clássica dos conjuntos, a lógica nebulosa utiliza uma estrutura básica formada de variáveis lingüísticas e regras de construção. Essa estrutura tem por objetivo aproximar a forma de se tratar os dados em um computador da maneira de pensar utilizada pelo ser humano. Um tipo de informação compreendida e interpretada pela técnica pode ser observada no exemplo a seguir.

"Se a temperatura está quente e aumentando lentamente, então aumente o resfriamento para frio"

Nesse exemplo, as variáveis lingüísticas são representadas pelas palavras: quente, lentamente e frio. Essas palavras são utilizadas pela técnica para criar as regras de construção. Uma maneira de criar regras de construção para essas variáveis lingüísticas é utilizando estruturas de decisão a seguir:

$$
\text { "if temperatura }>=n \text { and TaxadeAumento }<=x \text { then temperaturaNova }=y \text { " }
$$

Tem-se com essa descrição, $n$ representando a temperatura coletada do meio externo, sendo então comparada com a taxa que essa temperatura está sofrendo variações periódicas $x$. O resultado da comparação é uma nova temperatura $y$, apresentada como taxa correta de resfriamento necessário a ser aplicado.

Uma outra forma de representação utilizada para descrever as variáveis lingüísticas de um problema é a forma gráfica. Um exemplo dessa descrição pode ser observado na figura 3.6.

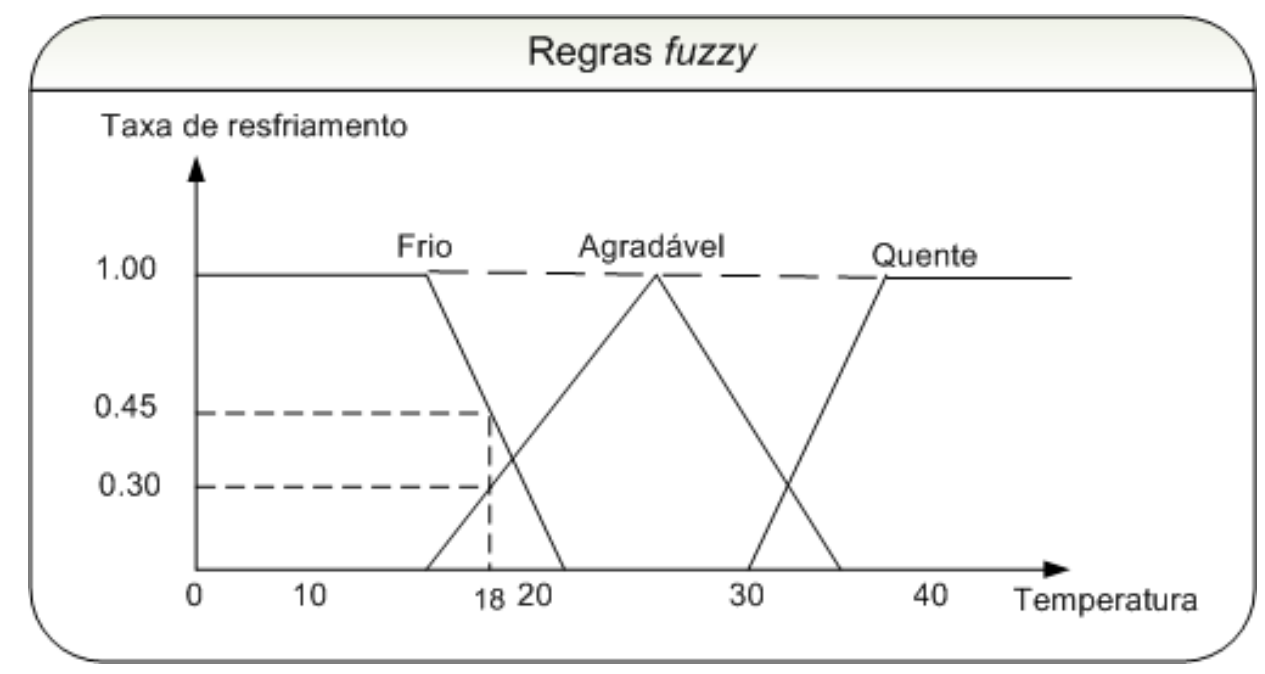

Figura 3.6: Gráfico fuzzy para representar a temperatura ambiente (WEBER; KLEIN, 2003) 
No exemplo da figura 3.6 a representação das variáveis lingüísticas pode, algumas vezes, tornar o problema mais simples de ser compreendido. Por exemplo, aplicando as regras fuzzy nessa representação, pode-se afirmar que: 18 graus de temperatura apresenta uma taxa de resfriamento de 0.45 para frio e, ao mesmo tempo, 0.30 para agradável. Dessa forma, tem-se que a temperatura 18 graus é considerada mais para frio do que para agradável, mas ao mesmo tempo não deixa de ser um pouco agradável dependendo da situação. Dessa forma, por meio dessa interpretação dos dados, pode-se optar por diferentes ações, dependendo do objetivo a ser alcançado.

Embora a lógica fuzzy trabalhe com dados imprecisos e confusos, sua aplicação não é tão simples de ser realizada, principalmente, no que se refere a criação de suas regras de construção. Essa dificuldade é contornada na área da inteligência artificial com a aplicação de métodos baseados nos algoritmos evolutivos.

\subsection{Algoritmos Evolutivos}

Os algoritmos evolutivos, ou computação evolutiva, é uma técnica de inteligência artificial inspirada na teoria da evolução natural de Darwin (ZUBEN, 2004). Seu princípio de funcionamento, criado na década de 50, está na utilização da seleção natural como paradigma para encontrar, dentre um conjunto de soluções candidatas, a solução que melhor pode compreender o escopo do problema a ser analisado.

A vantagem mais significativa da computação evolutiva está na possibilidade de resolver problemas complexos por meio de simples equações matemáticas, as quais são utilizadas para representar o que se deseja obter como solução. Uma outra vantagem está na não necessidade de se explicitar os passos até o resultado, os quais certamente seriam específicos para cada problema. Isso faz com que a computação evolutiva seja rotulada como uma técnica reutilizável, já que as equações criadas para determinado fim podem ser utilizadas, sem maiores alterações, para solucionar diversos outros problemas semelhantes. Dessa forma, essa técnica deve ser compreendida como um conjunto de métodos e procedimentos genéricos e adaptáveis, a serem utilizados como opção para a solução de problemas complexos, para os quais outras técnicas se apresentam ineficientes ou até mesmo não aplicáveis (ZUBEN, 2004).

Para encontrar soluções adequadas a esses problemas, a computação evolutiva apresenta, dentre seus métodos, três maneiras distintas, as quais são apresentadas a seguir (ZUBEN, 2004):

- Algoritmos Genéticos: utiliza-se da filosofia da teoria da genética humana aplicada à computação evolutiva. Os algoritmos genéticos, são em sua maioria, utilizados em problemas de otimização, cujo objetivo é acelerar o processo de resolução, obtendo de maneira rápida e eficiente bons resultados, mesmo que esses resultados não representem a melhor solução para o problema.

- Programação Evolutiva: A programação evolutiva foi proposta em meados da década de 60 por (FOGEL; OWENS; WALSH, 1966). Sua proposta original trata a predição de comportamento de máquinas de estado finito. Nesse enfoque, cada indivíduo gera um único 
descendente através da mutação, e a seguir a (melhor) metade da população ascendente e a (melhor) metade da população descendente são reunidas para formar a nova população. Utiliza-se da teoria de Darwin para a obtenção de resultados adequados. Seu processo de aquisição de soluções é visto como um processo classificatório, o qual analisa um conjunto de pré-supostas soluções na busca da melhor solução para o problema analisado. Esse algoritmo também possui como característica a possibilidade de indicar uma solução considerada eficiente, mas ao mesmo tempo não sendo a melhor alternativa a ser aplicada.

- Estratégias Evolutivas: Foram inicialmente propostas para solucionar problemas de otimização de parâmetros, tanto discretos quanto contínuos. Em virtude da aplicação de poucos recursos para identificar suas soluções, tal estratégia sofreu modificações as quais deram origem a programação evolutiva e algoritmos genéticos.

A aplicação da computação evolutiva pode apresentar como diferencial a fácil implementação e compreensão de seus resultados. Essa entre outras características são apresentadas na seção seguinte, a qual estabelece uma comparação entre as técnicas apresentadas neste capítulo visando relacioná-las ao problema de particionamento de modelos em simulação distribuída.

\subsection{Comparação entre as Técnicas}

A escolha da técnica a ser utilizada para automatizar a etapa de particionamento de modelos em simulação distribuída é de grande importância para o sucesso deste trabalho. Visando alcançar tal objetivo, foram realizadas algumas comparações que demonstram as vantagens e desvantagens da utilização de cada técnica para solucionar o problema em questão. As conclusões obtidas da análise realizada podem ser observadas a seguir:

- Redes neurais: As redes neurais artificiais utilizam a capacidade de auto-aprendizagem para facilitar o processo de reconhecimento de padrões complexos. Essa característica a torna uma técnica interessante. Entretanto, a complexidade envolvida em seu processo de criação juntamente com a dificuldade de analisar o caminho utilizado por ela para alcançar seus resultados são desvantagens que impedem sua aplicação a determinados problemas. Outro problema apresentado por essa técnica é a necessidade de extensas bases de dados para o treinamento. Visto que o particionamento de modelos deve ser realizado de forma compreensível e que seus padrões não são suficientes, tem-se que a rede neural não é uma técnica adequada para o problema de particionamento de modelos em simulações distribuídas.

- Lógica Fuzzy: A lógica fuzzy pode possui como característica positiva a possibilidade de trabalhar com dados imprecisos e confusos. Entretanto, ao avaliar sua atuação como ferramenta de auxílio a tomada de decisões para a etapa de particionamento de modelos, tem-se as seguintes restrições:

- Mesmo apresentando-se como uma técnica para tratamento de sistemas compléxos, a lógica fuzzy não se adequa suficientemente bem para o problema de particionamento 
de modelos em simulação distribuída. Isso é causado pela dificuldade na abstração das variáveis lingüísticas, visto que os modelos são detalhados por diferentes usuários e não apresentam padrões em comum.

- Os modelos desenvolvidos para representar cada sistema computacional não seguem uma única padronização, dificultando a obtenção de bons resultados para todos os problemas a serem considerados e avaliados.

- Algoritmos evolutivos: A desvantagem dessa técnica está na estabilização em mínimos locais. Essa característica impede que os melhores resultados, algumas vezes, não consigam ser alcançados. Entretanto, essa técnica é de simples compreensão e não necessita de informações de difícil acesso. Isso pode tornar as técnicas evolutivas adequadas para tratar o problema de particionamento, fornecendo não os melhores resultados, mas resultados bons para a maioria dos casos.

Como já mencionado em capítulos anteriores, o maior problema enfrentado neste trabalho é a não existência de padrões que possam ser utilizados como métricas pela técnica de IA para prover o particionamento para todos os casos. Por essa razão, as técnicas baseadas nas redes neurais e na lógica fuzzy se tornam ineficientes, visto que para seu perfeito funcionamento seria necessário a sua modificação a cada nova interação. Dessa forma, tem-se como melhor alternativa a utilização da computação evolutiva.

Dentre os método da computação evolutiva, o algoritmo genético é o mais indicado para o problema de particionamento de modelos. Isso porque, em sua maioria, são utilizados em problemas de otimização, cujo objetivo é acelerar o processo de resolução e obtenção de bons resultados. Para melhor compreender seu funcionamento e suas características é apresentado a seguir as etapas envolvidas na construção de um algoritmo genético clássico.

\subsection{Algoritmo Genético}

O algoritmo genético é aplicado, na maioria das vezes, para auxiliar problemas de otimização. Seu surgimento deu-se em 1975, onde foi descrito pela primeira vez em (HOLLAND, 1975). O objetivo de Holland foi desenvolver uma técnica que fosse simples de ser implementada e ao mesmo tempo eficiente na busca de soluções para problemas que apresentavam como característica a modificação continua de estado em um curto espaço de tempo.

O algoritmo genético em seu funcionamento básico aplica a evolução natural e a genética humana como paradigma computacional para a resolução de problemas. O princípio de construção encontra-se na aplicação de simples equações matemáticas, as quais conseguem descrever o que se deseja obter como solução ao término da execução (ZUBEN, 2004). A solução adequada é identificada a partir de um conjunto de soluções candidatas $\rrbracket^{1}$ que são classificadas pela equação matemática pré-definida. Decorrente disso, para que soluções cada vez melhores sejam apresentadas como solução, deve-se fazer com que o conjunto de possíveis soluções (indivíduos) passe

\footnotetext{
${ }^{1}$ população ou conjunto de indivíduos
} 
por uma série de modificações que podem trazer como benefício a localização de um melhor resultado no espaço de busca do problema em questão.

O conjunto de indivíduos que representam supostas soluções são considerados pertencentes a uma mesma população. Cada indivíduo da população corrente é representado por um único cromossomo, o qual é constituído de uma codificação (genótipo) de uma possível solução para o problema (fenótipo). O cromossomo, usualmente, é implementado em listas ou vetores, onde cada posição dessas estruturas é denominada gene. O valor atribuído a cada gene de um cromossomo designa-se alelo e pode ser representado tanto com números decimais (0...9) quanto pela numeração binária.

A alteração do alelo de um gene gera como resultado um novo indivíduo na população. Esse indivíduo fará parte de uma nova população, que terá como característica material genético melhor ou semelhante ao da população que o criou. Os operadores clássicos utilizados para realizar tal modificação no cromossomo de cada indivíduo de uma população, denominamse: crossover e mutação. A forma de modificação a ser executada por cada operador pode ser observada na figura 3.7, sendo descrito nas seções 3.6.1 e 3.6 .3 com maiores detalhes o funcionamento de cada operador.

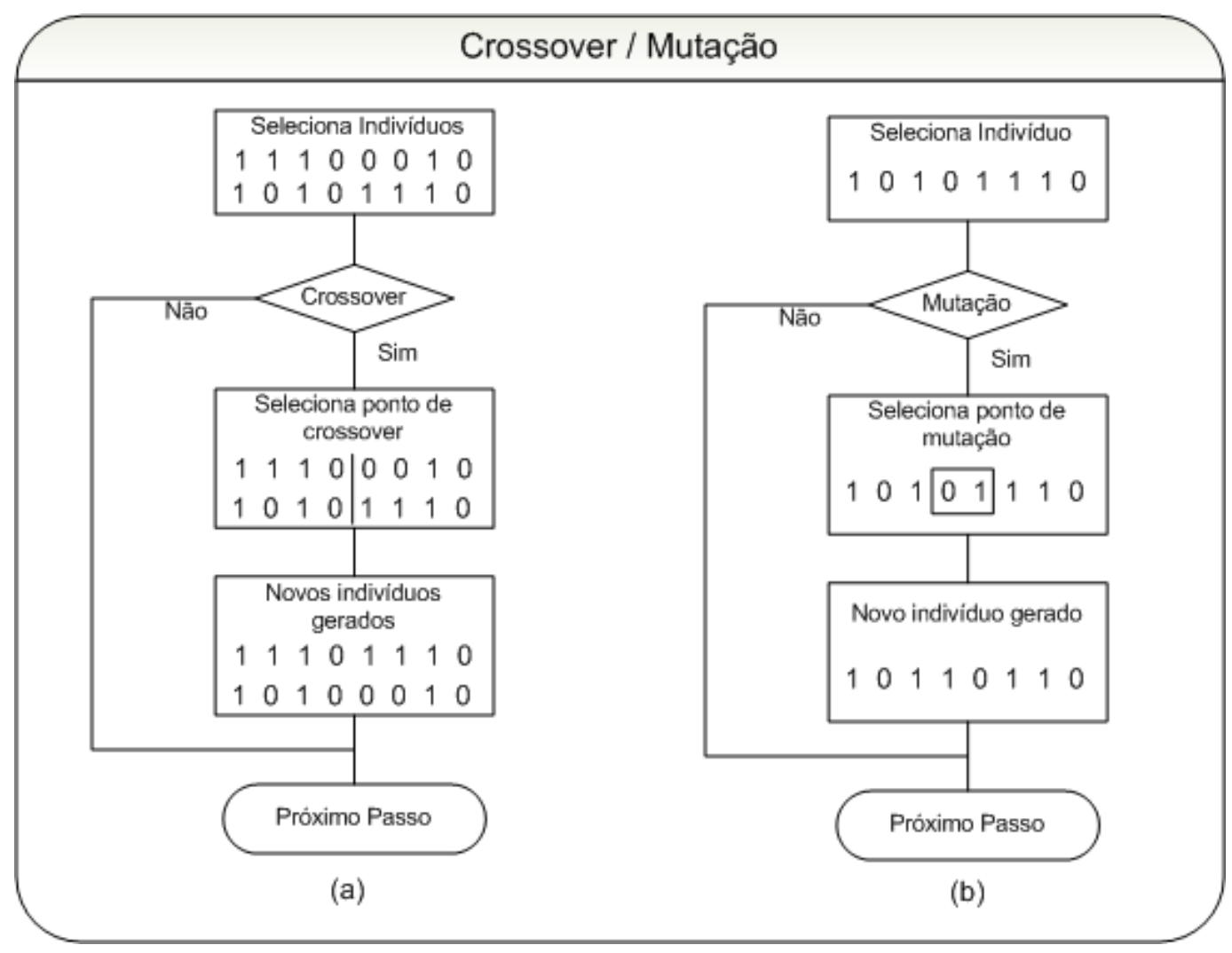

Figura 3.7: Processo de criação de novos indivíduos

Ao se aplicar os operadores em uma população, essa deve ser reclassificada de forma a identificar que indivíduo pertencente ao grupo que melhor pode representar uma solução. Essa reclassificação é realiza por uma função matemática aplicada a esse grupo, denominada função de fitness. A função de fitness é o núcleo do algoritmo genético. Devido a sua importância no processo de busca por soluções implementada pelo método, essa função é apresentada em 
detalhes na seção 3.6.3.

\subsubsection{Crossover}

O operador crossover, ou recombinação, cria novos indivíduos por meio da união de parte do material genético obtido de dois ou mais cromossomos (JUHASZ; TURNER, 2000) (ZUBEN, 2004). Essa recombinação é realizada dividindo-se o cromossomo em partes que são combinadas para criar novos indivíduos na população. Na representação clássica do algoritmo genético é apresentado um operador de crossover que realiza um único corte nos cromossomos (figura 3.7. a), sendo denominado crossover de único ponto.

Atualmente, o operador de crossover possui variações de implementação, as quais podem, em determinados casos, prover melhores soluções que as obtida pela implementação clássica. Essas variações têm por objetivo melhorar o desempenho tanto da criação de indivíduos quanto da quantidades de cortes realizados no cromossomo. Entretanto, tais variações devem ser utilizadas somente quando não for possível alcançar bons resultados utilizando o procedimento clássico. Assim, ao se deparar com um problema desse tipo, deve-se aplicar uma variação adequada para melhorar a compreensão do espaço de busca do problema e com isso prover a probabilidade de alcançar soluções melhores para o problema. Alguns exemplos de variações do operador crossover encontradas na literatura, são: crossover de dois pontos (LIN; YAO, 1997) e crossovers heurísticos (MAINI et al., 1994).

A diferença existente entre as variações de crossover está somente na forma com que o particionamento dos cromossomos é realizado. Sendo assim, ao se utilizar um algoritmo genético para resolver determinado problema é recomendado que se utilize na implementação inicial o crossover clássico e somente modifique-o se caso os resultados gerados não estão sendo satisfatórios para solucionar o problema em questão. Outro aspecto que deve ser observado antes de modificar o operador crossover clássico é a porcentagem da população que está sendo afetada pelo operador. Essa porcentagem deve ser alterada de forma a observar em testes realizados que tipo de influência pode vir a ocorrer com sua variação.

\subsubsection{Mutação}

O operador mutação, ao contrário do crossover, aplica as modificações a cada cromossomo selecionado individualmente, não necessitando de cruzamento de material genético. Sua função é alterar o material contido em cada um dos genes de um cromossomo de forma a obter um novo indivíduo totalmente diferente dos demais contidos na população atual. Essa porcentagem de modificações, chamada taxa de mutação tem como objetivo estabelecer uma determinada variabilidade extra na população sem destruir o processo já alcançado em aplicações passadas (ZUBEN, 2004). Um exemplo do funcionamento desse operador pode ser observado na figura 3.7.b, onde a taxa de mutação selecionada é de $25 \%$ de alteração dos genes do cromossomo escolhido.

Esse operador não possui variações como o crossover. Nesse caso, deve-se observar quais benefícios são oferecidos ao se submeter determinado problema a um algoritmo com e sem o operador de mutação e só depois decidir a viabilidade de sua implementação para ajudar na 
busca por soluções.

\subsubsection{Processo Classificatório}

O processo classificatório, conhecido como função de fitness, é um processo que se aplica a todos os indivíduos de uma população com o objetivo de classificá-los perante o problema a ser resolvido. Esse processo é realizado fazendo com que os indivíduos da população corrente sejam submetidos a uma equação matemática, a qual os classifica conforme as necessidades a serem alcançadas na solução. Por esse método, torna-se possível identificar qual é o indivíduo que se encontra mais próximo da melhor solução a ser submetida como resposta. Um exemplo da função de fitness pode ser observado na figura 3.8, sendo essa figura detalhada em seguida.

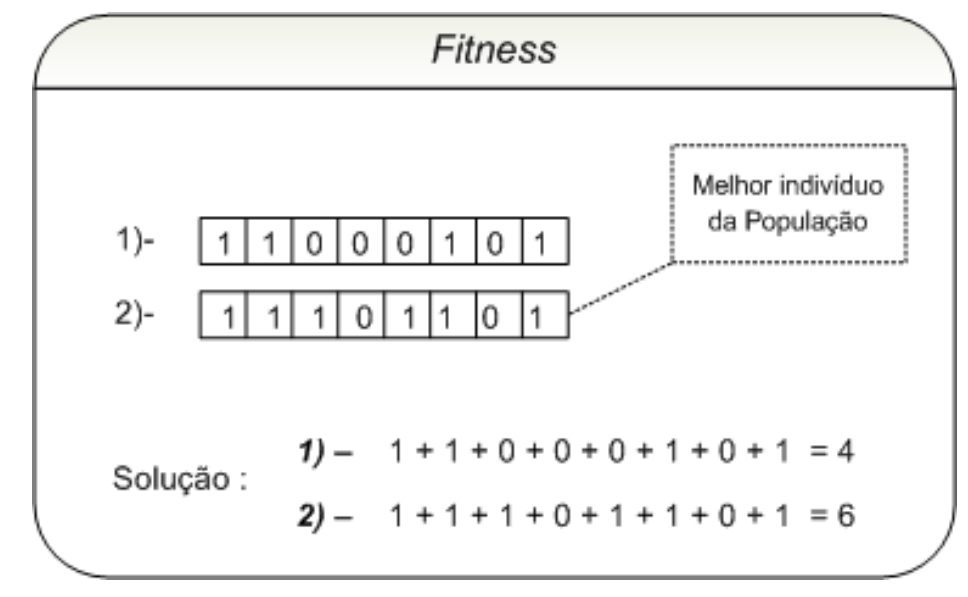

Figura 3.8: Representação do processo de fitness em uma população

No exemplo da figura 3.8, dois cromossomos binários são submetidos a uma função somatório (equação 3.2), a qual gera como resultado um valor que classifica os indivíduos da população. Esse processo somatório identifica o melhor cromossomo de uma população, sendo este considerado a melhor solução para o problema em questão.

$$
\sum_{i=0}^{n} X_{i}
$$

Muitas vezes, o procedimento utilizado pelo algoritmo genético clássico não é suficiente para se obter soluções adequadas. Nesses casos, deve-se utilizar outros tipos de operadores, os quais ampliam a busca de soluções no espaço de busca do problema. Um exemplo de operador que pode ser utilizado para tal feito é o predador.

O operador predador é utilizado para tentar minimizar uma grande desvantagem do algoritmo genético. Essa desvantagem é a estabilização em mínimos locais de busca, fazendo com que a melhor solução não seja alcançada facilmente. Esse operador é responsável por iniciar um processo de observação da população conforme essa vai evoluindo. Se por ventura for detectado que a população se estabilizou já há algum tempo, esse operador elimina uma parte da população e recria essa parte com indivíduos aleatórios. Esse processo de reconstrução da população pode gerar indivíduos melhores, os quais serão utilizados para fazer com que a população saia do mínimo estável e vá para um novo mínimo mais proximo da melhor solução. Entretanto, 
em determinados problemas sua influência é minima, fazendo com que sua utilização só atrase no tempo de busca.

\subsection{Considerações Finais}

Neste capítulo foram descritas algumas técnicas de inteligência artificial que podem ser aplicadas em ferramentas e ambientes de simulação para prover auxílio a tomada de decisões em determinadas etapas do desenvolvimento. Algumas dessas técnicas, mesmo sendo adequadas, apresentam características complexas e/ou restrições que as tornam de difícil compreensão e utilização para o problema em questão.

Dentre as técnicas apresentadas neste capítulo, após uma avaliação (seção 3.5), foi escolhido o algoritmo genético como método de auxílio para a tomada de decisões visando o particionamento. Representado em sua forma clássica na seção 3.6, objetivou-se demonstrar suas facilidades e formas de obtenção de resultados.

O próximo capítulo tem por objetivo detalhar alguns trabalhos relacionados, os quais servirão como base na pesquisa e obtenção dos padrões necessários para o particionamento de modelos. 


\section{Trabalhos Relacionados}

\subsection{Considerações Iniciais}

O problema do particionamento de modelos em simulação distribuída tem recebido uma maior atenção nos últimos tempos. Muitas das pesquisas aplicadas nessa etapa apresentam como objetivo a diminuição do tempo total de execução das simulações. A aplicação de boas técnicas nessa etapa melhoram consideravelmente o desempenho final em relação ao tempo médio de execução das simulações, como pode ser observado em (NANDY; LOUCKS, 1993; BOUKERCHE; TROPPER, 1994; KONAS; YEW, 1995; KIM; JEAN, 1996; SUBRAMANIAN; RAO; WILSEY, 2000; BOUKERCHE; DAS, 2004; XU; AMMAR, 2004).

Atualmente, as soluções aplicáveis ao problema do particionamento de modelos em simulação distribuída pode ser dividido em dois grupos: o grupo conservativo e o otimista. Enquanto o grupo conservativo visa minimizar o tempo total de execução das simulações a partir da redução do tráfego de mensagens nulas na rede, os otimistas buscam soluções esse problema a partir da diminuição da quantidade de rollbacks (ver pagina 11) executados. Este capítulo apresenta as técnicas encontradas na literatura, as quais foram classificadas em técnicas para particionamento de simulações que não enfocam nenhuma área em específico e técnicas de particionamento para simulações específicas, tais como circuitos lógicos e redes de computadores.

\subsection{Técnicas de Particionamento Para Problemas Gerais}

Nandy e Loucks (1993), apresentam uma solução aplicada ao grupo conservativo. Esse trabalho baseia-se em um conjunto de heurísticas apresentadas em (FIDUCCIA; MATTHEYSES, 1982) para desenvolver um algoritmo de particionamento paralelo que possa ser aplicado à simulações executadas sobre o protocolo CMB. Objetiva-se com isso, minimizar o overhead na comunicação e distribuir uniformemente a carga de processamento entre as máquinas que 
executam a simulação. O algoritmo proposto por (NANDY; LOUCKS, 1993) utiliza heurísticas para particionar modelos representados em forma de grafo. Seu processo de execução tem como fase inicial a geração de uma partição aleatória, a qual passa posteriormente por sucessivas trocas de processos entre os processos lógicos, tentando preservar o melhor balanceamento de carga possível. Segundo os autores, a aplicação dessa solução pode apresentar ganhos de até $25 \%$ na redução do tempo de execução das simulações. Entretanto, para que isso ocorra é necessária a execução de pré-simulações, as quais coletam informações da comunicação e da arquitetura para serem utilizadas pelo algoritmo durante o processo de particionamento. Porém, tais informações podem não ser coletadas com tanta facilidade ao se tratar de modelos e/ou arquiteturas complexas, limitando assim a utilização dessa solução.

Em (BOUKERCHE; TROPPER, 1994), é discutida uma outra solução para o problema do particionamento aplicado ao grupo conservativo. Baseado em mecanismos estatísticos (heurísticas) e motivado por analogias de comportamento de sistemas físicos na presença de calor, o simulated annealing (SA) representa vários avanços na resolução de problemas de otimização combinacional. Utilizando a mesma etapa inicial de particionamento aleatório que NANDY; LOUCKS, 1993), o SA executa uma série de movimentações seqüenciais entre os processos lógicos para garantir um melhor balanceamento de carga e a menor comunicação entre processos. Sua utilização, segundo (BOUKERCHE; TROPPER, 1994), pode prover até $35 \%$ de redução no tempo de execução de uma simulação.

Boukerche e Das (2004), definiram um algoritmo de balanceamento de carga dinâmico com migração de processos para simulações conservativas. Objetiva-se nesse trabalho a diminuição do atraso no sincronismo, a redução do tempo de execução das simulações e a avaliação da escalabilidade do algoritmo para diferentes modelos de carga de trabalho aplicadas a sistemas distribuídos com memória compartilhada. Para tanto, o primeiro problema tratado foi o possível gargalo gerado pelo algoritmo ao aplicar contínuas solicitações de informação para cada processo que se encontrasse em execução. Para prevenir tal gargalo, (BOUKERCHE; DAS, 2004) apresentaram uma alternativa baseada em um balanceamento de carga executado em dois estágios (níveis). No primeiro nível é utilizado um balanceamento centralizado, onde são executadas as migrações de processo quando necessário. O nível 2, o qual evita o gargalo, é responsável por agrupar uma certa quantidade de processos lógicos em clusters de processos. Cada cluster gerado é representado por um anel virtual, onde as informações de cada processo são coletadas e medidas. As medições são realizadas por uma série de cálculos locais, sendo cada resultado armazenado na fila de processos da CPU. Dessa forma, as informações necessárias para o balanceamento dinâmico só trafegam por toda rede quando solicitadas pelo nível 1.

Embora vários trabalhos apresentem soluções de particionamento que podem ser aplicadas para solucionar diversos tipos de problemas NANDY; LOUCKS, 1993; BOUKERCHE; TROPPER, 1994; BOUKERCHE; DAS, 2004), em alguns casos, para alcançar melhores resultados é necessário a aplicação de soluções específicas. Considerando o problema de simular circuitos lógicos, alguns exemplos podem ser observados em (KONAS; YEW, 1995; KIM; JEAN, 1996; SUBRAMANIAN; RAO; WILSEY, 2000). 


\subsection{Técnicas de Particionamento para Problemas Específicos}

Em (KONAS; YEW, 1995), o particionamento é tido como solução para problemas de simulações síncronas de circuitos lógicos executadas sobre o protocolo CMB. Nesse trabalho, os modelos utilizados para descrever os circuitos são representados por grafos, onde cada aresta é responsável por detalhar a carga de comunicação entre vértices adjacentes. Cada vértice do modelo tem associado às suas características a carga computacional de cada componente do circuito. Para prover o particionamento, três objetivos são vistos como importantes: o balanceamento entre os processos lógicos, a probabilidade de ativação de determinado componente durante a simulação e a carga computacional aplicada a cada componente do modelo. Visando alcançar tais objetivos, KONAS; YEW, 1995) descreve um algoritmo de particionamento sensitivo que utiliza três etapas. Na primeira etapa, o grafo submetido como entrada é avaliado para identificar qual a probabilidade que cada componente tem de ser ativado durante a simulação e por quanto tempo esse produzira informações. Após realizada essa avaliação, uma segunda etapa é iniciada para calcular qual a carga computacional que cada componente representa para o sistema. Por fim, no nível três as informações dos níveis anteriores junto ao modelo são aplicados como entrada para um algoritmo guloso, o qual provê o particionamento.

Para solucionar esse mesmo problema para protocolos otimistas, o trabalho de (KIM; JEAN, 1996) apresenta um algoritmo de particionamento utilizado em simulações executadas sobre o protocolo Time Warp. Para tanto, os objetivos estipulados nesse trabalho são: preservar a concorrência da simulação; executar o algoritmo em tempo linear, de forma rápida e não interativa; prover o balanceamento de carga e diminuir a comunicação entre processos; ter como compromisso a obtenção de um alto desempenho em simulações executadas sobre o protocolo Time Warp.

Na solução apresentada por (KIM; JEAN, 1996), os modelos são submetidos para o algoritmo de particionamento também em forma de grafo. Para a obtenção das partições, o modelo passa por um processo constituído de três etapas. Na primeira etapa, dividi-se o grafo em um conjunto de sub-grafos, onde cada sub-grafo contenha um nó de entrada primária e um conjunto relativamente grande de nós que apresentam comunicação com a entrada selecionada. Objetiva-se nessa etapa minimizar a comunicação entre os sub-grafos identificados.

Após a execução da primeira etapa, é realizado uma rotulação dos nós (vértices) de cada sub-grafo com valores numéricos, sendo dado a vértices com maiores pesos de carga, numerações com valores mais próximos (segunda etapa). Rotulado os vértices do modelo, uma terceira etapa é realizada, a qual tem como objetivo selecionar os vértices rotulados com numerações consecutivas para a criação dos processos lógicos. Cada processo lógico é criado com um conjunto de vértices que não ultrapassem o valor máximo da capacidade de processamento de cada máquina, atendendo às restrições impostas para o balanceamento de carga e para a diminuição da comunicação.

No trabalho apresentado por (SUBRAMANIAN; RAO; WILSEY, 2000) uma outra alternativa otimista para simulações de circuitos executadas sobre o Time Warp é apresentada. Nesse trabalho, o particionamento é realizado para minimizar o tempo total de execução de simulações de 
circuitos VHDL. Projetado para ser parte integrante do ambiente SAVANT (WILSEY; MARTIN; SUBRAMANI, 1998), o algoritmo de três níveis desenvolvido por (SUBRAMANIAN; RAO; WILSEY, 2000) executa em tempo linear uma série de heurísticas para prover o particionamento. Como em (KIM; JEAN, 1996), a busca por partições é realizada em três estágios (níveis), sendo esses: o particionamento primário, o particionamento inicial e o refinamento.

No particionamento primário, o grafo apresentado como entrada é dividido em sub-grafos, os quais são caracterizados por associarem em um mesmo conjunto somente vértices que tenham comunicação em comum. Após tal divisão, a etapa do particionamento inicial é executada. Nessa etapa, o objetivo é garantir o balanceamento de carga e ao mesmo tempo minimizar a comunicação entre processos. Para garantir um bom balanceamento, a etapa de refinamento é aplicada no resultado obtido do particionamento inicial. Esse, por sua vez, executa testes sucessivos na partição provida da etapa anterior para tentar maximizar o balanceamento e melhorar os resultados. Mesmo apresentando-se eficiente para o problema de particionamento de circuitos VHDL, o algoritmo não prove bons resultados para todos os casos, visto que cada circuito apresenta uma estrutura própria com formas de comunicação distintas.

Recentemente, Xu e Ammar (2004), apresentaram um conjunto de metodologias aplicadas ao particionamento de simulações de redes de computadores. Com o auxílio de heurísticas e de um benchmark, o algoritmo proposto cria as partições objetivando-se minimizar o tempo de execução em clusters computacionais, balancear a carga entre os processadores e minimizar a comunicação entre processos. Para isso, três fatores são inicialmente observados: a configuração do cluster, a topologia da rede simulada e a carga de trabalho do modelo. As informações coletadas são utilizadas no benchmark em um processo sub-dividido em duas etapas. Na primeira etapa, fatores e indicadores de desempenho do ambiente e da topologia da rede são coletados. Na segunda etapa, o particionamento propriamente dito é realizado. O fluxo de execução do algoritmo proposto por (XU; AMMAR, 2004) pode ser observado na figura 4.1.

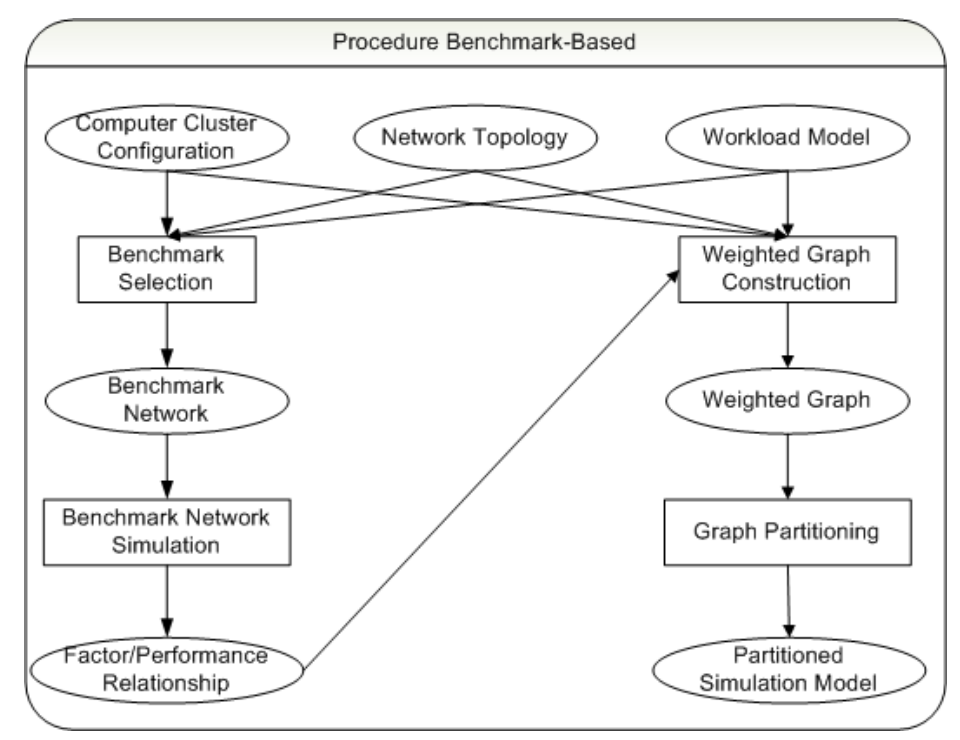

Figura 4.1: Etapas realizadas em (XU; AMMAR, 2004) para o particionamento 


\subsection{Considerações Finais}

A busca por partições que podem ser simuladas em um tempo mínimo fez com que vários pesquisadores apresentassem diferentes soluções para o problema do particionamento de modelos em simulação distribuída. Analisando os trabalhos apresentados neste capítulo, pode-se observar que todos possuem algumas características em comum: utilizam grafos para representar o modelo e objetivam minimizar a comunicação e balancear a carga. Visando esses mesmos objetivos, tem-se apresentado no próximo capítulo a descrição detalhada do algoritmo genético utilizado para auxiliar o particionamento de modelos em simulação distribuída. 


\section{Capítulo}

\section{5}

\section{Algoritmo Genético para Particionamento de Processos}

\subsection{Considerações Iniciais}

O particionamento do modelo é uma etapa da simulação distribuída que, se mal definida, pode aumentar o tempo de execução de uma simulação. O aumento nesse tempo pode ser gradativo à medida que o modelo e/ou a arquitetura de execução vão se tornando mais complexos, impossibilitando assim a total compreensão dos parâmetros utilizado para a criação dos processos lógicos. Ao particionar modelos tem-se, dentre os objetivos, a redução desse tempo. Atualmente, diferentes técnicas vêm sendo apresentadas para solucionar tal problema, sendo algumas dessas descritas em (BOUKERCHE; TROPPER, 1994), (HAO et al., 1996), (BOUKERCHE, $2002)$ e (BOUKERCHE; DAS, 2004). Na maioria desses trabalhos tem-se como fatores avaliados o balanceamento de carga, a comunicação entre processos e a topologia da arquitetura.

Visando obter bons resultados e avaliar os fatores relacionados ao balanceamento de carga e à comunicação entre processos, este capítulo tem por objetivo descrever as etapas de desenvolvimento e as características do algoritmo genético aplicado ao problema do particionamento de simulação distribuída. Objetiva-se com isso prover soluções para os mais diversos modelos, independente da complexidade e representatividade dos mesmos.

Para detalhar a seqüência utilizada na escolha e desenvolvimento do algoritmo genético proposto neste trabalho, este capítulo está estruturado da seguinte maneira: na seção 5.2 são apresentados os algoritmos genéticos avaliados e os respectivos resultados obtidos; na seção 5.3, tem-se detalhado uma visão geral da forma de obtenção do particionamento; nas seções 5.4 e 5.5 tem-se apresentado os parâmetros do modelo e da arquitetura utilizados como padrões de entrada para o algoritmo genético; a seção 5.6 detalha a estrutura e características do algoritmo 
genético identificado na seção 5.2 como melhor solução. Por fim, tem-se na seção 5.7 a descrição do processo que o algoritmo genético utiliza para a obtenção e apresentação de seus resultados para o usuário.

\subsection{Etapas de Desenvolvimento do Algoritmo Genético}

A fim de escolher o algoritmo genético utilizado neste trabalho, diferentes formas de implementação foram avaliadas. Nesse processo de seleção buscou-se o algoritmo que melhor pudesse representar o problema de particionamento de modelos. Para caracterizar cada algoritmo criado, uma combinação entre operadores / técnicas foi realizada. Os operadores e técnicas utilizados para isso foram: o crossover, a mutação e o predador. Na tentativa de melhorar os resultados, foi aplicado a cada algoritmo desenvolvido o elitismo. Sua aplicação teve por objetivo manter sempre o melhor indivíduo da população corrente nas gerações seguintes.

Para avaliar o elitismo, quatro diferentes algoritmos genéticos foram propostos. A escolha pela melhor combinação foi realizada ao submeter todas as combinações a uma avaliação aplicada ao modelos de redes de filas da figura 5.1. Para definir qual algoritmo seria aplicado como solução do problema de particionamento, a avaliação realizada consistiu em verificar qual dos algoritmos apresentaria o melhor fitness durante os testes realizados.

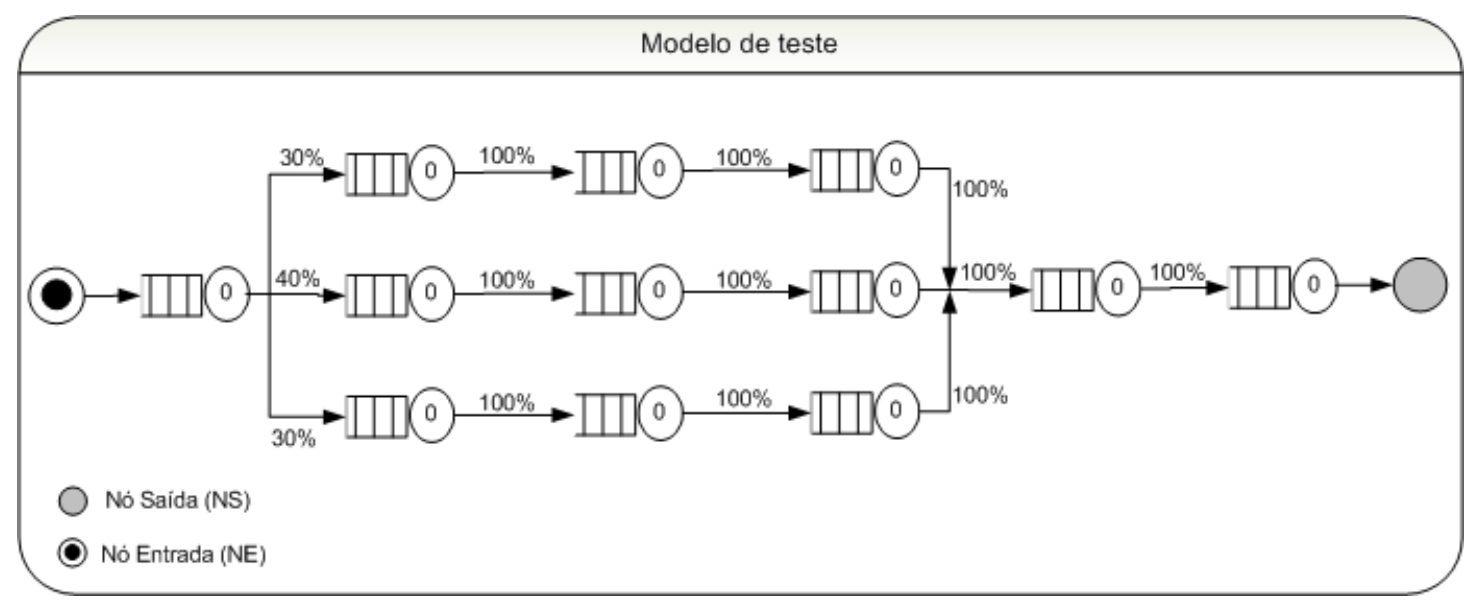

Figura 5.1: Modelo utilizado na avaliação dos algoritmos genéticos

O primeiro algoritmo genético desenvolvido utilizou para solucionar o problema do particionamento os operadores de crossover e mutação. A taxa de mutação aplicada foi de $10 \%$, sendo utilizada em $40 \%$ dos piores indivíduos. O objetivo foi melhorar o material genético desses indivíduos, propiciando o aparecimento de melhores soluções. Os $60 \%$ restantes sofreram alterações por meio de um crossover de um ponto, o qual utilizou o método da roleta para a seleção dos indivíduos utilizado nos cruzamentos. Esse método permite que melhores indivíduos sejam selecionados com maior freqüência. Dessa forma, foi possível garantir que um maior número de melhores indivíduos sofreriam cruzamento.

Para comparar os resultados obtidos com a execução do algoritmo genético acima descrito, alterações foram feitas para gerar uma segunda alternativa. O segundo algoritmo proposto utilizou um crossover de dois pontos para efetuar as combinações. Visando verificar se essa 
modificação poderia apresentar melhorias nas soluções, as mesmas taxas de transformação e a mesma população inicial foram utilizadas nas avaliações.

Ao aplicar as duas soluções já apresentadas para particionar o modelo da figura 5.1, notou-se que, algumas vezes, os algoritmos apresentavam como característica a rápida estabilização em mínimos locais. Como tentativa de solucionar esse problema a técnica do predador foi utilizada em duas outras soluções. Essas, por sua vez, utilizaram das mesmas características já apresentadas anteriormente, sendo somente acrescido a técnica em cada solução. O objetivo dessa modificação foi impedir que os melhores indivíduos ficassem a mais de 10 gerações estabilizados em um mesmo valor. Para garantir tal afirmação, a técnica do predador foi aplicada para eliminar 50\% dos piores indivíduos, sendo criados novos indivíduos de forma aleatória para compor o conjunto de indivíduos da população corrente. Ao caracterizar tal modificação em cada um dos dois algoritmos apresentados anteriormente, obteve-se como resultado as configurações apresentadas na tabela 5.1 .

Tabela 5.1: Configurações dos algoritmos genéticos avaliados

\begin{tabular}{c|c}
\hline \hline Cod. AG & Operadores e Técnicas \\
\hline AG1 & Elitismo, Crossover de um ponto e Mutação \\
AG2 & Elitismo, Crossover de dois ponto e Mutação \\
AG3 & Elitismo, Crossover de um ponto, Mutação e Predador \\
AG4 & Elitismo, Crossover de dois pontos, Mutação e Predador \\
\hline \hline
\end{tabular}

Uma vez que os indivíduos no algoritmo genético são criados de forma aleatória, faz-se necessário a elaboração de algumas regras para se obter meios de comparar os resultados das diferentes implementações. Na avaliação, uma mesma população inicial contendo 100 indivíduos foi utilizada. Tal população foi aplicada a um processo de execução com 80 gerações, sendo coletado a cada geração o melhor fitness obtido. Esse processo foi executado 30 vezes para cada algoritmo proposto. A média dos resultado foi utilizada para demonstrar o desempenho de cada algoritmo genético ao tentar particionar o modelo da figura 5.1 em três processos lógicos. Os resultados obtidos podem ser observados no gráfico apresentado na figura 5.2 .

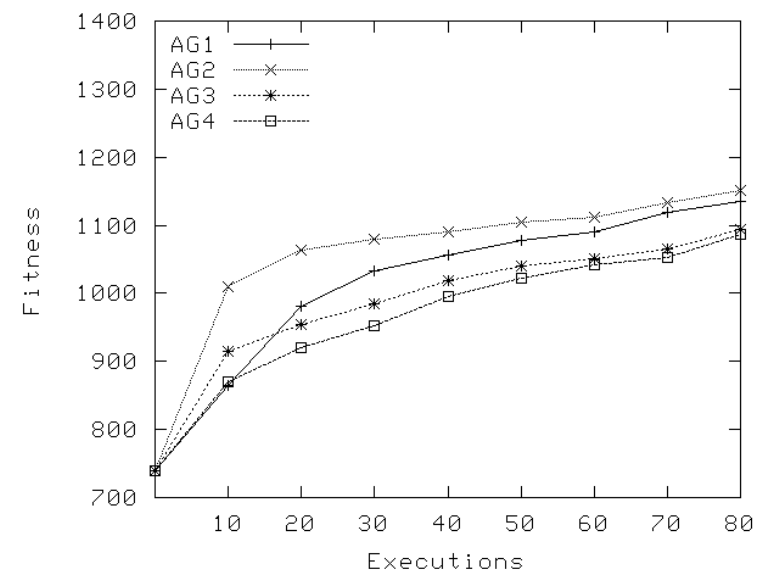

Figura 5.2: Classificação dos algoritmos genéticos avaliados

Como pode ser observado no gráfico da figura 5.2, a melhor solução para o problema do 
particionamento se manteve desde o início com o AG2. Dessa forma, será este o algoritmo apresentado em maiores detalhes a partir da seção seguinte.

\subsection{Visão Geral para a Obtenção do Particionamento}

Para realizar a etapa de particionamento, o algoritmo genético desenvolvido neste trabalho utiliza parâmetros contidos no modelo e na arquitetura de execução da simulação. Tais parâmetros criam os padrões de entrada necessários para se prover partições caracterizadas pelo balanceamento de carga e pela minimização da comunicação na rede. Objetiva-se com a criação desse algoritmo prover uma ferramenta de auxílio que possa ser integrada ao Ambiente de Simulação Distribuída Automático (ASDA).

O ASDA é um ambiente de simulação desenvolvido para avaliar o desempenho de sistemas computacionais (BRUSCHI, 2002), como descrito na seção 2.4. O processo de modelagem aplicado a esse ambiente visa transcrever as características do sistema real de forma simples, facilitando a análise realizada pelo usuário. Para tanto, as representações realizadas no ambiente são convertidas e armazenadas em forma de grafo. Uma vez que os modelos são transcritos em grafos, faz-se necessário que o algoritmo genético tenha capacidade de interpretar tais informações e, a partir dessas, prover o particionamento. Os passos seguidos para a automatização do etapa de particionamento e utilização do algoritmo genético podem ser observados na figura 5.3 ,

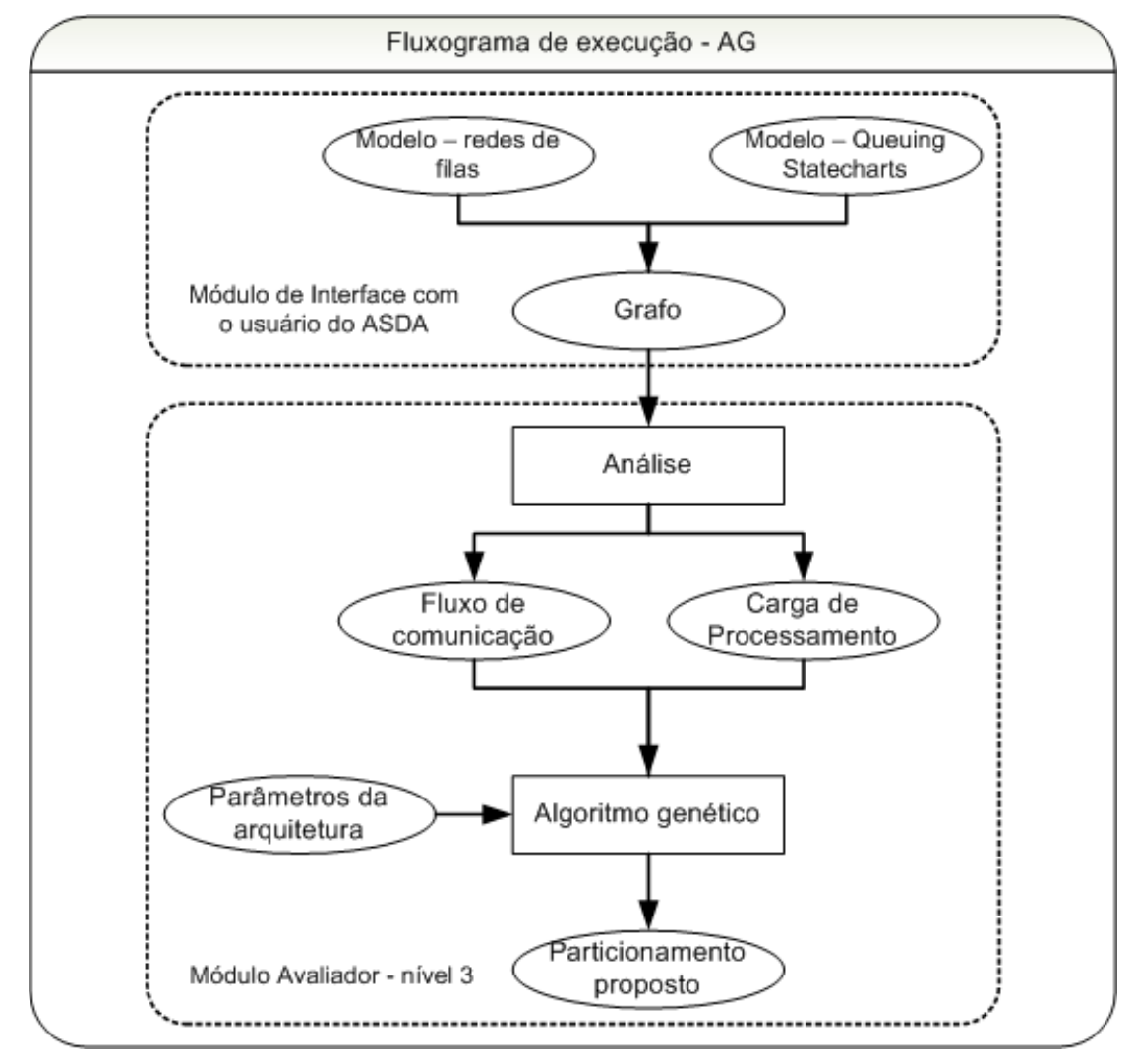

Figura 5.3: Fluxograma aplicado para a obtenção dos particionamentos

O processo de análise realizado nos dados fornecidos pelo módulo de interface com o usuário do ASDA, tem por objetivo coletar parâmetros do modelo, os quais representam o fluxo de 
comunicação e a carga de processamento associado a cada centro de serviço. Também é realizada uma coleta na arquitetura, onde informações referentes à capacidade em MIPS 11 de cada processador são coletadas. Para compreender como o processo de aquisição desses parâmetros é realizado, tem-se nas próximas seções a descrição em maiores detalhes de cada um dos passos utilizados.

\subsection{Obtenção dos Parâmetros do Modelo}

A obtenção dos parâmetros do modelo é realizada a partir da representação gerada automaticamente no módulo de interface com o usuário do ASDA. Tem-se nessa descrição a representação de cinco diferentes nós (BRUSCHI, 2002): o nó centro de serviço (NCS), o nó entrada (NE), o nó saída (NS), o nó servidor sem fila (NSSF) e o nó posse múltipla (NPM). Visando facilitar a compreensão do processo adotado pelo algoritmo genético para a obtenção de suas partições, será utilizado para representar os modelos deste trabalho somente os três primeiros tipos. Um exemplo do tipo de descrição adotada pode ser observado na figura 5.4 .

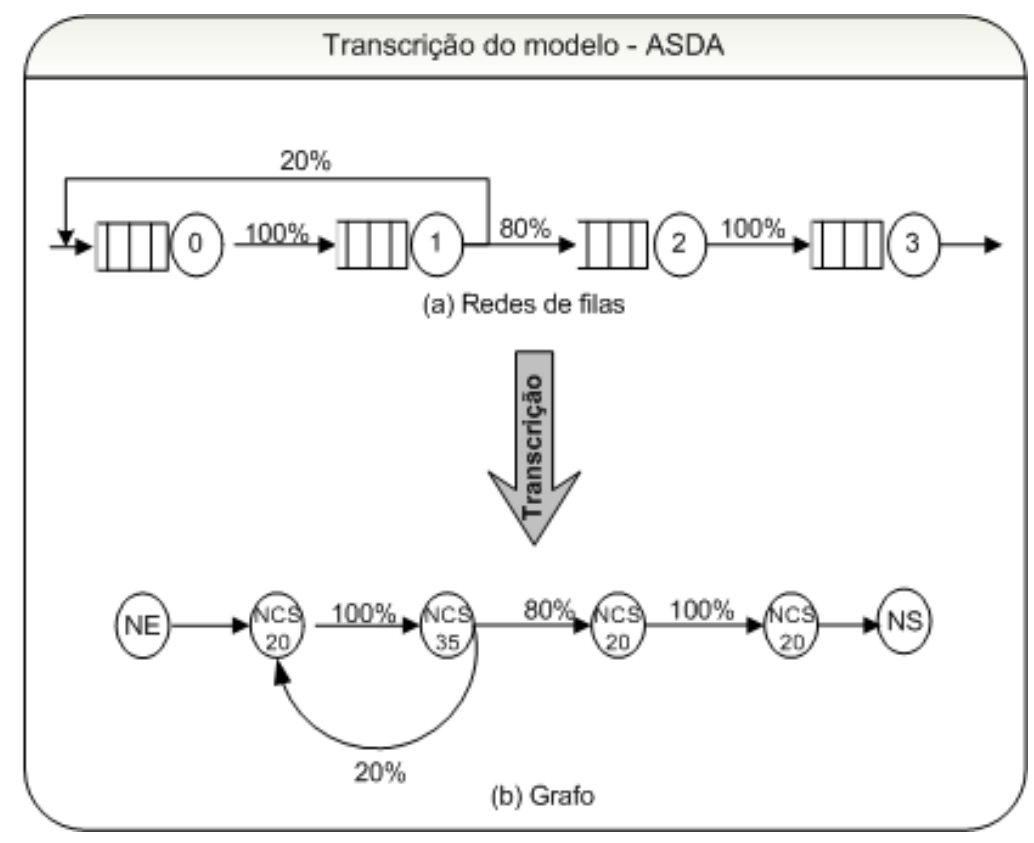

Figura 5.4: Transcrição utilizada no ambiente ASDA para a representação de modelos

Como pode ser observado na figura 5.4, os vertices NE e NS são utilizados na representação do modelo somente para denotar a existência de entradas e saídas. Dessa forma, durante o processo de coleta das informações esses vértices não serão considerados.

O processo de coleta dos parâmetros associados ao modelo é realizado em duas etapas, sendo a partir dessas identificado: o fluxo de comunicação e a carga de processamento associado a cada vértice do grafo.

O fluxo de comunicação representa o percentual de comunicação existente entre os centros de serviço (CS). Essa informação é utilizada pelo algoritmo genético para minimizar o tráfego de mensagens na rede. Para isso, os CS's que apresentam valores altos de fluxo de comunicação

\footnotetext{
${ }^{1}$ Milhões de Instruções por Segundo
} 
são agrupados em um mesmo processo lógico (PL). Esses parâmetros são passados para o algoritmo por meio de uma matriz denominada, Matriz Communication. Essa matriz utiliza suas linhas e colunas para descrever a ligação existente entre dois vértices de um grafo. As linhas são utilizadas para representar cada vértice, sendo as colunas de cada linha indicadores de comunicação entre vértices. Um exemplo da descrição adotada para representar a Matriz Communication associada ao modelo da figura 5.4 pode ser observada na figura 5.5 .

\section{Communication Matrix $=$}

\begin{tabular}{|c|c|c|c|}
\hline $\mathrm{NCs} 0$ & NCs1 & $\mathrm{NCs} 2$ & $\mathrm{NCs} 3$ \\
\hline 0 & 100 & 0 & 0 \\
\hline 20 & 0 & 80 & 0 \\
\hline 0 & 0 & 0 & 100 \\
\hline 0 & 0 & 0 & 0 \\
\hline
\end{tabular}

Figura 5.5: Representação da comunicação na Matriz Communication

A utilização da matriz para representar a comunicação é uma solução simples para identificar as ligações existentes entre os vértices do modelo. Outra vantagem dessa descrição é a fácil identificação do grafo armazenado na matriz, visto que, ao aplicar o processo reverso pode-se obter a representação gráfica do modelo a partir das informações contidas na matriz.

A tentativa isolada de minimizar a comunicação por meio da Matriz Communication, pode gerar como resultado a sobrecarga nos processadores. Isso é causado pelo número excessivo de CS's alocados em um mesmo PL. Para evitar que a sobrecarga prejudique a obtenção de um bom particionamento para a maioria dos casos, é aplicado como padrão de entrada, juntamente com o fluxo de comunicação, a carga de processamento por vértice do grafo. Esse parâmetro é utilizado para balancear a carga, evitando que determinado PL sature a capacidade máxima do processador a ser utilizado como parte da arquitetura de execução.

Para armazenar a carga de processamento associada a cada vértice do modelo é utilizado um vetor denominado mipsProcesss. Esse, por sua vez, é aplicado como parte dos padrões exigidos para realizar o balanceamento de carga entre as máquinas da arquitetura. Sua forma de representação pode ser observado na figura 5.6, a qual detalha a carga de processamento aplicada ao modelo da figura 5.4 (b).

$$
\text { mipsProcess }=\begin{array}{|l|l|l|l|}
\hline \mathrm{NCs} 0 & \mathrm{NCs} 1 & \mathrm{NCs} 2 & \mathrm{NCs} 3 \\
\hline \hline 25 & 35 & 40 & 40 \\
\hline \hline
\end{array}
$$

Figura 5.6: Descrição do carga de processamento para o grafo da figura 5.4

Embora a utilização do vetor mipsProcesss torne prático a análise e distribuição da carga, tem-se algumas situações que o valor da carga não é descrita no modelo. Nesses casos, é gerado uma distribuição de carga homogênea, a qual é aplicada a todas as posições do vetor. Essa distribuição é obtida através da equação 5.1 apresentada a seguir.

$$
\Delta \text { mips }=\frac{\sum_{i=0}^{n} \text { mipsCapacity }_{i}}{\text { Qtd } d_{\text {Vertex }}}
$$


Onde, Qtd $d_{\text {Vertex }}$ representa a quantidade de centros de serviço do modelo, o

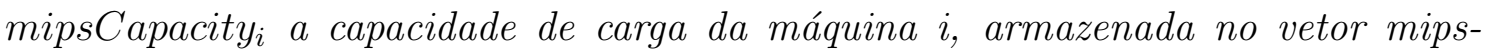
Capacity (a ser explicado na próxima seção); e $\Delta$ mips o valor a ser atribuído a cada posição do vetor mipsProcess.

Supondo uma arquitetura com 3 máquinas com capacidades 465.00, 116.44 e 167.86 MIPS e o modelo da figura 5.4 que possui 4 centros de serviço, a aplicação da formula 5.1 seria da seguinte maneira:

$$
\Delta \text { mips }=\frac{465.00+116.44+167.86}{4} \cong 187.33
$$

Entretanto, para garantir que o balanceamento dos processos lógicos possa ser realizado de forma correta em arquiteturas caracterizadas pela heterogeneidade, informações associadas a arquitetura devem ser utilizada em conjunto com as informações do vetor mipsProcesss para prover o balanceamento. Para compreender como tais informações foram coletadas, a seção seguinte descreve o processo de obtenção dos parâmetros associados a arquitetura.

\subsection{Obtenção dos Parâmetros da Arquitetura}

A avaliação da arquitetura consiste em identificar a capacidade máxima de processamento de cada máquina a ser utilizada na execução da simulação. Essa informação é obtida através da execução de um benchmark, o qual identifica a carga máxima em MIPS que cada máquina pode suportar no exato momento da execução. Esse processo de obtenção da capacidade das máquinas torna possível a utilização de arquiteturas constituídas por máquinas não ociosas e/ou arquiteturas heterogêneas.

O programa de benchmark utilizado neste trabalho para coletar informações da arquitetura é o TSCP. Esse benchmark é similar ao SPEC CINT2000 (HENNING, 2000) (KERRIGAN, 2005). Sua base para comparações é uma estação de trabalho SiliconGraphics ${ }^{\circledR}$ (SGI) que consome 11.233 MIPS para executar a função bench(). Também é utilizado pelo TSCP um comando para coletar dados referentes ao seu desempenho. Esse comando, denominado perfex, pode ser utilizado em conjunto com outros programas de benchmark para fins de comparação de seu próprio desempenho como programa (ISHII, 2004).

Ao executar o TSCP para coletar informações das máquinas utilizadas para estabelecer as arquiteturas de teste, obteve-se como resultado os dados apresentados na coluna MIPS da tabela 5.2. Essa tabela também é utilizada para detalhar a configuração das máquinas utilizada durante os testes. Essas características representam informações sobre o número da máquina (NMAQ), o nome da máquina (Máquina), a configuração do processador (CPU) e a quantidade de memória disponível (Memória).

Os dados coletados pelo TSCP são trasmitidos para o algoritmo genético através de um vetor denominado mipsCapacity. A finalidade desse vetor é manter as informações referente às máquinas utilizadas para a execução da simulação sempre atualizadas no algoritmo, visto que é por meio dessas informações que o balanceamento de carga entre processadores é realizado. A figura 5.7 apresenta uma representação desse vetor para a tabela 5.2 . 
Tabela 5.2: Descrição das máquinas utilizadas nos testes

\begin{tabular}{|c|c|c|c|c|c|c|}
\hline NMAQ & Máquina & \multicolumn{2}{|c|}{ CPU } & \multicolumn{2}{|c|}{ Memória } & MIPS \\
\hline M1 & Lasdpc06 & \multicolumn{2}{|c|}{$450 \mathrm{Mhz}$} & \multicolumn{2}{|c|}{$128 \mathrm{MB}$} & 465.00 \\
\hline M2 & Lasdpc05 & \multicolumn{2}{|c|}{$233 \mathrm{Mhz}$} & \multicolumn{2}{|c|}{$128 \mathrm{MB}$} & 116.44 \\
\hline M3 & Lasdpc07 & \multicolumn{2}{|c|}{$233 \mathrm{Mhz}$} & \multicolumn{2}{|c|}{$64 \mathrm{MB}$} & 167.86 \\
\hline M4 & Notebook & \multicolumn{2}{|c|}{$2.8 \mathrm{Ghz}$} & \multicolumn{2}{|c|}{$512 \mathrm{MB}$} & 1007.00 \\
\hline & & M1 & \multicolumn{2}{|c|}{$\mathrm{M} 2$} & M3 & M4 \\
\hline \multicolumn{2}{|c|}{ mipsCapacity = } & 465.00 & & .44 & 167.86 & 1007.00 \\
\hline
\end{tabular}

Figura 5.7: Representação do vetor mipsCapacity para os dados da tabela 5.2

Após a aquisição das informações da arquitetura, esses valores são combinados aos parâmetros do modelo para que juntos possam constituir os padrões de entrada utilizados pelo algoritmo genético para prover suas partições. Para compreender como essas informações são trabalhadas, é apresentadas na seção seguinte as características do algoritmo genético utilizado neste trabalho.

\subsection{Algoritmo Genético}

Para a aquisição automática das partições, o algoritmo genético utilizado neste trabalho seguiu os mesmos princípios de desenvolvimento que os aplicados na criação de sua forma clássica, a qual foi apresentada no capítulo 3. O algoritmo proposto para auxiliar o processo de particionamento de modelos em simulação distribuída foi projetado para fazer dos parâmetros apresentados nas seções 5.3 e 5.4 os padrões necessários para aquisição de boas partições.

Para obter bons resultados foi necessário associar aos parâmetros do modelo e da arquitetura padrões que representassem o tamanho da população e a quantidade de gerações utilizada para obter as soluções. Por questões de projeto, foi criado um processo de obtenção para esses padrões baseado no tamanho do modelo.

Para modelos que descrevem até 10 centros de serviço o algoritmo genético utiliza 10 indivíduos por população, os quais são modificados por 100 gerações. Acima dessa quantidade, as populações sobem para 100 indivíduos e as gerações para 1000. Alguns resultados alcançados utilizando essa padronização podem ser observados na seção 5.7.

Uma vez finalizada a aquisição de todos os parâmetros, esses são submetidos como entrada para o algoritmo genético o qual gera os cromossomos responsáveis por representar supostas soluções para o problema do particionamento. O cromossomo desenvolvido neste trabalho utiliza seus genes para representar os centros de serviço do modelo, sendo e o material genético associado a esses (alelos) para descrever a máquina/processador que o centro de serviço está alocado. A forma de descrição do cromossomo pode também ser utilizada para identificar quais centros de serviço pertencem ao mesmo processo lógico. Basta para isso, verificar quais posições do vetor apresentam uma mesma numeração. Um exemplo de tal representação pode ser observado na figura 5.8, onde um cromossomo com 4 genes é utilizado para representar um indivíduo para o grafo da figura 5.4 . 


\section{Cromossomo $=$\begin{tabular}{|c|c|c|c|}
$\mathrm{NCs} 0$ & $\mathrm{NCs} 1$ & $\mathrm{NCs} 2$ & $\mathrm{NCs} 3$ \\
\hline \hline 3 & 3 & 1 & 2 \\
\hline \hline
\end{tabular}}

Figura 5.8: Cromossomo utilizado pelo algoritmo genético

Considerando a representação da figura 5.8 como suposta solução para o problema, pode-se obter como particionamento neste caso a divisão descrita na figura 5.9.

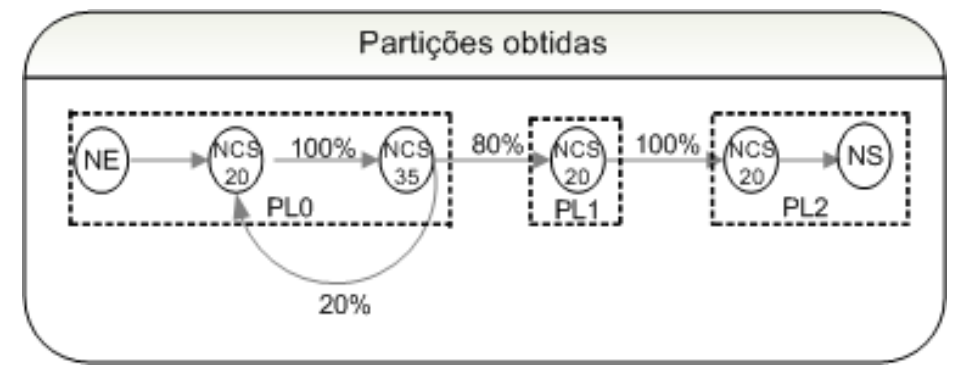

Figura 5.9: Representação do cromossomo da figura 5.8 no modelo

A identificação dos processos lógicos em um modelo é realizada através de uma análise feita no cromossomo apresentado como solução. Em uma primeira etapa, os alelos são separados por categorias, as quais são orientadas pelo número do processador. Após realizado esse processo, tem-se como resultado uma pré-divisão, onde todos os centros de serviço associados a um único processador já se encontram em um mesmo processo lógico. A numeração desses PL's, como pode ser observado na figura 5.9, é realizada a partir do centro de serviço 0, sendo sua alteração feita a medida que, no cromossomo, for sendo identificado alterações no alelo. Com a aplicação desse critério para a criação dos processos lógicos, os particionamentos obtidos sempre serão caracterizados por conter o centro de serviço 0 no PL0.

Para que se tenha representado no modelo o particionamento adequado, primeiramente é necessário identificar o cromossomo que será apresentado como suposta solução. Para isso, é necessário classificar cada indivíduo da população corrente por meio de uma função de fitness.

A função de fitness utilizada pelo algoritmo genético deste trabalho, classifica os indivíduos de uma população através de três equações matemáticas. Cada equação tem por objetivo identificar determinadas características, tais como, o balanceamento de carga, a comunicação entre processos, a sobrecarga nos processadores e, se necessário, corrigir os casos de erros esporádicos.

A primeira equação (equação 5.2) utilizada nesse processo é aplicada para verificar o balanceamento de carga. Essa equação busca no material genético do cromossomo anomalias que representem excesso de carga em determinado processo/processador. Essa operação é realizada em cada processo lógico, sendo a cada geração feita uma nova checagem.

$$
P L_{x}=\sum_{i \mid \text { Cromossomo }_{i}=P L_{x}}^{n} \text { mipsProcess }_{x} \leq \text { mipsCapacity }_{P_{x}}
$$


onde, $P L_{x}$ indica o processo lógico a ser validado; $\sum_{i \mid \text { Cromossomo }_{i}=P L_{x}}^{n}$ mips Process $_{x}$ indica o somatório das cargas dos centros de serviço associados à $P L_{x} ; \quad e$ mipsCapacity $P_{P_{x}}$ indica a capacidade máxima comportada pelo processador $P_{x}$ que receberá o processo lógico para a execução.

O resultado da equação 5.2 é utilizado para verificar se o cromossomo testado apresenta algum processo lógico com excesso de carga. Se o valor obtido da equação for maior que mipsCapacity $_{P_{x}}$, o processo lógico que excedeu a carga do processador corrente é modificado para se adequar a carga máxima aplicada a $P L_{x}$. Essa modificação implica na transferência do centro de serviço com a menor taxa de comunicação 22 para o próximo processo lógico a ser testado. Isso ocorre desde que o processo corrente não apresente somente um vértice associado ao processo. Caso exista somente 1 vértice, o cromossomo é eliminado da seleção e um novo cromossomo, criado aleatóriamente, é colocado em seu lugar.

A etapa executada pela equação 5.2 gera um loop entre o primeiro e o último processo lógico, onde a condição de parada é o balanceamento adequado ou a eliminação do cromossomo avaliado. Um exemplo desse processo pode ser observado a seguir, onde os parâmetros estipulados para o grafo da figura 5.4(b) são utilizados para analisar a carga do processo lógico 0 para o cromossomo descrito na figura 5.8 e alocado na máquina descrita na tabela 5.2 .

$$
P L_{0}=20+35 \leq 167.86
$$

Analisando o resultado apresentado no exemplo acima, tem-se que o processo lógico 0 utiliza uma carga de aproximadamente 55 MIPS, a qual é inferior à capacidade total do processador 3. Essa equação garante que o balanceamento entre processo e processador sempre será realizado, evitando que um excesso de carga prejudique o desempenho da simulação.

Após a validação dos indivíduos em relação ao balanceamento, é necessário, como próxima etapa, classificar os indivíduos da população corrente. Essa etapa permite identificar o melhor cromossomo, facilitando a busca pelo melhor resultado obtido ao termino da ultima geração.

Para a execução da etapa classificatória, um somatório é realizado em cada cromossomo para identificar a quantidade de comunicação existente em cada processo lógico. Essa etapa encarrega-se de classificar os indivíduos, apresentando como melhor solução o cromossomo que possuir o maior valor de comunicação. A classificação é realizada pela equação 5.3 descrita a seguir.

$$
\text { Fitness }_{i}=\sum_{j=0}^{n-1} P L_{j}
$$

Sendo,

$$
P L_{j}=\sum_{\substack{\mathrm{l} \mid \text { cromossomo }_{\mathrm{l}}=\mathrm{PL}_{\mathrm{j}} \\ \mathrm{k} \mid \text { cromossomo }_{\mathrm{k}}=\mathrm{PL}_{\mathrm{j}}}} M C_{l, k}
$$

\footnotetext{
${ }^{2}$ taxa armazenada na matriz Communication
} 
Onde, l e $k$ são utilizados para percorrer as linhas e colunas da Matriz Communication (MC) para identificar a comunicação interna total do processo lógico $P L_{j}$.

O somatório descrito na equação 5.4 é aplicado a cada processo lógico de um cromossomo. O valor resultante da equação identifica o fluxo de comunicação interno de cada processador. O somatório desses valores é utilizado pelo algoritmo genético como resultado da função classificatória de fitness, sendo esse valor armazenado no indivíduo junto ao seu cromossomo. Um exemplo desse processo pode ser observado a seguir, onde os parâmetros representados no cromossomo da figura 5.8 são utilizados para identificar a comunicação interna total gerada por esse indivíduo ao ser avaliado com os parâmetros da Matriz Communication descrita na figura 5.5 .

$$
P L_{0}=100+20=120
$$

A descrição apresentada no exemplo acima é aplicada a todos os processos lógicos criados, sendo o valor final do fitness obtido ao utilizar a equação 5.3. Mediante a obtenção dos valores de fitness para cada indivíduo da população corrente, faz-se necessário realizar a classificação da população de acordo com os valores alcançados. Essa ordenação é realizada decrescentemente de forma a deixar no topo da população sempre o melhor indivíduo ou solução. Esse, por sua vez, é passado para a próxima geração (elitismo), sendo seu material genético utilizado durante os novos cruzamentos.

Caso a quantidade de gerações não tenha chegado ao fim, a população corrente é submetida a um processo de transformações para gerar a próxima geração de indivíduos a ser avaliada. Essa nova geração é criada a partir das transformações feitas pelos operadores de crossover e mutação associados ao elitismo.

O crossover é o primeiro operador a ser executado após o elitismo. Sua função está em receber os indivíduos fazendo com que $60 \%$ desses sejam alterados geneticamente por meio de cruzamentos. Para isso, o operador busca randomicamente dois indivíduos, sendo um entre os 50\% dos melhores e um outro aleatoriamente na população. Após selecionados os indivíduos, são aplicados dois cortes em cada um (crossover de dois pontos), sendo utilizada a combinação das partes geradas para a criação de dois novos indivíduos (figura 5.10). Esse operador inicia a criação da nova população, a qual é completada após a aplicação do operador de mutação.

A mutação é aplicada nos $40 \%$ restantes da população que ainda não sofreram transformações. Esses indivíduos recebem uma taxa de $10 \%$ de mutação, taxa essa utilizada para indicar quantos genes de cada cromossomo vão ser modificados aleatoriamente pelo operador. O objetivo de sua aplicação é fornecer uma variabilidade na população. Essa variabilidade permite que o espaço de busca se amplie, fazendo com que melhores resultados sejam alcançados. Esse processo finaliza a criação da nova geração, a qual será aplicada a uma nova execução do algoritmo genético. Para compreender como as gerações são criadas e o resultado é obtido, tem-se apresentado a seguir (figura 5.11) os passos aplicados durante a execução do algoritmo genético. 


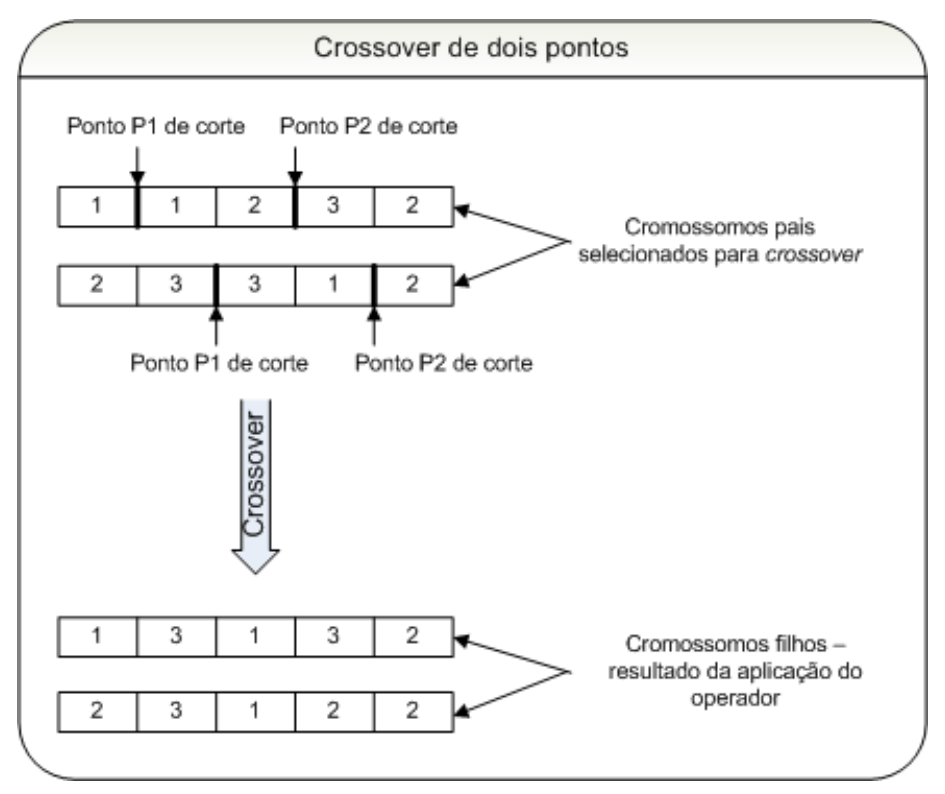

Figura 5.10: Processo executado pelo crossover

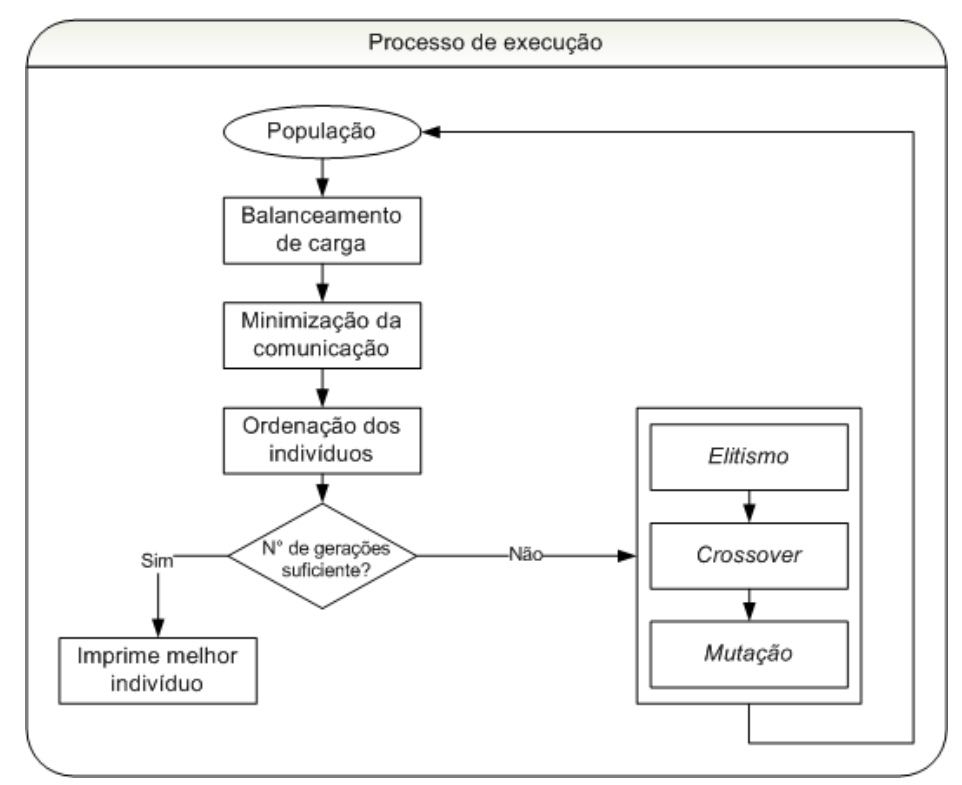

Figura 5.11: Processo de execução do algoritmo genético

\subsection{Particionamento Sugerido pelo Algoritmo Genético}

As soluções propostas pelo algoritmo genético seguem um padrão de representação para facilitar a compreensão destes pelo usuário. Um exemplo da forma descritiva utilizada pelo algoritmo genético deste trabalho para demonstrar seus resultados é apresentado na tabela 5.3, a qual representa o particionamento sugerido para o modelo representado pelo grafo da figura 5.4. Esses resultados foram obtidos submetendo o algoritmo genético a execução de 100 gerações para populações constituídas de 10 indivíduos.

Como pode ser observado pela representação da tabela 5.3, os resultados obtidos a partir do algoritmo genético apresentam todas as informações necessárias para a construção da simulação distribuída. Essas informações fornecem ao usuário dados que o permitem saber em qual processo lógico (PL) cada centro de serviço (CS) estará associado e também em que processador 
o processo lógico deverá ser executado.

Tabela 5.3: Representação das informações ao usuário

\begin{tabular}{cccc}
\hline \hline \multicolumn{4}{c}{ Particionamento } \\
\hline CS1 & CS2 & CS3 & CS4 \\
P3 & P3 & P1 & P2 \\
PL0 & PL0 & PL1 & PL2 \\
\hline \hline Tempo de Execução: & $\mathbf{0 . 1 ~ s e g ~}$ \\
\hline \hline
\end{tabular}

\subsection{Considerações Finais}

O algoritmo genético proposto neste trabalho pode apresentar resultados satisfatórios ao ser utilizado como ferramenta de auxílio para o particionamento de modelos em simulação distribuída. A sua integração com o Ambiente de Simulação Distribuída Automático (ASDA) pode facilitar essa etapa do desenvolvimento, apresentando como benefício, simulações caracterizadas pelo balanceamento de carga adequado entre os processos lógicos e a diminuição do overhead na rede durante a execução devido a baixa comunicação entre processos. Outro benefício obtido pela utilização do algoritmo genético é a possibilidade de se obter bons resultados para a grande maioria dos casos de particionamento, evitando que modelos complexos dificultem a utilização da simulação distribuída.

Para demonstrar a eficiência e desempenho associados ao algoritmo genético, tem-se apresentado no próximo capítulo os estudo de caso realizados para demonstrar o comportamento das simulações automaticamente particionadas. 


\section{Estudos de Casos}

\subsection{Considerações Iniciais}

Os estudos de casos apresentados neste capítulo têm como objetivo avaliar o desempenho e a eficiência do algoritmo genético para solucionar o problema de particionamento de modelos em simulação distribuída. Para isso, foram definidos vários experimentos com simulações distribuídas utilizando o protocolo conservativo CMB (ver página 10). Esses experimentos coletaram informações do tempo de execução das simulações com várias configurações de processos lógicos e duas arquitetura. Esses parâmetros foram combinados e constituíram diferentes estudos de casos para validar a utilização do algoritmo genético como ferramenta de auxílio em ambientes de simulação distribuída automáticos.

A análise realizada neste trabalho também é utilizada para identificar os parâmetros que causam maior influência no tempo de execução das simulações. Para isso, foram utilizadas duas arquiteturas computacionais com heterogeneidade diferentes. Isso permitiu estabelecer uma avaliação dos parâmetros do modelo em duas diferentes situações, sendo possível identificar qual o impacto da arquitetura para o processo de execução.

Para tornar compreensíveis os passos acima apresentados e assim concluir sobre os resultados alcançados, a seção 6.2 detalha a metodologia adotada nas execuções das simulações e coleta dos resultados; a seção 6.3 descreve a configuração das arquiteturas utilizadas nos testes; na seção 6.4 são apresentados os modelos e partições avaliadas pelos experimentos simulados e por fim, a seção 6.5 descreve os resultados alcançados e as respectivas avaliações e análises realizadas.

\subsection{Metodologia Adotada}

A metodologia adotada neste trabalho visa avaliar o desempenho e a eficiência do algoritmo genético proposto no capítulo 4 para o problema de particionamento de modelos. Para tal 
avaliação, os resultados obtidos a partir da aplicação do algoritmo genético nos casos de teste propostos simulados e utilizaram as mesmas configurações aplicadas como padrões de entrada no algoritmo genético.

Para que a solução fornecida pelo algoritmo genético pudesse ser avaliada, cada modelo foi particionado de seis diferentes formas. Dessas partições, duas foram obtidas pelo algoritmo genético e quatro de forma manual, baseadas no conhecimento de especialistas da área de simulação distribuída. Para a obtenção das partições providas pelo algoritmo genético, esse foi executado diversas vezes, até que uma porcentagem de $85 \%$ de resultados iguais fossem gerados. Isso garantiu a confiabilidade das partições propostas pelo algoritmo genético e permitiu analisar seu desempenho ao comparar os resultados obtidos com os das demais partições.

Para realizar as comparações, foi criado um processo para coletar das simulações o tempo médio de execução a cada seqüência de quinze rodadas. Durante esse processo, o valor da semente de números aleatórios e a quantidade de clientes foram modificadas.

A modificação da semente seguiu um padrão de alterações contínua, ou seja, a cada execução uma nova semente foi aplicada como entrada para a mesma quantidade de clientes simulados. A troca de semente faz com que a seqüência de números aleatórios seja alterada, fazendo com que outros caminhos no modelo sejam explorados, gerando assim diferentes tempos de execução para uma mesma simulação.

A quantidade de clientes, ao contrário da semente, foi modificada a cada seqüência. Inicialmente, as simulações executaram com 100 clientes, sendo esse valor acrescido de 100 a cada quinze rodadas até atingir o máximo de 500 evento por seqüência. Isso permitiu identificar se a quantidade de clientes poderia vir a influenciar diretamente no tempo de execução das simulações.

Para facilitar a aquisição dos resultados, foi desenvolvido neste trabalho um comando padrão para executar as seqüências de rodadas. A descrição do comando utilizado pode ser observado na representação a seguir:

$$
. / \text { plo }<\text { Semente }><\text { Clientes }>
$$

plO: nome do programa executável que inicia a simulação.

<Semente>: Representa o valor da semente utilizada pela rodada corrente. Os valores utilizados para as seqüências alternaram de 1 a 15 para as duas arquiteturas avaliadas.

$<$ Clientes >: Representa a quantidade de clientes simulados. Essa quantidade foi modificada a cada seqüência executada, sendo o valor iniciado em 100 e acrescido de 100 até atingir o limite de 500 clientes por seqüência. Esse fator também foi aplicado às duas arquiteturas avaliadas.

Os programas de simulação distribuída desenvolvidos utilizaram a extensão funcional ParSMPL (ULSON, 1999), a qual implementa o protocolo conservativo CMB (BRYANT, 1977) (CHANDY; MISRA, 1979). Desse modo, os resultados apresentados nesta dissertação são válidos para simulações que utilizam o protocolo conservativo CMB e a transcrição de mensagens nulas para 
evitar deadlocks. Para fazer uso dessa extensão funcional, as simulações criadas foram compiladas utilizando o gcc 2.95 e PVM (Parallel Virtual Machine) 3.4.4.

Todas as simulações geradas pelo processo acima descrito foram executadas nas respectivas arquiteturas para as quais foram desenvolvidas. Para uma melhor compreensão das características de cada uma das arquiteturas utilizadas, é apresentada na próxima seção uma visão detalhada das configurações e suas respectivas características.

\subsection{Características das Arquiteturas}

As simulações distribuídas foram executadas em duas arquiteturas que se diferem pelo grau de heterogeneidade, ou seja, pelo poder computacional das máquinas. As máquinas utilizadas nas arquiteturas são pertencentes à rede local de computadores do Laboratório de Sistemas Distribuídos e Programação Concorrente (LaSDPC) do ICMC-USP São Carlos.

Para estabelecer a comunicação entre as máquinas de cada arquitetura foi utilizada uma rede de $100 \mathrm{Mbits} / \mathrm{seg}$ conectada a um switch de mesma velocidade. Cada arquitetura é composta por três máquinas executando o sistema operacional Linux com distribuições do Slackware 8.1 e Kernel 2.4.18. As composições das arquiteturas podem ser observadas nas tabelas 6.1 (arquitetura 01) e 6.2 (arquitetura 02).

Tabela 6.1: Configuração da arquitetura 01

\begin{tabular}{ccccc}
\hline \hline NMAQ & Nome & Processador & Memória & MIPS(Benchmark) \\
\hline M1 & LaSDPC05 & Pentium II 233Mhz & $128 \mathrm{Mb}$ & 116.44 \\
M2 & LaSDPC07 & Pentium II 233Mhz & $64 \mathrm{Mb}$ & 167.86 \\
M3 & Notebook & AMD Atlhon 2.8Mhz & $512 \mathrm{Mb}$ & 1007.00 \\
\hline \hline
\end{tabular}

As configurações das máquinas utilizadas na arquitetura 01 permitiu a criação de um grau de heterogeneidade médio, o qual tornou a arquitetura em si desbalanceada. Esse desbalanceamento, apresentado principalmente pela inclusão do Notebook, foi utilizado para avaliar se o poder de processamento contido em cada máquina está associado diretamente às variações de tempo de execução de determinadas partições simuladas.

Para identificar se a configuração da arquitetura está associada à perda ou ganho de tempo de execução, foi proposto uma segunda configuração, onde o ponto de maior heterogeneidade foi substituído por uma nova máquina com capacidade mais próxima às demais. Isso permitiu criar uma arquitetura de testes que apresentasse como diferencial um poder computacional menor.

Tabela 6.2: Configuração da arquitetura 02

\begin{tabular}{ccccc}
\hline \hline NMAQ & Nome & Processador & Memória & MIPS(Benchmark) \\
\hline M1 & LaSDPC05 & Pentium II 233Mhz & $128 \mathrm{Mb}$ & 116.44 \\
M2 & LaSDPC07 & Pentium II 233Mhz & $64 \mathrm{Mb}$ & 167.86 \\
M3 & LaSDPC06 & Pentium III 450Mhz & $128 \mathrm{Mb}$ & 465.00 \\
\hline \hline
\end{tabular}

Cada arquitetura apresentada nesta seção foi utilizada no processo de obtenção de resultados apresentados na seção 6.5. Para que tal tarefa fosse realizada, vários experimentos foram 
executados, os quais se basearam em três diferentes modelos. Esses modelos, bem como as partições utilizadas nos testes são detalhados na próxima seção.

\subsection{Modelos e Particionamentos Avaliados}

Esta seção visa detalhar as características dos modelos e partições utilizadas nos estudos de casos apresentados na seção 6.5. Três diferentes modelos foram utilizados para formar os diferentes cenários a serem analisados, sendo esses projetados para ressaltarem diferentes fatores que podem vir a influenciar no tempo de execução das simulações. Os fatores avaliados neste trabalho foram:

- Porcentagem de comunicação entre centros de serviço

- Tamanho do modelo

- Influência causada pela quantidade de processos lógicos

- Saídas do modelo

Os modelos utilizados para a realização dos experimentos deste trabalho foram obtidos em um arquivo gerado automaticamente pelo ASDA. Esse arquivo é utilizado pelo algoritmo genético para a criação dos padrões de entrada necessários para a obtenção das partições para cada arquitetura.

Alguns parâmetros foram mantidos fixos para todos os experimentos realizados neste trabalho, sendo: a taxa de chegada, a taxa de atendimento e a latência de comunicação, onde todos utilizam uma distribuição de probabilidade exponencial. Para a taxa de atendimento de requisições e a taxa de chegada entre solicitação foi estipulado um valor de distribuição exponencial de média 10. A latência de comunicação entre os centros de serviço recebeu um valor de mesma distribuição, porém menor, de média 5. Como as duas arquiteturas definidas possuem 3 máquinas, todos os modelos serão particionados em 3 processos lógicos, sendo cada um executado em uma das máquinas.

\subsubsection{Características do Modelo 01}

O modelo 01 representado na figura 6.1 é utilizado para descrever um sistema computacional hipotético, o qual possui 10 centros de serviço com uma taxa de chegada e tempo de atendimento como definido no início desta seção.

O modelo 01 foi particionado de 6 diferentes formas, sendo cada uma responsável por coletar parte dos resultados apresentados na seção 6.5. No processo de particionamento adotado, formam criadas manualmente 4 partições, as quais foram executadas nas duas arquiteturas de teste. O algoritmo genético forneceu mais duas partições, sendo cada uma executada na arquitetura para a qual foi calculada. As partições obtidas a partir desse processo podem ser observadas na tabela 6.3 , onde estão também definidas as arquiteturas de execução para cada partição e os centros de serviço associados a cada processo lógico criado. 


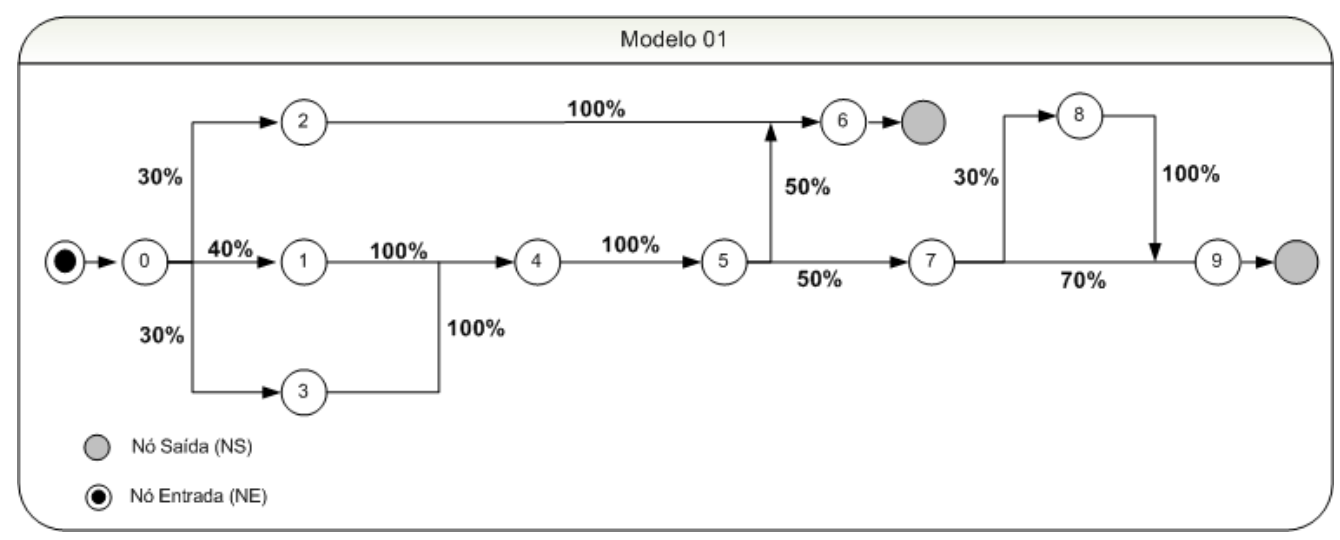

Figura 6.1: Notação gráfica do modelo 01

Tabela 6.3: Partições propostas para o Modelo 01

\begin{tabular}{ccccc}
\hline \hline Arquitetura & Partição & PL0 & PL1 & PL2 \\
\hline 01 e 02 & 01 & 023 & 145 & 6789 \\
01 e 02 & 02 & 0123 & 456 & 789 \\
01 e 02 & 03 & 01 & 2346 & 5789 \\
01 e 02 & 04 & 013 & 2456 & 789 \\
01 & 05 & 0 & 26 & 1345789 \\
02 & 06 & 01345 & 26 & 789 \\
\hline \hline
\end{tabular}

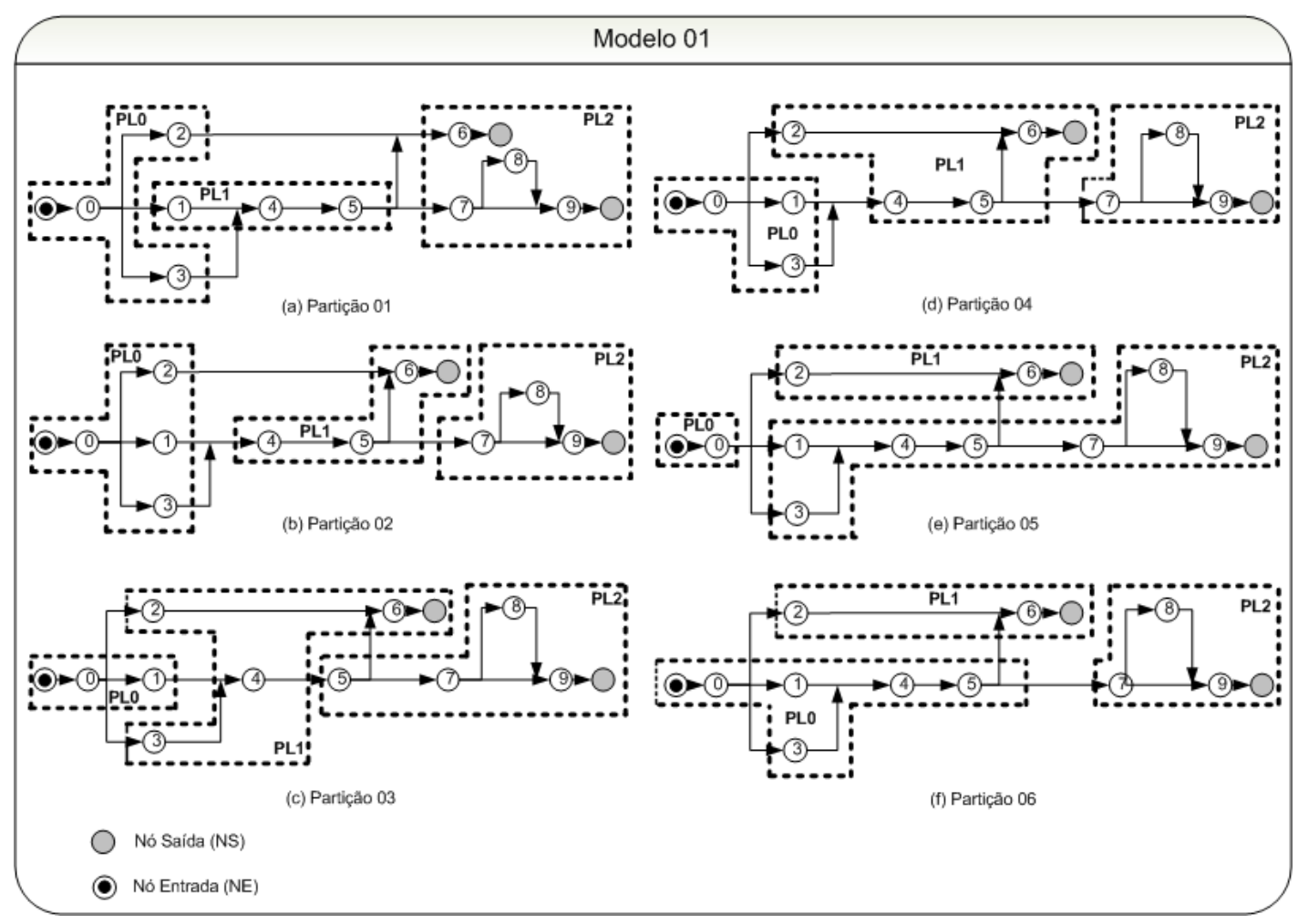

Figura 6.2: Partições definidas para o modelo 01

A representação gráfica das partições obtidas para o modelo 01 podem ser observadas na figura 6.2 ,

Os critérios utilizados para a obtenção de cada partição representada na figura 6.2 foram obtidos a partir da experiência dos conhecedores da área de simulação associado às necessidades 
de se estar avaliando determinadas influências que poderiam vir a prejudicar a execução da simulação.

O primeiro critério avaliado foi a influência causada na combinação de centros de serviço agrupados em cada processo lógico. Para realizar esse critério as partições 01 e 02 foram propostas. Nessas, como pode ser observado na figura 6.2 (a) e (b), os centros de serviço foram agrupados de forma a manter os mais próximos em um mesmo processo lógico. Para diferenciar as partições 01 e 02, outro critério foi proposto para avaliação. Esse critério é aplicado às saídas do modelo para avaliar sua influência durante a execução da simulação. Para isso, essas apresentam-se agrupadas em um mesmo processo lógico na partição 01 e distribuídas entre os processos lógicos na partição 02 .

A partição 03 (figura 6.2 (c)) foi criada para apresentar como característica predominante a criação de processos lógicos que agrupassem somente os centros de serviço que apresentem as maiores taxas de comunicação. Esse critério permitiu estabelecer uma avaliação tanto da influência causada pelo balanceamento quanto pela comunicação.

Utilizando os mesmos critérios aplicados para a obtenção do particionamento 03, foi criada uma quarta partição, que difere da partição 3 por prover processos lógicos caracterizados pelo perfeito balanceamento de carga, visto que a quantidade de centros de serviço por processo lógico é o mesmo. As duas partições restantes foram obtidas a partir do algoritmo genético, sendo a partição 5 (figura 6.2(e)) para ser executada na arquitetura 1 e a partição 6 (figura $6.2(f))$ na arquitetura 2.

\subsubsection{Características do Modelo 02}

Para avaliar outros fatores e obter dados para fins comparativos, foi proposto o modelo 02 apresentado na figura 6.3. Esse modelo também representa um sistema computacional hipotético e possui como diferencial a realimentação entre as arestas 3 e 0. Outro fator representado e avaliado no decorrer dos testes foi o tamanho do modelo, visto que esse foi projetado com apenas 6 centros de serviço. Isso permitiu avaliar se a influência causada pelo particionamento em modelos menores apresenta-se proporcionalmente equivalente à modelos maiores.

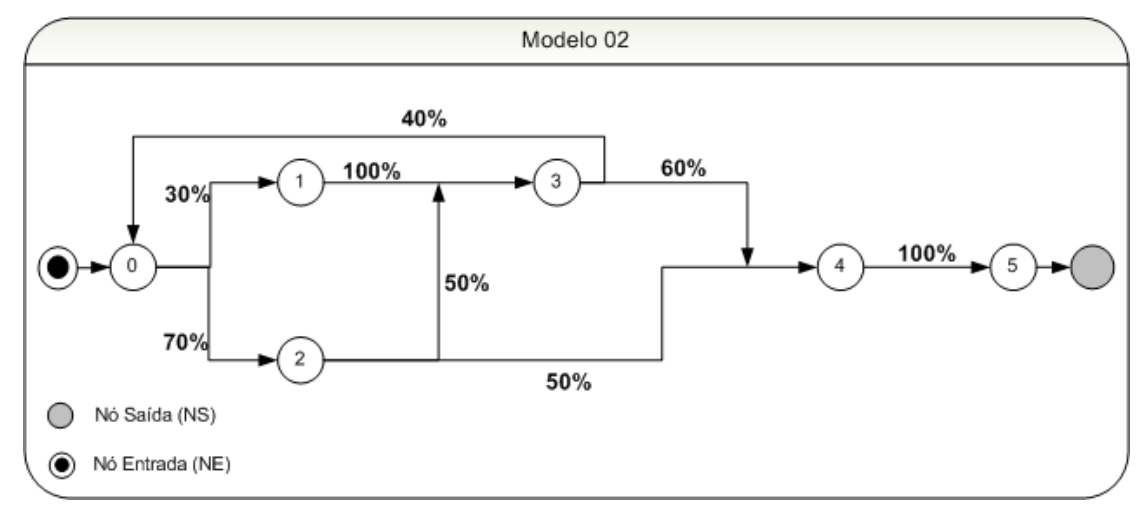

Figura 6.3: Representação do segundo modelo avaliado

Uma vez que o objetivo dessa avaliação é demonstrar que independente do tamanho e complexidade do modelo, o algoritmo genético pode auxilar o processo de particionamento de 
modelos e com isso prover bons resultados, o mesmo processo aplicado ao modelo anterior foi utilizado. Terminado esse processo, obteve-se como resultado, para o modelo 02, as partições apresentadas na tabela 6.4 .

\begin{tabular}{ccccc}
\multicolumn{5}{c}{ Tabela 6.4: } \\
\hline \hline Arquitetura & Partiçãos propostas & PL0 & PL1 & PL2 \\
\hline 01 e 02 & 01 & 01 & 23 & 45 \\
01 e 02 & 02 & 01 & 2 & 345 \\
01 e 02 & 03 & 0 & 123 & 45 \\
01 e 02 & 04 & 02 & 13 & 45 \\
01 & 05 & 0234 & 1 & 5 \\
02 & 06 & 012 & 3 & 45 \\
\hline \hline
\end{tabular}

Para particionar o modelo 02, obtendo as 4 partições que serão executadas nas duas arquiteturas de teste, os mesmos critérios adotados na criação dos processos lógicos utilizados no modelo anterior foram adotados. Objetiva-se com esse modelo avaliar novas característica que possam vir a influenciar a aplicação da simulação distribuída. Para isso, serão utilizadas durante os testes as partições apresentadas na figura 6.4.

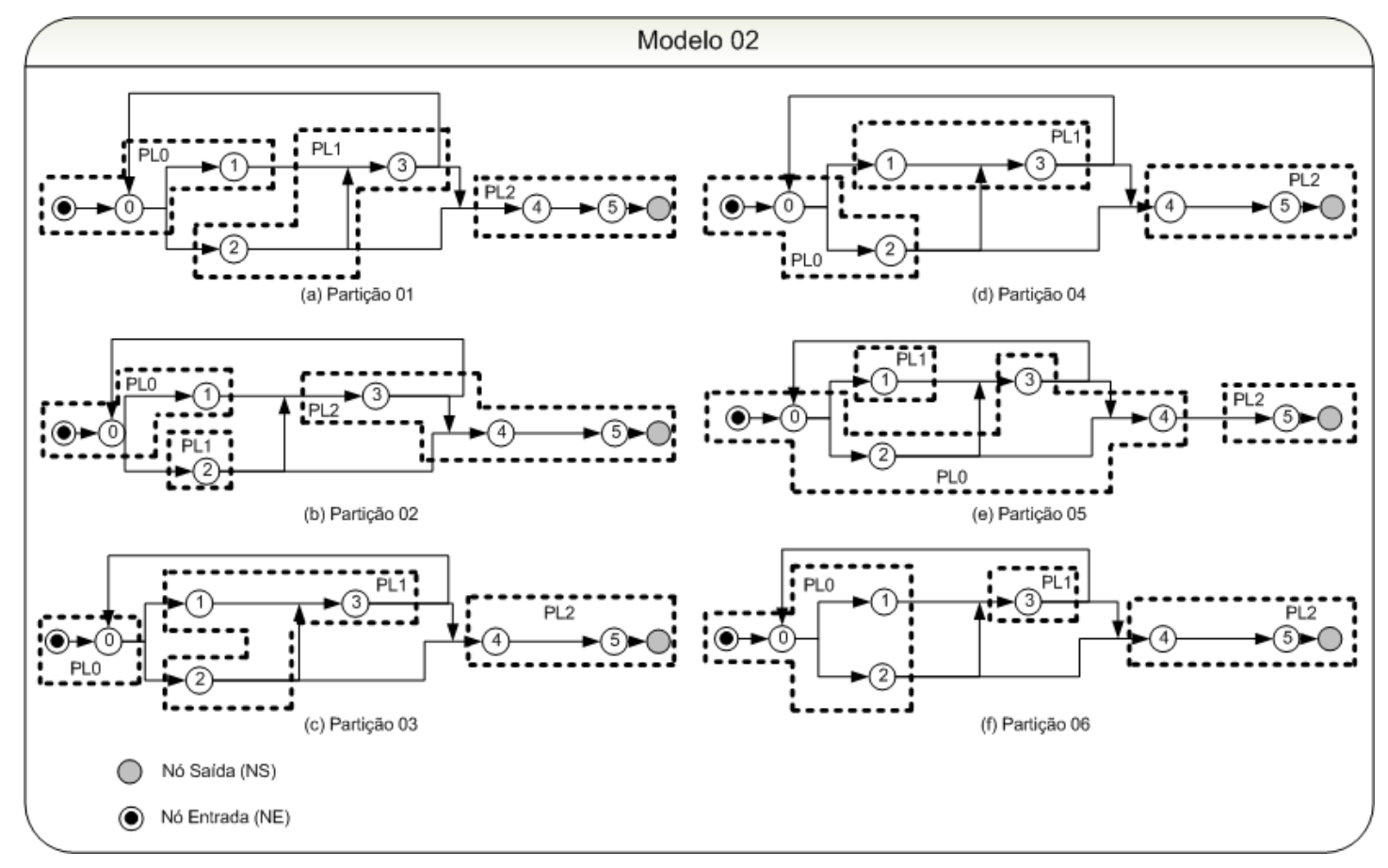

Figura 6.4: Partições definidas para o modelo 02

Os fatores analisados pelas partições (a) e (d) visam avaliar o desempenho da simulação quando os processos lógicos encontram-se balanceados, mas, sem critérios para o agrupamento visando a diminuição da comunicação na rede. O objetivo é identificar qual a influência causada por particionamentos que visam somente o balanceamento de carga.

Os critérios utilizado para a avaliação da influência causada pelo balanceamento de carga e/ou pela comunicação entre processos foi também aplicada para a obtenção das partições (b) e (c). O critério adotado para a obtenção dessas partições, baseou-se na seleção de centros de 
serviço que apresentassem como característica a segmentação de sua comunicação entre outros centros de serviço do modelo. Como resultado desse processo foram criadas duas partições, as quais podem ser observadas na figura 6.4 (b) e (c). Objetiva-se com isso identificar se esse tipo de conduta aplicada ao particionamento pode vir a aumentar a comunicação entre processos e conseqüentemente influenciar no desempenho de execução da simulação.

Como no modelo anterior (modelo 01), duas partições foram propostas pelo algoritmo genético (figuras 6.4 (e) e (f)). Essas, por sua vez, são utilizadas para demonstrar que o algoritmo genético desenvolvido não está relacionado ao particionamento de casos específicos, mas a todos os casos de representação que possam vir a ocorrer.

\subsubsection{Características do Modelo 03}

Para coletar maiores informações sobre o comportamentos das partições providas pelo algoritmo genético, foi criado o modelo 03 (figura 6.5). Embora apresentando-se com características já representadas no modelo 01 (figura 6.1), como a descrição de um sistema hipotético com 10 centros de serviço, esse terceiro modelo se diferenciou pela forma como foram criadas as conexões entre os centros de serviço.

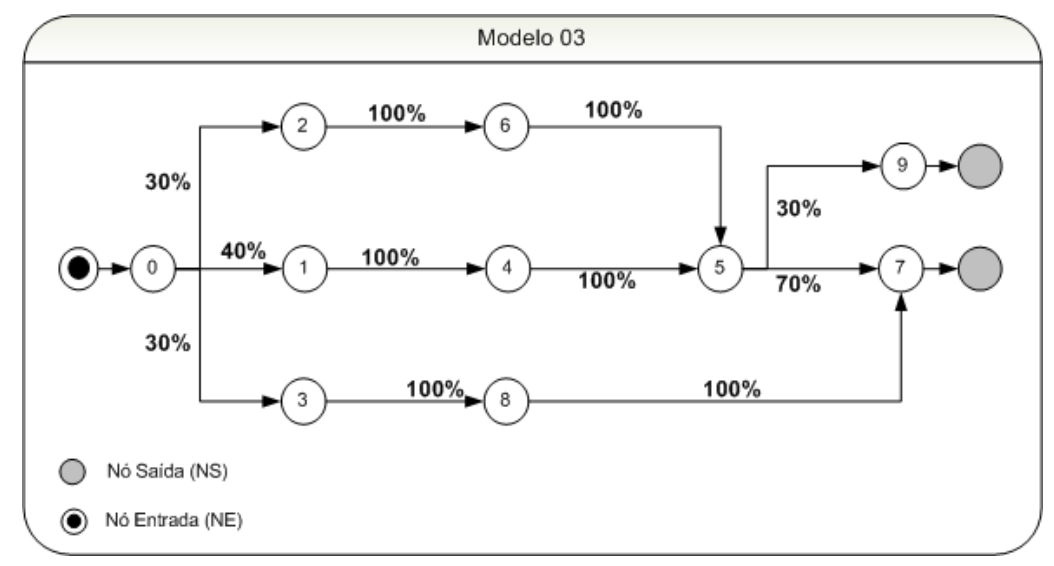

Figura 6.5: Notação gráfica do modelo 03

As partições obtidas a partir do modelo representado na figura 6.5 seguiram os mesmos critérios aplicados para particionar os modelos anteriores. As partições obtidas a partir da aplicação desse processo podem ser observadas na tabela 6.5 .

Tabela 6.5: Partições propostas para o Modelo 03

\begin{tabular}{ccccc}
\hline \hline Arquitetura & Partição & PL0 & PL1 & PL2 \\
\hline 01 e 02 & 01 & $0,2,3$ & $1,4,5$ & $6,7,8,9$ \\
01 e 02 & 02 & $0,1,2,3$ & $4,5,6$ & $7,8,9$ \\
01 e 02 & 03 & 0,1 & $2,3,4,6$ & $5,7,8,9$ \\
01 e 02 & 04 & $0,1,3$ & $2,4,5,6$ & $7,8,9$ \\
01 & 05 & $0,1,2,3,4,6,8$ & 5 & 7,9 \\
02 & 06 & 0,9 & $1,2,4,5,6$ & $3,8,7$ \\
\hline \hline
\end{tabular}

Como pode ser observado na tabela 6.5, o particionamento realizado randomicamente para a obtenção das quatro primeiras partições seguiu os mesmos critérios adotados nos modelos 
anteriores. A representação gráfica dessas partições pode ser observada na figura 6.6.

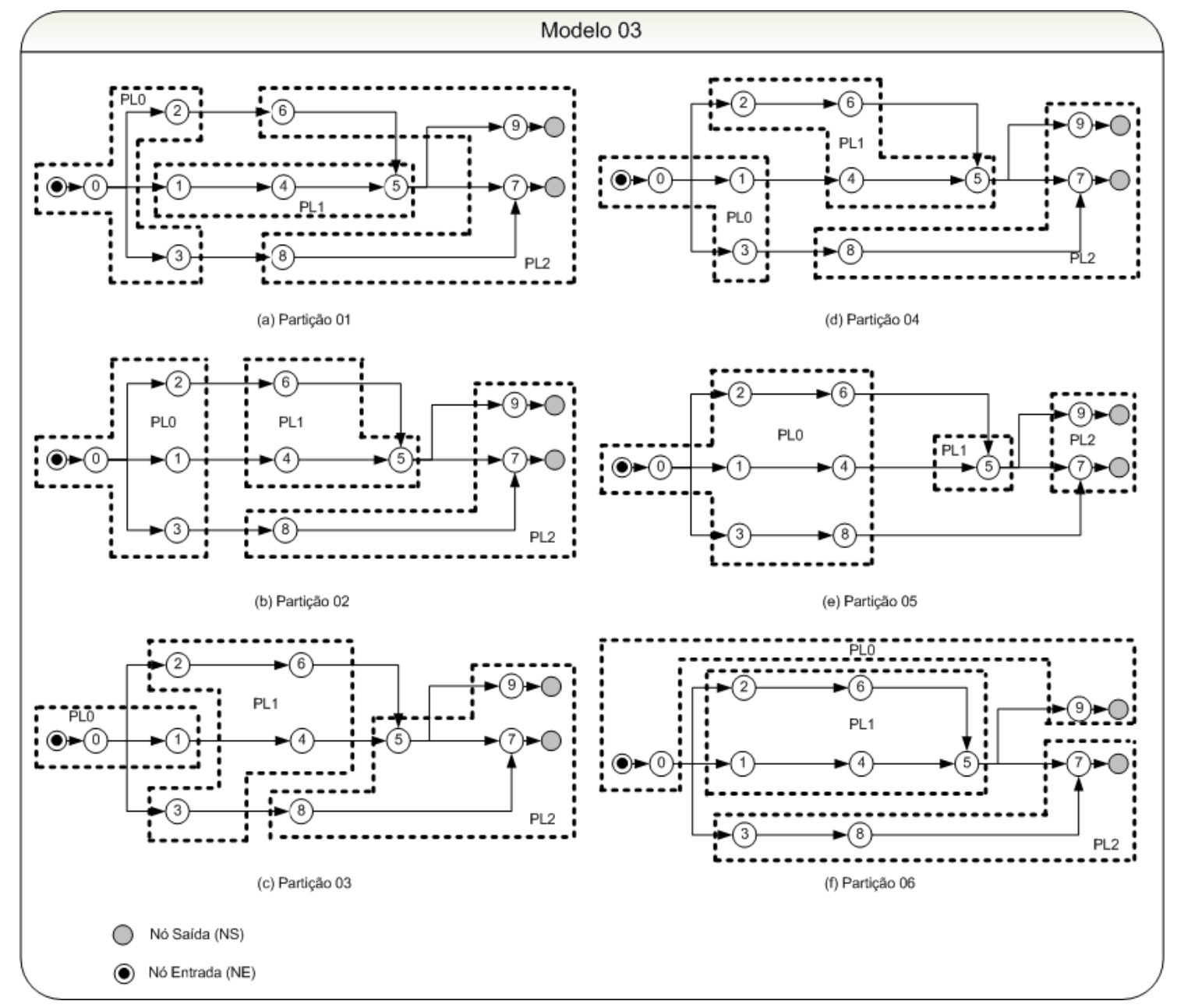

Figura 6.6: Partições definidas para o modelo 03

Sabendo-se que vários pesquisadores utilizam a simulação distribuída como ferramenta para aumentar o desempenho computacional na busca por resultados, torna-se válida a verificação do desempenho e eficiência do algoritmo genético em outros trabalhos. Para tanto, um quarto modelo é proposto, sendo esse descrito e avaliado no trabalho de doutorado de KAWABATA, 2005).

\subsubsection{Características do Modelo 04}

No trabalho de (KAWABATA, 2005) foi realizado um estudo sobre a viabilidade de se ter dois protocolos de simulação distribuída sendo executados simultaneamente durante a simulação. Nesse estudo, alguns modelos foram avaliados, sendo um desses apresentado na figura 6.7.

No estudo realizado por (KAWABATA, 2005), o modelo (figura 6.7) foi particionado para obter somente dois processos lógicos. Essas partições, associadas a partição proposta pelo algoritmo genético, foram utilizadas para coletar informações sobre o speedup das simulações. A arquitetura utilizada nesse teste é detalhada na tabela 6.6.

A arquitetura apresentada na tabela 6.6 foi utilizada por Kawabata (2005) para coletar os resultados, os quais são avaliados na seção 6.5.4. As partições utilizadas para tal feito são detalhadas na tabela 6.7 e podem ser visualizadas na figura 6.8 . 


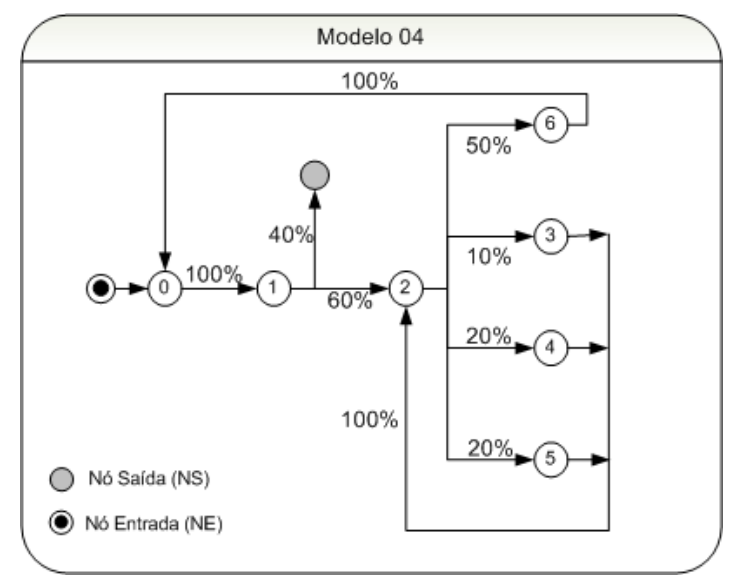

Figura 6.7: Modelo estudado por (KAWABATA, 2005)

Tabela 6.6: Configuração da arquitetura utilizada

\begin{tabular}{ccccc}
\hline \hline NMAQ & Nome & Processador & Memória & MIPS(Benchmark) \\
\hline M1 & LaSDPC05 & Pentium II 233Mhz & $128 \mathrm{Mb}$ & 116.44 \\
M2 & LaSDPC07 & Pentium II 233Mhz & $64 \mathrm{Mb}$ & 167.86 \\
\hline \hline
\end{tabular}

Tabela 6.7: Partições analisadas no trabalho de (KAWABATA, 2005)

\begin{tabular}{cccc}
\hline \hline Arquitetura & Partição & PL0 & PL1 \\
\hline 01 & 01 & 0,1 & $2,3,4,5,6$ \\
01 & 02 & $0,1,2,6$ & $3,4,5$ \\
01 & 03 & $0,1,6$ & $2,3,4,5$ \\
\hline
\end{tabular}

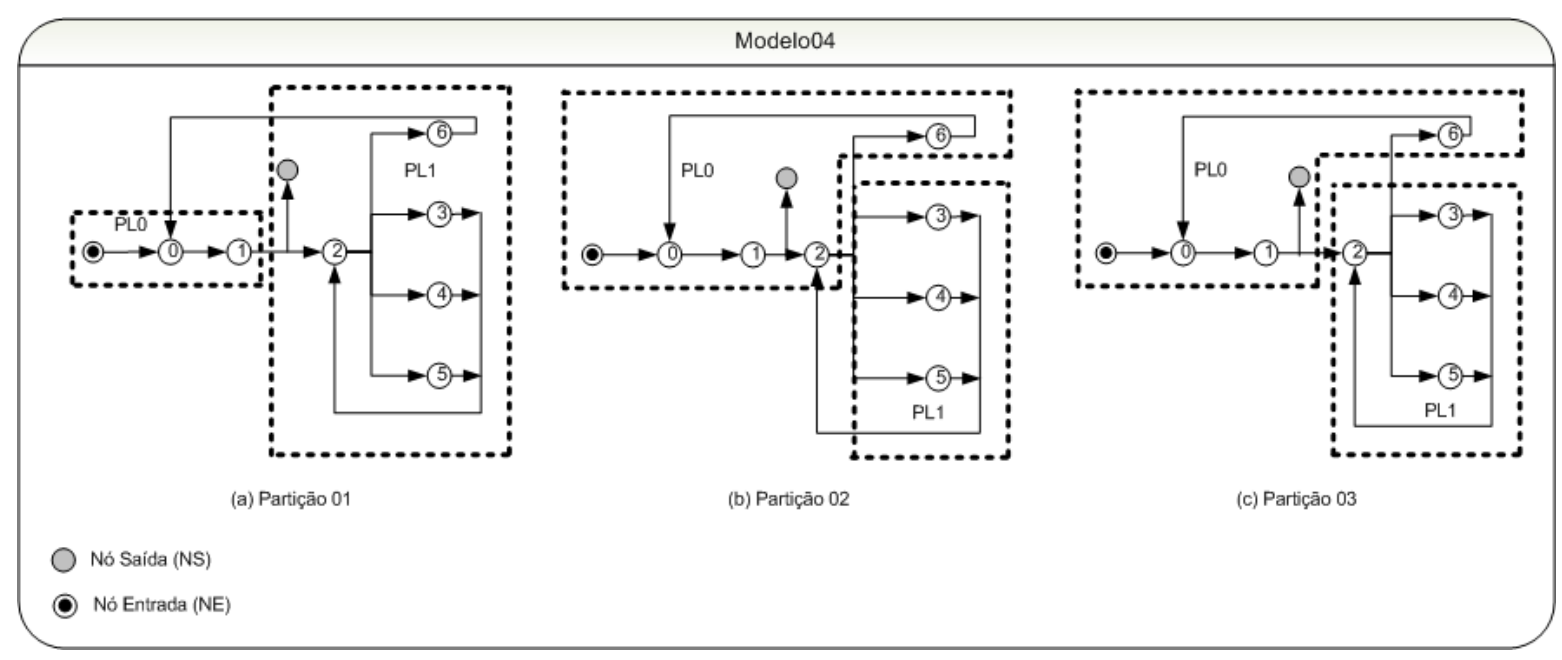

Figura 6.8: Partições definidas para o modelo 04 (KAWABATA, 2005)

Para compreender como cada modelo foi utilizado para coletar os resultados analisados neste trabalho, tem-se apresentado na próxima seção a descrição do processo de análise realizado para demonstrar a eficiência e o desempenho alcançados pelo algoritmo genético quando aplicado como ferramenta de auxílio para o particionamento de modelos em simulação distribuída. 


\subsection{Análise dos Resultados}

Esta seção apresenta os resultados obtidos com a execução das simulações distribuídas dos quatro casos de testes estabelecidos na seção 6.4. Os resultados alcançados foram utilizados para representar o tempo médio de execução gasto e a porcentagem de ganho $(\mathrm{G})$ e perda $(\mathrm{P})$ que a partição do algoritmo genético (PGA) obteve ao ser comparada com o melhor (representado pelo símbolo $\star$ nas tabelas) e o pior (representado pelo símbolo . nas tabelas) tempo de execução. As equações utilizadas para obter os valores de P e G são descritas a seguir:

$$
\begin{gathered}
P=\frac{P G A-\text { MelhorTempo }}{\text { MelhorTempo }} * 100 \\
G=\frac{\text { PiorTempo }-P G A}{\text { PiorTempo }} * 100
\end{gathered}
$$

Para melhor representar os resultados coletados das simulações distribuídas, quatro estudos de caso foram criados. Cada estudo foi utilizado para representar um modelo, sendo a cada análise realizada novas conclusões estabelecidas.

\subsubsection{Estudo de Caso 1}

Neste estudo de caso é avaliado o desempenho das simulações criadas para representar as partições do modelo 01. A tabela 6.8 fornece os resultados obtidos com as execuções na arquitetura 01 das simulações distribuídas definidas na seção anterior. Nota-se que, mesmo a partição do algoritmo genético não apresentando-se como a melhor solução, essa pode ser considerada viável. Isso pode ser observado pelo fato de que tal solução se manteve estável no decorrer das execuções e não apresentou-se como a pior solução em nenhum dos testes realizados. Essa estabilidade pode ser comprovada ao observar na tabela 6.8 as porcentagens

\begin{tabular}{|c|c|c|c|c|c|c|c|}
\hline Qtd. clientes & $\mathrm{P} 01$ & $\mathrm{P} 02$ & $\mathrm{P} 03$ & $\mathrm{P} 04$ & PGA & $\mathrm{P}(\%)$ & $\mathrm{G}(\%)$ \\
\hline 100 & 39.75 . & 3.47 & 4.16 & $3.27 \star$ & 5.38 & 64.52 & 86.46 \\
\hline 200 & 77.55 . & 6.63 & 8.13 & $6.45 \star$ & 9.22 & 42.94 & 88.11 \\
\hline 300 & 97.73 . & $9.74 \star$ & 12.02 & 9.79 & 13.50 & 38.60 & 86.19 \\
\hline 400 & 120.41 . & 13.08 & 15.93 & $12.72 \star$ & 17.62 & 38.52 & 85.37 \\
\hline 500 & • & 16.15 & 19.62 & $15.97 \star$ & 22.38 & 40.13 & 86.06 \\
\hline
\end{tabular}
de ganho $(\mathrm{G}(\%))$ e de perda $(\mathrm{P}(\%))$ obtidos na análise realizada.

Ao analisar as partições da figura 6.2 com os resultados apresentados na tabela 6.8, pode-se concluir que o primeiro fator que pode vir a influenciar no tempo de execução da simulação é a forma como as saídas do modelo são agrupadas. Essa suposição pode ser melhor compreendida ao observar as partições 01 e 03 representadas na figura 6.2 (a) e (c). Por essa representação pode-se observar que na partição 01, o centro de serviço 06 fica desprovido de comunicação com os dois centros de serviço que se comunicam com ele, fazendo com a simulação apresente 
resultados ruins. Na partição 03, a divisão dos centros de serviço foi realizada de forma a deixar centros de serviço que se comunicam com as saídas em um mesmo processo lógico, isso fez com que os resultados se alterassem e melhores tempos de execução fossem alcançados.

Outro fator identificado como influente é a quantidade de clientes simulados. Sua influência está diretamente associada às partições propostas pelo algoritmo genético, visto que a execução com poucos clientes implica em resultados não tão satisfatórios para essas partições. Tal influência pode ser observada ao avaliar os resultados da tabela 6.8, a qual detalha a porcentagem de $\mathrm{G}$ se mantendo a índices altos e a porcentagem de $\mathrm{P}$ diminuindo a medida que uma quantidade de clientes maior é simulado.

As conclusões apresentadas para a arquitetura 01 procedem na arquitetura 02 já que, para as duas situações, o comportamento dos resultados se mostrou o mesmo. Isso pode ser observado ao comparar os dados representados na tabela 6.8 com os da tabela 6.9. Observa-se nesses dados que, dependendo da quantidade de clientes, a melhor solução se alterna entre as partições P2 e P4. Com isso pode-se concluir que, nem sempre, a melhor solução estará agregada a uma única partição independentemente da arquitetura a ser utilizada para a execução da simulação.

Tabela 6.9: Avaliação das partições do modelo 01 para a arquitetura 02

\begin{tabular}{c|c|c|c|c|c|c|c}
\hline \hline Qtd. clientes & P01 & P02 & P03 & P04 & PGA & P(\%) & G(\%) \\
\hline 100 & 32.23. & 4.35 & 5.37 & $4.28 \star$ & 4.82 & 12.65 & 85.05 \\
200 & 65.48. & 8.54 & 10.76 & $8.32 \star$ & 8.80 & 5.77 & 86.56 \\
300 & 75.74. & $12.42 \star$ & 15.62 & 12.60 & 13.53 & 8.94 & 82.14 \\
400 & 105.68. & 16.98 & 20.73 & $16.60 \star$ & 17.98 & 8.31 & 82.99 \\
500 & 134.14. & 21.14 & 25.90 & $21.05 \star$ & 23.19 & 10.17 & 82.71 \\
\hline \hline
\end{tabular}

As tabelas apresentadas neste estudo de caso podem ser observadas em notações gráficas apresentadas nas figuras 6.9(a) e 6.9(b).

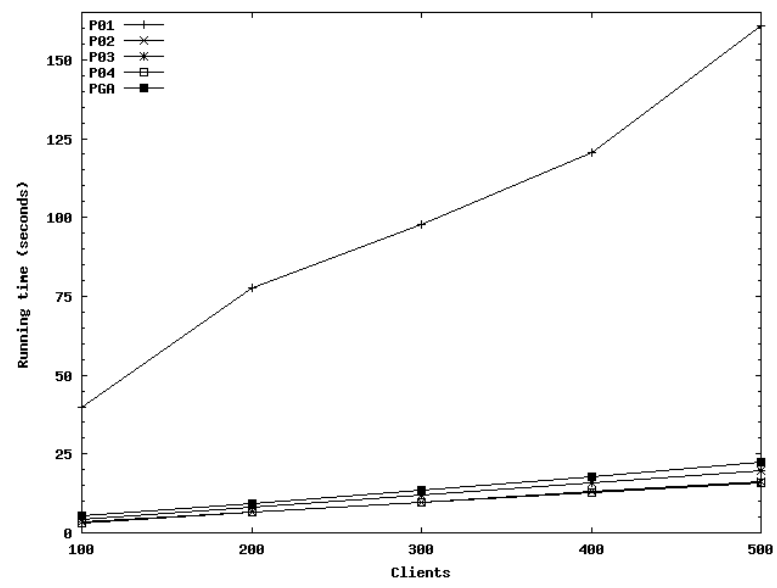

(a) Arquitetura 01

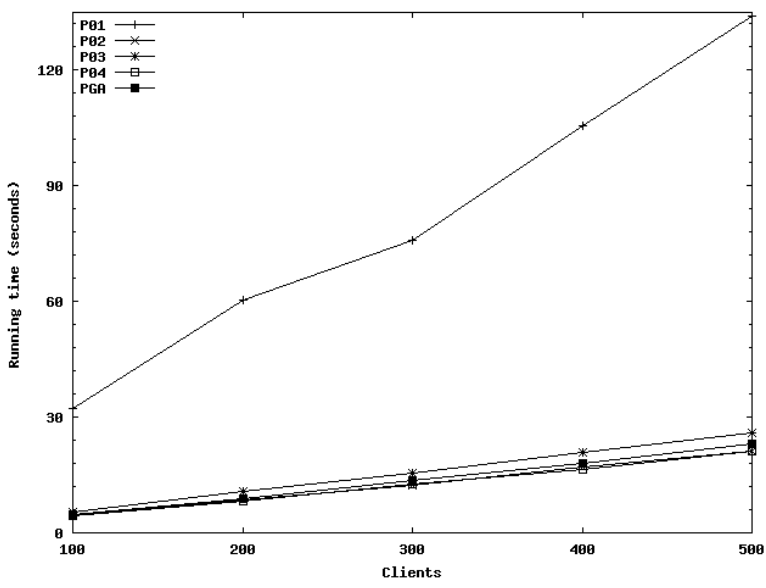

(b) Arquitetura 02

Figura 6.9: Resultados obtidos para o modelo 01 


\subsubsection{Estudo de Caso 2}

No estudo de caso 2 é realizada uma análise para identificar se o fator realimentação apresentado no modelo 02 (seção 6.4) pode influenciar o desempenho das partições obtidas pelo algoritmo genético. Os experimentos realizados para verificar tal observação seguiram a mesma metodologia aplicada no estudo de caso anterior.

Os dados coletados ao executar as simulações na arquitetura 01 demonstraram que a realimentação, de fato, pode influenciar o desempenho das simulações se o modelo for particionado incorretamente. Relacionando os valores da tabela $6.10 \mathrm{com}$ as partições apresentadas na figura 6.4. pode-se concluir que a melhor solução em casos de realimentação é agrupar os centros de serviço que têm comunicação em comum com os associados a realimentação em um mesmo processo lógico.

Embora a realimentação possa prejudicar os resultados, a influência causada por ela é minima e não apresenta-se como risco para inviabilizar a utilização do algoritmo genético. Como pode ser observado na tabela 6.10, a porcentagem de perda tende a minimizar e a de ganho se estabilizar à medida que a quantidade de clientes aumenta, sendo esse comportamento similar ao já demonstrado no estudo de caso anterior.

Tabela 6.10: Avaliação das partições do modelo 02 para a arquitetura 01

\begin{tabular}{c|c|c|c|c|c|c|c}
\hline \hline Qtd. Clientes & P01 & P02 & P03 & P04 & PGA & P(\%) & G(\%) \\
\hline 100 & 29.16 & 41.67 & $28.06 \star$ & 90.97. & 34.05 & 21.35 & 62.57 \\
200 & 49.59 & 87.97 & $47.49 \star$ & 144.24. & 75.43 & 58.53 & 47.71 \\
300 & 86.96 & 142.51 & $84.80 \star$ & 196.16. & 117.56 & 38.63 & 40.07 \\
400 & 220.29 & 185.69 & $139.35 \star$ & 230.65. & 141.88 & 1.82 & 38.49 \\
500 & 241.03 & 283.13 & $172.20 \star$ & 265.03. & 175.02 & 1.64 & 38.18 \\
\hline \hline
\end{tabular}

Os resultados descritos na tabela 6.10 podem ser associados aos apresentados no estudo de caso 1 para pressupor que a arquitetura não reflete no desempenho da simulação, pois, a pequena variação no tempo médio de execução obtido nos testes realizados se repetiu na arquitetura 02. Para tal comparação, os resultados referentes à arquitetura 02 podem ser observados na tabela 6.11. Para detalhar os resultados obtidos por meio da execução das simulações e com isso ilustrar que a influência causada pela alternância da heterogeneidade da arquitetura é minima, tem-se apresentado nas figuras 6.10(a) e 6.10(b) os gráficos gerados para esse estudo de caso.

Tabela 6.11: Avaliação das partições do modelo 02 para a arquitetura 02

\begin{tabular}{c|c|c|c|c|c|c|c}
\hline \hline Qtd. Clientes & P01 & P02 & P03 & P04 & PGA & P(\%) & G(\%) \\
\hline 100 & $23.48 ~$ & 33.12 & 23.54 & $68.33 \star$ & 40.39 & 72.01 & 69.17 \\
200 & 40.51 & 62.63 & 40.09. & $93.14 \star$ & 74.22 & 85.13 & 25.49 \\
300 & 69.14. & 96.66 & 69.87 & $159.57 \star$ & 119.58 & 72.95 & 33.44 \\
400 & $202.44 \star$ & 130.92 & 117.82. & 165.76 & 153.96 & 30.67 & 31.49 \\
500 & $237.29 \star$ & 212.63 & 140.15. & 190.54 & 178.62 & 27.45 & 32.84 \\
\hline \hline
\end{tabular}




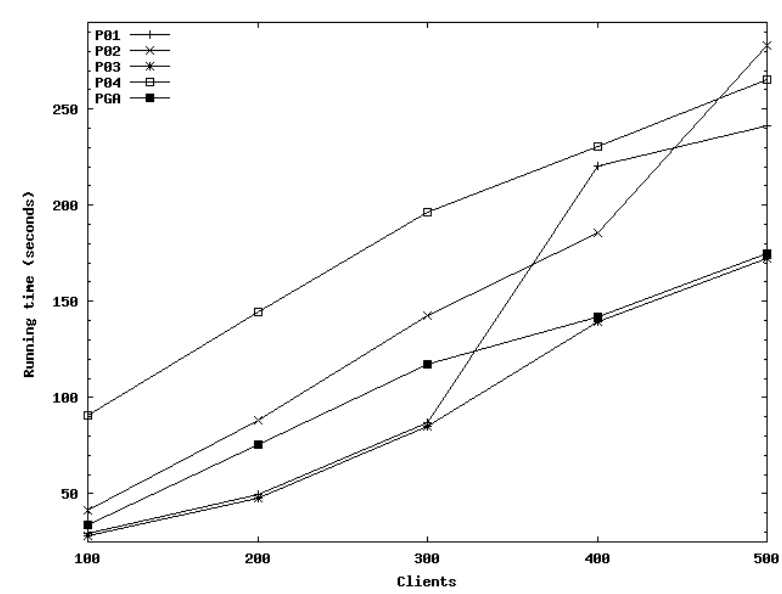

(a) Arquitetura 01

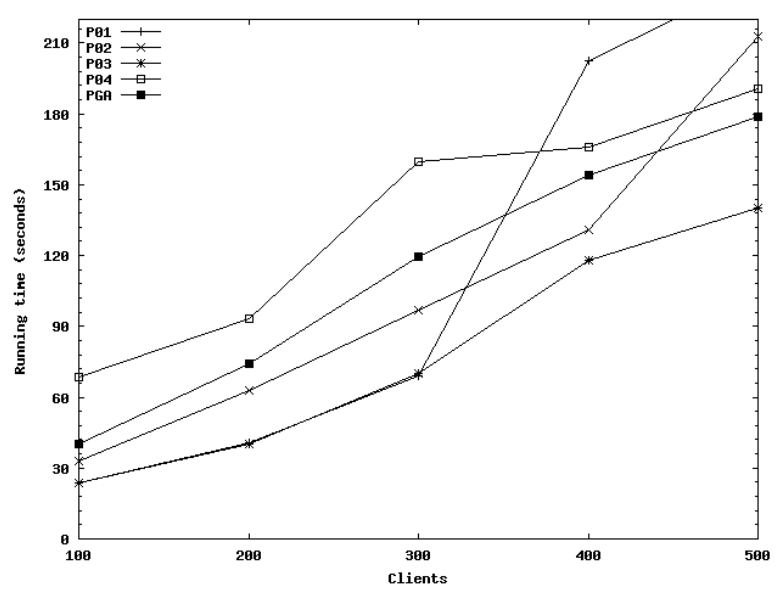

(b) Arquitetura 02

Figura 6.10: Resultados obtidos para o modelo 02

\subsubsection{Estudo de Caso 3}

As avaliações realizadas até o momento comprovam que, independente do tamanho e arquitetura, tem-se bons resultados ao particionar o modelo utilizando o algoritmo genético como ferramenta de auxílio. Outra comprovação é que melhores resultados podem vir a aparecer ao aplicar a técnica em simulações com quantidades de clientes elevados. Para reforçar as afirmações e conclusões apresentadas, é detalhado neste estudo de caso a análise realizada no modelo 03 .

Neste estudo, a quantidade de clientes e os parâmetros da arquitetura são reavaliados para identificar a influência causada por esses durante a execução das simulações. Os primeiros resultados apresentados demonstram o comportamento do modelo 03 na arquitetura 01. Esses, por sua vez, podem ser observados na tabela 6.12, onde as observações sobre a quantidade de clientes é, mais uma vez, comprovada.

Tabela 6.12: Avaliação das partições do modelo 03 para a arquitetura 01

\begin{tabular}{c|c|c|c|c|c|c|c}
\hline \hline Qtd. clientes & P01 & P02 & P03 & P04 & PGA & P(\%) & G(\%) \\
\hline 100 & 34.91 & $22.36 \star$ & 26.27 & 28.68 & 35.47. & 58.63 & 0 \\
200 & 61.70. & 50.28 & $46.06 \star$ & 54.68 & 60.56 & 31.48 & 1.88 \\
300 & 83.05. & 80.70 & $70.85 \star$ & 76.61 & 82.52 & 16.47 & 0.64 \\
400 & 115.22 & 167.82. & $108.88 \star$ & 114.30 & 110.67 & 1.64 & 51.64 \\
500 & 151.26 & 198.46. & $136.90 \star$ & 145.90 & 142.25 & 3.91 & 56.21 \\
\hline \hline
\end{tabular}

Ao analisar os resultados apresentados com os gerados na arquitetura 02 (tabela 6.13), podese concluir que a pequena quantidade de clientes realmente influencia a execução da simulação. O comportamento desses dados mostram que, conforme a quantidade de clientes é acrescida tem-se uma probabilidade maior de se obter melhores resultados ao optar pelo particionamento automático. Para fins de comparação, após o detalhamento dos dados obtidos na arquitetura 02, é apresentado nas figuras 6.11(a) e 6.11(b) os gráficos criados para representar o estudo de caso 3 . 
Tabela 6.13: Avaliação das partições do modelo 03 para a arquitetura 02

\begin{tabular}{c|c|c|c|c|c|c|c}
\hline \hline Qtd. clientes & P01 & P02 & P03 & P04 & PGA & P(\%) & G(\%) \\
\hline 100 & 31.00 & $19.52 \star$ & 21.91 & 27.72 & 44.63. & 128.64 & 0 \\
200 & 52.76 & 43.30 & $40.11 \star$ & 49.15 & 66.86. & 66.69 & 0 \\
300 & 73.50 & 67.41 & $61.63 \star$ & 67.75 & 97.14. & 57.62 & 0 \\
400 & 103.67 & 146.51. & $95.30 \star$ & 97.79 & 134.62 & 41.26 & 8.83 \\
500 & 136.70 & 175.57. & 124.89 & $121.11 \star$ & 160.74 & 32.72 & 9.23 \\
\hline \hline
\end{tabular}

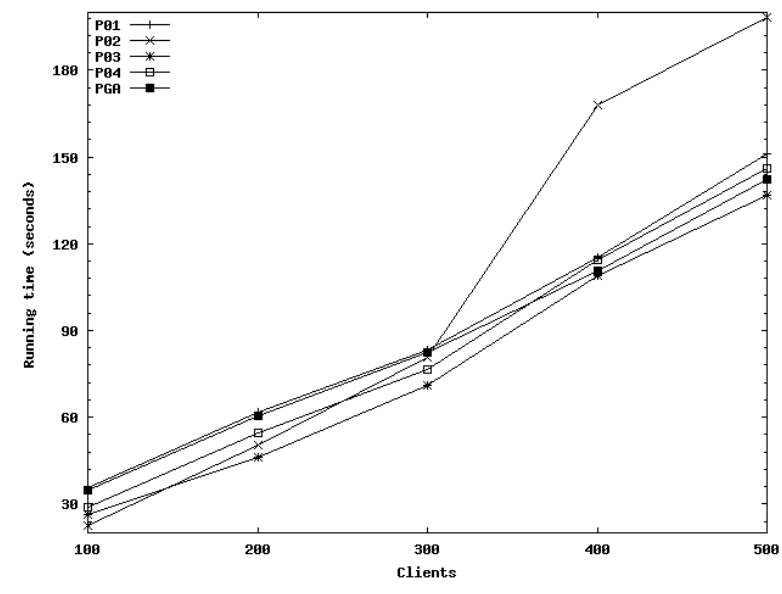

(a) Arquitetura 01

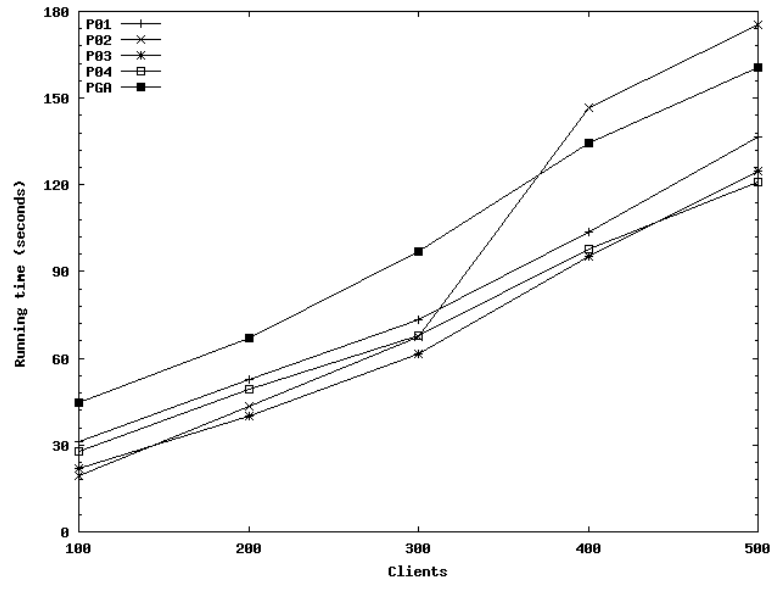

(b) Arquitetura 02

Figura 6.11: Resultados obtidos para o modelo 03

\subsubsection{Estudo de Caso 4}

Como já mencionado anteriormente, os resultados descritos nesta seção foram coletados em experimentos realizados na tese de doutorado da aluna Célia Leiko Ogawa Kawabata em KAWABATA, 2005). Os resultados apresentados aqui são utilizados para auxiliar na análise feita para validar o algoritmo genético junto a influência causada na simulação pela quantidade de processos lógicos criados. Os dados a serem levados em consideração nesse caso podem ser observados na tabela 6.14.

A coluna granulosidade indica o tamanho de uma matriz que foi multiplicada, em um processo inserido nos centros de serviço. Esse processo tem por objetivo aumentar a granulosidade das simulações.

Tabela 6.14: Speedup alcançado na execução das simulações - (KAWABATA, 2005)

\begin{tabular}{c|c|c|c|c|c}
\hline \hline Granulosidade & P01 & P02 & PGA & P(\%) & $\mathrm{G}(\%)$ \\
\hline 0 & 10.51. & $8.87 \star$ & 9.62 & 8.45 & 10.53 \\
25 & 27.95. & 27.47 & $26.47 \star$ & 0 & 5.6 \\
50 & 123.74 & 127.90. & $118.85 \star$ & 0 & 7.61 \\
75 & 360.81 & 376.10. & $347.37 \star$ & 0 & 8.27 \\
100 & 800.73 & 838.08. & $770.26 \star$ & 0 & 8.80 \\
\hline \hline
\end{tabular}

A análise realizada nesses resultados permitiram a avaliação um novo fator, a quantidade de processos lógicos. Ao observar os resultados obtidos, pode-se concluir que quantidades menores 
de processos lógicos tendem a melhorar ainda mais os resultados obtidos do algoritmo genético. Isso é alcançado quando o espaço de busca se limita a uma quantidade menor de soluções, sendo possível obter o melhor particionamento em um número menor de interações.

\subsection{Considerações Finais}

Neste capítulo foram apresentados os estudos de casos realizados para comprovar a eficiência e o comportamento das partições obtidas com o algoritmo genético para o problema de particionamento de modelos em simulação distribuída. Durante esse processo, notou-se que tal método pode ser utilizado para auxiliar usuários na etapa de particionamento independentemente do modelo e da arquitetura a ser utilizada para a execução das simulações.

Os resultados coletados nas simulações foram utilizados como forma comparativa para ilustrar os ganhos e perdas de tempo associados à execução das partições automaticamente obtidas. Esses resultados demonstraram que a eficiência e desempenho do algoritmo genético melhoram conforme a quantidade de clientes simulados aumenta. Nota-se também que na maioria dos casos analisados a solução proposta pelo algoritmo genético foi a que se manteve mais estável, com tempos de resposta crescendo de maneira linear conforme o aumento do número de clientes. Além disso, a solução fornecida pelo algoritmo genético se manteve próximo dos tempos do melhor particionamento.

Para demonstrar quais conclusões foram alcançadas e qual a importância deste trabalho para a área de pesquisa, tem-se apresentado no próximo capítulo as conclusões finais, o relacionamento deste trabalho com trabalhos do grupo de pesquisa e os trabalhos futuros que podem ser realizados a partir da pesquisa apresentada nesta dissertação. 


\section{Capítulo}

\section{Conclusões}

\subsection{Considerações Finais}

Um fator muito importante quando se decide utilizar simulação distribuída com a abordagem SRIP é o particionamento. O desempenho de uma simulação distribuída depende de diversos fatores, como por exemplo a arquitetura, as características do modelo e as características do protocolo de sincronização. No entanto, se um particionamento for realizado de uma maneira incorreta, este pode influir diretamente no protocolo de sincronização e a arquitetura pode não ser utilizada com toda sua capacidade, afetando o desempenho da simulação distribuída.

O trabalho desenvolvido nesta dissertação de mestrado tem como objetivo propor e avaliar o uso de algoritmos genéticos como método de auxílio no particionamento de modelos em simulação distribuída. Com esse estudo, foi possível avaliar a influência causada pelo particionamento no desempenho da execução de simulações. A motivação para o tema surgiu da necessidade de se propor um método para ser integrado ao ambiente de simulação distribuída ASDA, o qual possui como uma de suas características a possibilidade de fornecer particionamento automático de modelos que utilizem a abordagem SRIP.

Para tornar isso possível, foi realizada inicialmente uma revisão sobre alguns tópicos pertinentes à área. A técnica de simulação foi discutida no capítulo 2, sendo apresentadas as abordagens existentes (seqüencial e distribuída) e as etapas de construção associadas a cada uma. Optando por prover uma forma automática de particionamento, tornou-se necessário o estudo de algumas técnicas de inteligência artificial, as quais foram apresentadas no capítulo 3. Concluiu-se nesse capítulo que a melhor técnica a ser utilizada para o problema analisado seria a técnica evolutiva baseana em um algoritmo genético.

O capítulo 4 apresentou as características do algoritmo genético proposto para prover os resultados desejados para o problema em questão. Os parâmetros fornecidos como entrada para o algoritmo genético são as características do modelo (quantidade de centros de serviço, 
conexão entre esses centros de serviço e a carga computacional de cada um) e da arquitetura (capacidade em MIPS de cada máquina). Com essas informações, o algoritmo genético proposto tem como objetivo balancear o número de centros de serviço nos processos lógicos de acordo com a capacidade de cada máquina e também minimizar a comunicação entre os processos lógicos. O resultado fornecido pelo algoritmo genético é o número de processos lógicos e os respectivos centros de serviço alocados em cada processo lógico.

Para finalizar, foi discutido no capítulo 5 os estudos de casos realizados por meio de comparações para demonstrar o desempenho e a eficiência das partições obtidas automaticamente perante as adquiridas manualmente. O algoritmo apresentado no capítulo 4, ao ser avaliado em duas diferentes arquiteturas, demonstrou-se eficaz ao particionar 3 diferentes modelos propostos neste trabalho e mais um modelo definido em uma tese de doutorado de uma aluna do grupo de Sistemas Distribuídos e Programação Concorrente do ICMC/USP (KAWABATA, 2005). Os testes realizados demonstraram que a utilização do método genético é uma possível solução para o particionamento automático, principalmente quando se tem um número grande de clientes no sistema.

\subsection{Relacionamento com Trabalhos do Grupo de Pesquisa}

O desenvolvimento deste trabalho baseou-se em vários projetos desenvolvidos e em andamento no grupo de Sistemas Distribuídos e Programação Concorrente do ICMC-USP. Como já mencionado em capítulos anteriores, o objetivo principal foi prover um método e/ou ferramenta que tornasse possível o particionamento automático de modelos em ambientes de simulação distribuída. Para tal feito, este trabalho utilizou como base o ASDA - Ambiente de Simulação Distribuída Automático (BRUSCHI, 2002) (BRUSCHI et al., 2004), o qual tem por princípio oferecer a diferentes níveis de usuários um ambiente de simulação distribuída onde a simulação possa ser desenvolvida sem a necessidade de conhecimentos e experiências especificas das áreas de Computação Paralela, Simulação ou Simulação Distribuída (BRUSCHI et al., 2004).

Além do ambiente ASDA, outros projetos do grupo foram utilizados para prover suporte ao desenvolvimento, sendo esses apresentados a seguir:

- Tese de doutorado de Roberta Spolon Ulson (ULSON, 1999): fornece conclusões sobre a utilização de um protocolo de sincronização que utiliza a abordagem conservativa CMB, através da definição de um conjunto de testes que foram executados em diferentes plataformas. Nesse trabalho foi também desenvolvida uma biblioteca para simulação distribuída utilizando o protocolo CMB, denominada ParSMPL. Essa biblioteca tem como base a extensão funcional SMPL (MACDOUGALL, 1987) e foi utilizado neste trabalho para a definição dos programas de simulação desenvolvidos nos testes;

- Teste de doutorado de Renata Spolon (SPOLON, 2001): fornece conclusões sobre a utilização de um protocolo de sincronização que utiliza a abordagem otimista Time Warp (JEFFERSON, 1985) através de uma meta simulação, onde o protocolo Time Warp é simulado em diferentes situações. Esse trabalho também fornece uma completa classificação dos protocolos otimistas; 
- Dissertação de mestrado de Mara Andréa Dota (DOTA, 2001): esse trabalho realizou a instalação e configuração da linguagem Warped (que implementa o protocolo Time Warp) para o desenvolvimento de simulações utilizando redes de filas, e realizou também um conjunto de testes para verificar a viabilidade de utilização do protocolo otimista Time Warp;

- Teste de doutorado de João Carlos Moraes Morselli Junior (MORSELLI, 2000): esse trabalho propõe um mecanismo para troca de protocolo de sincronização em tempo de execução.

- Mestrado de Eliane Sayuri Tatsumi (TATSUMI, 2004): esse trabalho faz o estudo para inserção da extensão funcional ParSMPL (que implementa o protocolo CMB) no ASDA e também implementa a característica de lookahead dinâmico no ParSMPL.

- Doutorado de Célia Leiko Ogawa Kawabata (KAWABATA, 2005): estende o trabalho de MORSELLI, 2000) e propõe a execução simultânea de diferentes protocolos de sincronização em uma mesma simulação.

\subsection{Contribuições}

As principais contribuições deste trabalho são detalhadas a seguir, apresentando-se as relevâncias para a área.

- Revisão Bibliográfica - Foi realizado uma revisão da bibliografia existente para contextualizar o presente trabalho e por meio desta apresentar uma solução para o problema de particionamento de modelos em simulação distribuída.

- Automatização da etapa de particionamento de modelos - Foi desenvolvido a partir da revisão bibliográfica um método baseado nas técnicas da computação evolutiva para prover a usuários com diferentes níveis de conhecimento uma forma simples de particionar modelos em ambientes de simulação. O método proposto pode ser adaptado e inserido em outros ambientes de simulação, bem como ser utilizado independentemente, bastando para isso fornecer os parâmetros de entrada referentes ao modelo e à arquitetura (mipsCapacity, Matriz Communication e mipsProcess).

- O estudo dos resultados obtidos com as partições forneceram as seguintes conclusões:

- O particionamento manual faz com que o usuário não atente para o fato do poder computacional das máquinas, induzindo a divisões com números próximos de centros de serviço por processo lógico criado.

- Não é aconselhável deixar as saídas do modelo isoladas dos centros de serviço que fornecem mensagens para ela. Isso pode gerar como conseqüência a perda de desempenho, devido ao aumento na comunicação entre processos / processadores. 
- Quantidades maiores de clientes tendem a melhorar as partições propostas pelo algoritmo genético. Isso porque um maior número de clientes implica em uma maior quantidade mensagens nulas. Sabendo-se que o algoritmo genético leva em consideração o balanceamento dos processos lógicos, seus resultados tendem a melhorar.

- As partições obtidas pelo algoritmo genético tendem a manter um desempenho mais estável em termos de tempo de execução X quantidade de clientes que as manualmente obtidas. Isso pode ser observado nos resultados apresentados no capítulo 6 , onde algumas das partições obtiveram bons resultados para certo número de clientes e resultados não tão bons para outros.

- Ao realizar o particionamento, quantidades menores de processos lógicos tentem a melhorar o desempenho e eficiência do algoritmo genético. Isso é causado pela minimização do espaço de busca percorrido pelo algoritmo, fazendo com que as probabilidades de se obter o máximo global (melhor solução) cresçam.

Este trabalho apresentou várias contribuições para as áreas afins, deixando para futuros trabalhos novas idéias de implementação e aplicação da técnica.

\subsection{Trabalhos Futuros}

Através das contribuições e resultados apresentados neste trabalho, pode-se avaliar como possibilidade de realização os seguintes trabalhos futuros:

- Aplicação do algoritmo genético proposto em simulações que utilizem protocolos otimistas;

- A validação da eficiência e desempenho do algoritmo genético em situações que envolvem modelos reais, verificando as variações de resultados ao se trabalhar com dados hipotéticos e/ou reais.

- Aplicação da técnica genética para realizar não só o particionamento mas também o monitoramento e avaliação do desempenho da simulação em tempo de execução. Esse processo pode ser realizado para modificar, se necessário, o protocolo e o tipo de particionamento utilizado.

- Modificação do algoritmo utilizado para identificar previamente que abordagem (MRIP ou SRIP) pode fornecer melhores resultados.

- Aplicação do algoritmo genético para a troca de abordagem se identificado um atraso para a apresentação dos resultados esperados. Essa troca envolve também a escolha do melhor protocolo de comunicação a ser utilizado ao iniciar novamente as execuções.

- Análise de alguns fatores que foram identificados como influentes no tempo de execução:

- Utilização da máquina mais lenta para executar o processo lógicos que contenha as entradas do modelo. Isso tende a avaliar a sincronização entre os processos lógicos, visto que o tempo para submissão de mensagens será afetada. 
- Realização de uma análise para verificar quais influências são causadas pelo tempo de serviço de cada CS e pelo crescimento da taxa de entrada na quantidade de mensagens geradas.

- Realização de um estudo para avaliar qual a carga em MIPS que cada centro de serviço exige da arquitetura ao ser associado a um determinado processo lógico. E viável que se realize este estudo com diferentes partições, pois, a cada nova partição o centro de serviço avaliado estará conectado com outros centros de serviço, os quais podem produzir um número maior ou menor de mensagens durante a execução.

- Realizar um estudo aprofundado sobre o comportamento das simulações apresentadas na análise realizada, a fim de abstrair maiores informações que podem ser utilizadas para melhorar os padrões de entrada submetidos ao algoritmo genético e conseqüentemente melhorar as suas soluções. 


\section{Referências Bibliográficas}

ALMEIDA, P. E. M. de; EVSUKOFF, A. G. Sistemas inteligentes: Fundamentos e aplicações. In: . São Paulo: Manole, 2003. cap. Sistemas Fuzzy, p. 169-201.

AYANI, R. Parallel simulation. Lecture Notes in Computer Sience, v. 729, 1993.

BANKS, J. Handbook of Simulation: Principles, Methodology, Advances, Applications, and Practice. [S.l.]: John Wiley, 1998.

BAPAT, V.; SWETS, N. The arena product family: Enterprise modeling solutions. Winter Simulation Conference, p. 163-169, 2000.

BOLCH, G. et al. Queueing Networks and Markov Chains: Modeling and performance evaluation with computer science applications. [S.l.]: John Wiley \& Sons, INC, 1998.

BOUKERCHE, A. An adaptive partitioning algorithm for distributed discrete event simulation systems. J. Parallel Distrib. Comput., Academic Press, Inc., Orlando, FL, USA, v. 62, n. 9, p. 1454-1475, 2002. ISSN 0743-7315.

BOUKERCHE, A.; DAS, S. K. Reducing null messages overhead through load balancing in conservative distributed simulation systems. J. Parallel Distributed Computer, Academic Press, Inc., Orlando, FL, USA, v. 64, n. 3, p. 330-344, 2004. ISSN 0743-7315.

BOUKERCHE, A.; TROPPER, C. A static partitioning and mapping algorithm for conservative parallel simulations. In: PADS '94: Proceedings of the eighth workshop on Parallel and distributed simulation. New York, NY, USA: ACM Press, 1994. p. 164-172. ISBN 1-56555-027-7.

BRAGA, A.; CARVAlhO, A. C.; LUDERMIR, T. B. Redes Neurais: teoria e aplicações. [S.1.]: JC Press, 2000.

BRAGA, A. de P.; CARVAlHO, A. C. P. L. F. de; LUDERMIR, T. B. Sistemas inteligentes: Fundamentos e aplicações. In: . São Paulo: Manole, 2003. cap. Redes Neurais Artificiais, p. $141-168$. 
BRUSCHI, S. M. Um Ambiente de Simulação Distribuída Automático. Tese (Doutorado) Instituto de Ciências Matemáticas e Computação, São Carlos - SP, 2002.

BRUSCHI, S. M. et al. Asda: An automatic distributed simulation environment. In: . [S.1.]: Washington - DC, 2004. p. 378-385.

BRYANT, R. E. Simulation of Packet Communications Architeture Computer. [S.l.]: Massachusetts, 1977. Massachusetts Institute of Tecnology (Relatório Técnico).

CHANDY, K. M.; MISRA, J. Distributed simulation: A case study in design and verification of distributed programs. IEEE Transactions on Software Engineering, v. 5, n. 5, p. 440-452, 1979.

DIAS, P. de S.; CORREA, C.; ABRãO, I. C. Modelagem e simulação de redes de computadores utilizando o opnet. XI CIC-Congresso de iniciação Cientifica da UFSCar, 2003.

DOTA, M. A. Avaliação de Desempenho de uma Ferramenta para Simulação Distribuída Baseada no Protocolo Otimista Time Warp. Dissertação (Mestrado) - ICMS-USP, São Carlos, 2001.

EWING, G.; MCNICKLE, D.; PAWLIKOWSKI, K. Akaroa 2.5: User's manual, department of computer science, university of caterbury. New Zeland: [s.n.], 1998.

FALL, K.; VARADHAN, K. The NS Manual. August 2000. Disponível em: <www.isi.edu/nsnam/ns $>$.

FERSCHA, A.; TRIPATHI, S. K. Parallel and Distributed Simulation of Discrete Event Simulation. [S.l.]: MacGrawHill, 1995.

FIDUCCIA, C. M.; MATTHEYSES, R. M. A linear-time heuristic for improving network partitions. In: Proceedings of 19th design automation conference. Las Vegas: ACM/IEEE, 1982. p. $175-181$.

FOGEL, L. J.; OWENS, A. J.; WALSH, M. J. Artificial intelligence through simulated adaptation. Forty Years of Evolutionary Programming., New York, NY, USA, 1966.

FRANCÊS, C. R. L. Statecharts Estocásticos e Queuing Statecharts: Novas abordagens para avaliação de desempenho baseadas em especificação statecharts. Tese (Doutorado) — Instituto de Ciências Matemáticas e Computação, São Carlos - SP, 2001.

FUJIMOTO, R. M. Parallel and Distributed Simulation Systems. [S.l.]: John Wiley Computer, 2000.

HAO, F. et al. Logical process size in parallel simulations. In: Proceedings of the 28th conference on Winter simulation - WSC. New York, NY, USA: ACM Press, 1996. p. 645-652. 
HAREL, D. et al. On the formal semantics of statecharts. In: Proceeding of the $2^{\text {nd }}$ IEEE Symposium on Logic in Computer Science. New York - USA: [s.n.], 1987. p. 54-64.

HAYKIN, S. Redes Neurais: princípios e práticas. 2. ed. Porto Alegre: Bookman, 2001.

HEIDELBERGER, P. Statistical analysis of parallel simulations. In: WSC '86: Proceedings of the 18th conference on Winter simulation. New York, NY, USA: ACM Press, 1986. p. 290-295.

HENNING, J. L. Spec cpu2000: Measuring cpu performance in the new milennium. Computer, IEEE Computer Society Press, v. 33, n. 7, p. 28-35, 2000.

HOLLAND, J. H. Adaptation in natural an artificial systems. [S.l.]: University of Michigan Press, 1975.

IRME, S. et al. Simulation Environment for Ad-Hoc Networks in OMNet++. 2001. Disponível em: <www.omnet.orgg $>$.

ISHII, R. P. NBSP: Uma política de escalonamento network-bound para aplicações paralelas distribuídas. Dissertação (Mestrado) - Instituto de Ciências Matemáticas e Computação, 2004.

JAIN, R. The Art of Computer Systems Performance Analysis. 1. ed. Canada: John Wiley \& Sons INC, 1991.

JEFFERSON, R. D. Virtual time. ACM Transactions on Programming Languages and Systems, v. 7, n. 3, p. 404-425, 1985.

JUHASZ, Z.; TURNER, S. J. A new heuristic for the process-processor mapping problem. $G$. Kotsis and P. Kacsuk, p. 91-94, 2000.

KAWABATA, C. L. O. Simulação Distribuída Utilizando Protocolos Independetes e Troca Dinâmica nos Processos Lógicos. Tese (Doutorado) - ICMC-USP, São Carlos, 2005.

KERRIGAN, T. C. TSCP Benchmark Scores. 2005. Disponível em: <http://home.comcast.net/ tckerrigan/bench.html>. Acesso em: 7 mai.

KIM, H. K.; JEAN, J. Concurrency preserving partitioning for parallel logic simulation. Proceidings of the 10th workshop on Parallel and Distributed Simulation, 1996.

KONAS, P.; YEW, P.-C. Partitioning for synchronous parallel simulation. Proceedings of the 9th workshop on Parallel and Sistributed Simulation, Care Placid, NY, 1995.

LIN, G.; YAO, X. Analysing crossover operators by search step size. IEEE Int'l Conf. on Evolutionary Computation, 1997.

MACDOUGALL, M. H. Simulating Computer Systems Techniques and Tools. Massachussets: The MIT Press, 1987. 
MAINI, H. S. et al. Genetic algorithms for graph partitioning and incremental graph partitioning. Center for Research on Parallel Computation, 1994.

MCCULLOCH, W.; PITTS, W. A logical calculus of de ideas immanent in nervous activity. Bulletin of Mathematical Biophysics, 1943.

MENASCé, D. A.; ALMEIDA, V. A. F. Planejamento de capacidade para servidores na web: Métricas, modelos e métodos. Rio de Janeiro - Brasil: Editora Campus Ltda, 2003.

MOORE, K. E.; BRENNAN, J. E. Petri nets and simulation: a tutorial. In: Proceeding of the 1995 Summer Computer Simulation Conference (SCSC'95). Ottawa - Canada: [s.n.], 1995. p. $45-50$.

MORSELLI, J. J. C. M. Um Mecanismo para Troca de Protocolos de Sincronização de Simulação Distribuída em Tempos de Execução. Tese (Doutorado) — Instituto de Física de São Carlos, USP, 2000.

NANDY, B.; LOUCKS, W. M. On a parallel partitioning technique for use with conservative parallel simulation. In: PADS '93: Proceedings of the seventh workshop on Parallel and distributed simulation. New York, NY, USA: ACM Press, 1993. p. 43-51.

REZENDE, S. O. Sistemas Inteligentes: Fundamentos e aplicações. São Paulo: Manole, 2003.

SANDRI, S.; CORREA, C. Lógica Nebulosa. 2004. Iinstituto Nacional de Pesquisas Espaciais - INPE.

SANTANA, R. H. C. et al. Automatic generation of discrete-system simulation programs. Proceedings of the 1996 Summer Computer Simulation Conference (SCSC'96), Oregon-USA, p. 133-138, July 1996.

SANTANA, R. H. C. et al. Graphical user-interface for an automatic simulation system. Proceedings of the 1996 Summer Computer Simulation Conference (SCSC'96), Oregon-USA, p. 139-143, July 1996.

SPOLON, R. Um Método para Avaliação de Desempenho de Protocolos de Sincronização Otimistas para Simulação Distribuída. Tese (Doutorado) — ICMC-USP, São Carlos, 2001.

SUBRAMANIAN, S.; RAO, D. M.; WILSEY, P. A. Study of a multilevel approach to partitioning for parallel logic simulation. In: IPDPS: Proceedings of the 14th International Symposium on Parallel and Distributed Processing. Washington, DC, USA: IEEE Computer Society, 2000. p. 833.

TATSUMI, E. S. Análise e Avaliação do uso da Ferramenta ParSMPL em um Ambiente de Simulação Distribuída Automático - ASDA. Dissertação (Mestrado) - ICMC-USP, São Carlos, 2004. 
ULSON, R. S. Simulação Distribuída em Plataformas de Portabilidade: Viabilidade de uso e comportamento do protocolo cmb. Tese (Doutorado) - Instituto de Física de São Carlos, USP, 1999.

WEBER, L.; KLEIN, P. A. T. Aplicação da Lógica Fuzzy em Software e Hardware. Canoas: Editora da ULBRA, 2003.

WILSEY, P. A.; MARTIN, D. E.; SUBRAMANI, K. Savant/tyvis/warped: Components for the analysis and simulation of vhdl. In: . Santa Clara, CA, USA: IEEE Press, 1998. p. 195-201.

XU, D.; AMMAR, M. Benchmap: Benchmark-based, hardware and model-aware partitioning for parallel and distributed network simulation. 12th IEEE International Symposium on Modeling, Analysis, and Simulation of Computer and Telecommunications Systems (MASCOTS'04), p. pp. 455-463, 2004.

ZUBEN, F. J. V. Computação Evolutiva: Uma Abordagem Pragmática. 2004. Disponível em: $<$ www.dca.fee.unicamp.br/ gudwin/ftp/ea072/tutorialEC.pdff>. Acesso em: 7 dez. 